\title{
Investigating Mineral Weathering and Metal Transport through Century-Old Ore Chimney Waste Rock
}

\author{
Author: Andrew Hicks \\ A thesis addressed to the Department of Earth Sciences \\ and submitted to the Faculty of Graduate and Postdoctoral Affairs \\ in partial fulfilment of the requirements for the degree of \\ Master of Science \\ In \\ Earth Sciences \\ Carleton University, Ottawa, ON, Canada \\ (Ottawa-Carleton Geoscience Centre)
}

Copyright (C) Andrew Hicks, 2021. All Rights Reserved. 


\section{Author's Declaration and Dedication}

I hereby declare that I am the sole author of this thesis. To the best of my knowledge, this thesis contains no materials previously published or written by another person and any contribution made by others is explicitly acknowledged. This is a true copy of the thesis, including any required final revisions, as accepted by my examiners.

I understand that this thesis may be made electronically available to the public.

As a testimony of gratitude, this thesis is dedicated to the companionship and memory of Clark Bolliger. Clark always pointed his compass in the right direction and establishing a friendship over the years was a privilege. Even when times were tough, Clark's optimism and wonderful sense of humour always shined through. Thank you for the positive influence you had on my life and may you forever live on through my acquired character and cherished memories. 


\section{Abstract}

Sulfide minerals have an affinity to react with oxygen in the atmosphere when exposed above ground surface with the potential to release metals and acidity into the surrounding environment. The extent of contaminant release can be a function of time, and the myriad of historically abandoned mines across Canada create concern for how mine-waste systems, especially waste-rock piles, are affected by long-term exposure at Earth's surface. This thesis investigates the long-term weathering of a historical waste-rock pile at the Ore Chimney mine, which was developed $\sim 100$ years ago. Three trenches that transect the entire depth were excavated and 5 to $6 \mathrm{~kg}$ of waste-rock material were sampled at $0.5 \mathrm{~m}$ depth intervals. Waste-rock material was sieved into fine $(<0.5 \mathrm{~mm})$ and coarse $(0.5$ to $2.0 \mathrm{~mm}$ ) grain size fractions and in situ solid-phase geochemical signatures were investigated with optical microscopy, scanning electron microscopy with energy dispersive spectrometry, powdered X-ray diffraction, total carbon and sulfur analysis, and solid-phase digestions followed by inductively coupled plasma atomic emission and mass spectrometry (ICP-AES/MS). Samples were centrifuged to extract porewaters and analyzed by spectrophotometry, anion chromatography, and ICP-AES/MS. The geochemical modelling software PHREEQC was used to explore possible secondary controls on porewater chemistry.

Solid-phase geochemical investigations revealed average total carbon and sulfur concentrations of $1.38 \mathrm{wt} \%$ [C] (comprised of calcite and dolomite) and 2.02 wt.\% [S], respectively, and $\mathrm{Zn}$ and $\mathrm{Pb}$ concentrations of 1.56 and $1.38 \mathrm{wt} . \%$, respectively. Sulfur content was associated with a sulfide mineral assemblage primarily composed of sphalerite and galena, with less frequent occurrence of pyrite and chalcopyrite sourced from carbonate-bearing quartz veins. Porewater $\mathrm{pH}$ was near-neutral suggesting ongoing acid neutralization and elevated Eh $(\mu=+421 \mathrm{mV})$ indicate that oxygen was the main oxidizing agent independent of depth. Porewater ICP-AES measured $\mathrm{Zn}$ as high as $87.5 \mathrm{ppm}$ accounting for $92 \%$ [M] of average heavy metal concentrations and is attributed to the oxidative 
dissolution of sphalerite. High alkalinity levels $\left(\mu=60.2 \mathrm{mg} / \mathrm{L} \mathrm{CaCO}_{3}\right)$ suggest that calcite and dolomite are likely controlling $\mathrm{pH},[\mathrm{Pb}],[\mathrm{Zn}],[\mathrm{Cd}]$, and $[\mathrm{Cu}]$ in the porewaters. Results from this study indicate that the source lithology of sulfides plays a strong role in weathering. After $\sim 100$ years, sphalerite and galena grains are strongly altered but pyrite and chalcopyrite remain relatively unweathered suggesting that chemical weathering processes may continue for some time, but abundant Ca-carbonates will provide long-term buffering. This study shows that a detailed understanding of in situ solid- and aqueous-phase geochemistry is required to delineate waste-rock weathering as a function of long-term exposure. 


\section{Acknowledgements}

This project was made possible by the Ontario Research Fund - Research Excellence Grant "Integrated tools and technologies for environmentallyresponsible management of metal-bearing wastes" awarded to Dr. David Blowes and Dr. Carol Ptacek (Principal Investigators from the University of Waterloo) by the Ontario Ministry of Research, Innovation, and Science. First and foremost, I wish to extend my sincerest gratitude to my supervisor, Dr. Richard Amos, for recognizing my potential and continually showing support since my freshman year as an undergraduate student. Thank you for providing me with unparalleled opportunities throughout my experience at Carleton University including this project. The results from this study were arguably $\sim 100$ years in the making and completing this project may have taken just as long if not for your advisement, enthusiasm, and encouragement. I would also like to thank Timothy Mount for the tireless effort in completing the polished grain mounts and to Dr. Maryam Shahabi Far for your incredible work on the scanning electron microscope and for prioritizing my research to ensure I graduated on time. All your insights and recommendations were invaluable and provided me with the open mind necessary to develop a proper understanding in this field. A great deal of credit is owed to advisory board members Dr. Tom Al from the University of Ottawa and Dr. James Mungall from Carleton University for their expertise, knowledgeable recommendations, and for working within the parameters of a stressed timeline.

I wish to acknowledge Jeff Bain and Danielle Marie Simons from the University of Waterloo for undertaking the responsibility to analyze and post-process the total carbon and sulfur data. Field and laboratory work was mostly conducted independently; thus, I am very grateful for your contributions, which facilitated the research progress significantly. Furthermore, I would like to thank Dr. Jeffery Ovens and Dr. Lilianne Pagé from the University of Ottawa for treating me with overwhelming respect and for their exceptional work with powdered X-ray diffraction (PXRD) ensuring that proper analytical techniques were employed, and appropriate adjustments were made to collect data at the highest resolution. The 
freeze-drying was permitted thanks to accommodations by Dr. Myron Smith and the post-processing of PXRD data was made possible by Dr. George Dix at Carleton University. Special thanks are owed to Dr. Nimal De Silva from the University of Ottawa for your incredible work on solid- and aqueous-phase atomic emission and mass spectrometry in addition to anion chromatography. I commend your knowledge, patience, and attention to detail, which are paramount qualities for gathering such a valuable dataset and I am incredibly fortunate to have been able to confine most of my analyses within the Ottawa-Carleton Geoscience Centre, which otherwise would not have been possible without your extraordinary help.

I am deeply indebted to Ken Cuddy for navigating through rough terrain with his excavator and for single-handedly deconstructing the waste-rock pile in sub-zero temperatures. There would be no project without a successful field season, which could only be attempted once, and your work ethic, skill, and composure deserves the utmost respect. Likewise, the field work would have not been possible without the help of Thomas Hicks who is a phenomenal field assistant and an even better brother. From clearing toppled spruce trees, to hauling hundreds of kilograms of waste-rock material off site by hand using a toboggan, and for always having my back; I owe you some serious favours and cannot thank you enough. I also wish to recognize Gary Smith and John Archibald for granting permission to conduct research at the privatized Ore Chimney property. I would like to thank Carleton University and the Department of Earth Sciences for their acceptance and accommodation throughout my graduate studies. Above all, I wish to formally congratulate my parents, Pauline and Steve, for recently celebrating their $30^{\text {th }}$ anniversary and forever exemplifying the importance of family. Your unrivaled love and support have always provided me with the incentive to embrace life's toughest challenges and this project was certainly no exception. For all the hardships endured and sacrifices made, I thank you from the bottom of my heart. 


\section{Table of Contents}

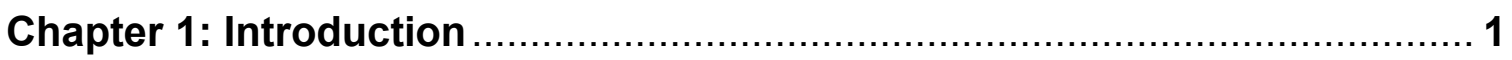

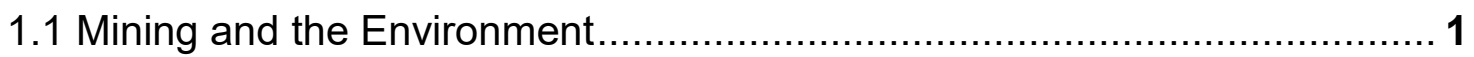

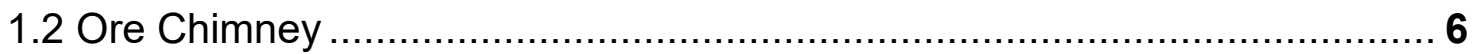

1.3 Thesis Structure and Objectives of Research .................................... 9

Chapter 2: Mineralogy and Solid-Phase Geochemistry ........................... 12

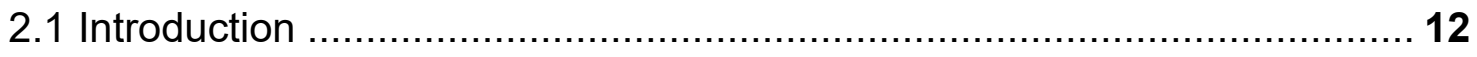

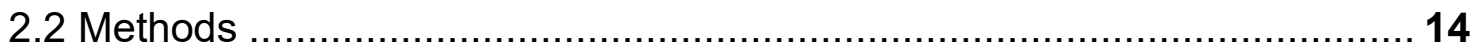

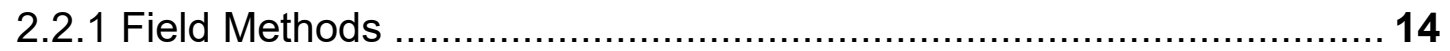

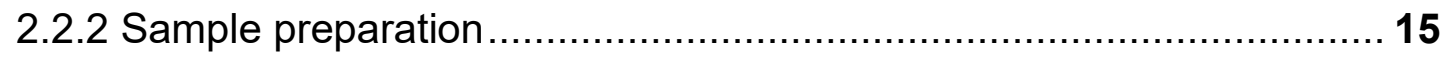

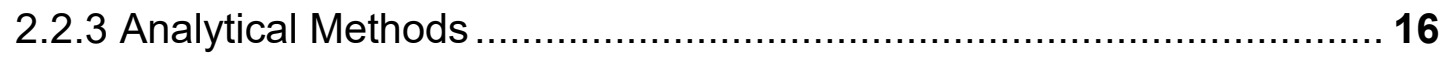

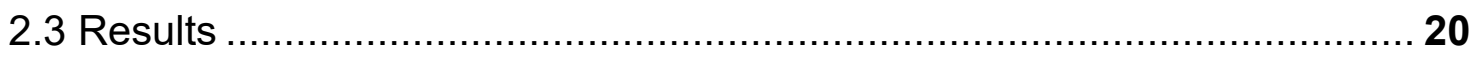

2.3.1 X-ray Diffraction: Phase Identification and Quantitation ..................... 21

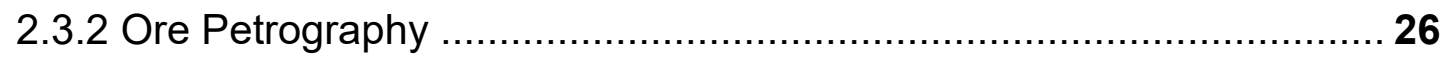

2.3.3 Total Inorganic Carbon and Sulfur (C/S) Analysis............................ 34

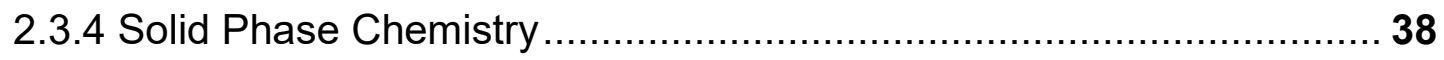

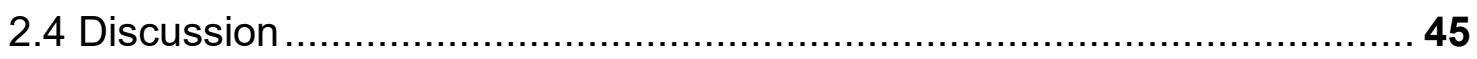

2.4.1 General Lithology and Mineralogy ............................................. 45

2.4.2 Mineral-Derived Metals in the Waste Rock .................................... 50

2.4.3 Sulfide Mineral Weathering ......................................................... 55

2.4.4 Total Carbon and Sulfur ............................................................ 59

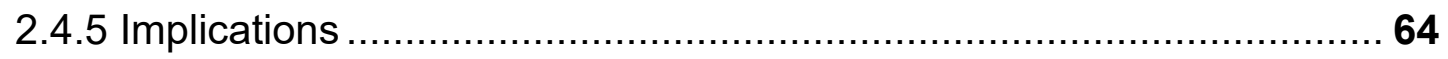

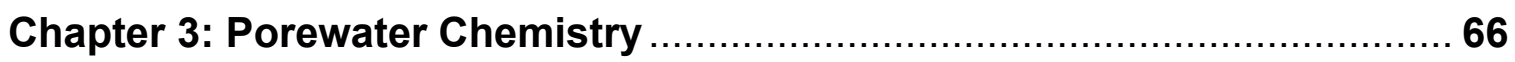

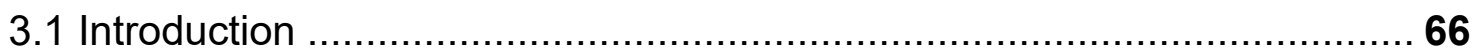

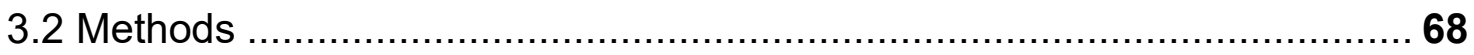

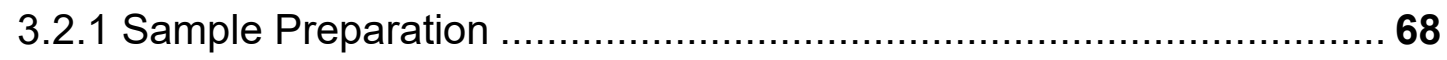

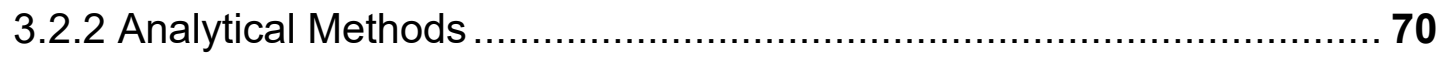

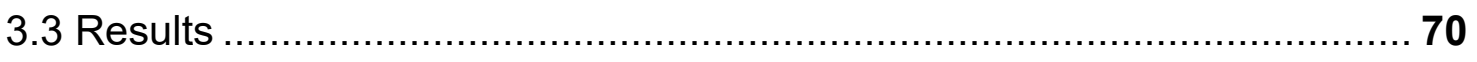

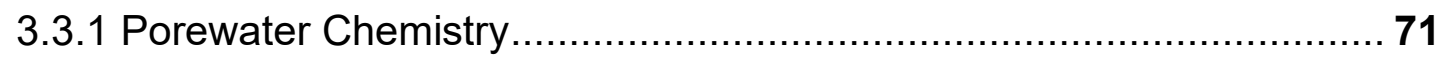

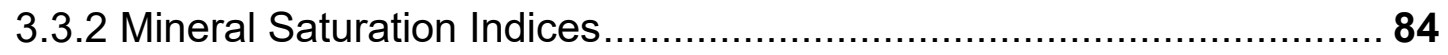

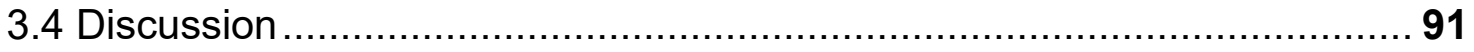

3.4.1 Porewater Chemistry and Secondary Controls ................................ 91 


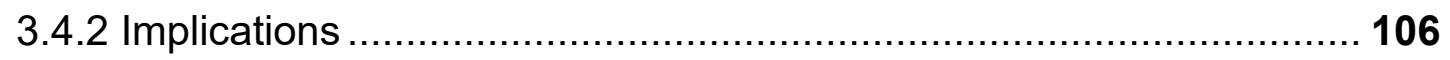

Chapter 4: Conclusions ….................................................................... 110

4.1 General Summary of Implications ................................................... 110

4.2 Recommendations for Areas of Future Research ................................. 111

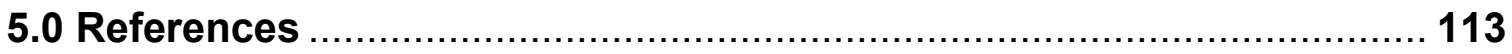




\section{List of Tables}

Table 2.1: Sulfide mineral oxidation ranking …............................................ 17

Table 2.2: Sulfide alteration index (SAI) of the Ore Chimney waste-rock pile .... 17 


\section{List of Figures}

Figure 1.1: Historical imagery (1934) of Ore Chimney (Natural Resources Canada, 2016).

Figure 2.1: a) Aerial schematic of the waste-rock pile with location of vertical transects (stars; $T=$ trench), b) Cross-sectional view of sampling locations ( $8 \times$ vertically exaggerated).

Figure 2.2: Major mineral phase depth plots for trench 1 (left), trench 2 (middle), and trench 3 (right).

Figure 2.3: Minor mineral phase depth plots for trench 1 (left), trench 2 (middle), and trench 3 (right). 25

Figure 2.4: Average pyrite, chalcopyrite, sphalerite, and galena oxidation ranking for each waste-rock sample location for trench 1 (left), trench 2 (middle), and trench 3 (right).

Figure 2.5: Common ore minerals under reflected light ( 0.5 to $2.0 \mathrm{~mm}$ grain size) (i.e. C1 refers to coarse grain fraction at trench 1). 30

Figure 2.6: Common ore minerals under reflected light ( $<0.5 \mathrm{~mm}$ grain size) (i.e. F3 refers to fine grain fraction at trench 3 ).

Figure 2.7: Trace ore minerals under reflected light (F: $<0.5 \mathrm{~mm}, \mathrm{C}: 0.5$ to 2.0 $\mathrm{mm}$ grain size). 32

Figure 2.8: BSE images of pyrite ( $a$ and $b$ ) and chalcopyrite ( $c$ and $d)$ weathering phases under SEM ( $<0.5 \mathrm{~mm}$ grain size).

Figure 2.9: BSE images of sphalerite ( $a$ and $b$ ) and galena ( $c$ and $d$ ) weathering phases under SEM (<0.5 mm grain size).

Figure 2.10: BSE images of pyrite and Ca-carbonate phases under SEM $(<0.5$ $\mathrm{mm}$ grain size)

Figure 2.11: Total $C$ and $S$ content (wt.\%) for coarse (left) and fine (right) grain fractions for a) trench 1, b) trench 2, c) trench 3. Error bars show the standard deviation from three consecutive measurements 35

Figure 2.12: Acid generation potential for a) trench 1, b) trench 2, c) trench 3. . 37 
Figure 2.13: Solid-phase iron ( $\mathrm{Fe})$, copper $(\mathrm{Cu})$, zinc $(\mathrm{Zn})$, and lead $(\mathrm{Pb})$ depth plots for trench 1 (left), trench 2 (middle), and trench 3 (right).

Figure 2.14: Solid-phase manganese (Mn), cadmium (Cd), arsenic (As), and antimony $(\mathrm{Sb})$ depth plots for trench 1 (left), trench 2 (middle), and trench 3 (right).

Figure 2.15: Solid-phase titanium (Ti), chromium ( $\mathrm{Cr}$ ), cobalt (Co), and nickel (Ni) depth plots for trench 1 (left), trench 2 (middle), and trench 3 (right).

Figure 2.16: Historical sketch of the Ore Chimney waste-rock pile updated with study sampling locations (modified from Kingston, 1980).

Figure 2.17: BSE images of Fe- and Ti-oxide phases in the Ore Chimney waste rock.

Figure 2.18: BSE images $(a$ and $b)$ and reflected light images $(c-f)$ of sulfide minerals bound with quartz $(Q)$.

Figure 3.1: a) Falcon ${ }^{\mathrm{TM}}$ tubes shortened to $45 \mathrm{~mL}$ and filled with loose wasterock material ( $2 \mathrm{~mm}$ hole drilled at the base and lined with glass wool), b) Falcon ${ }^{\mathrm{TM}}$ tubes shortened to $10 \mathrm{~mL}$ and placed underneath for porewater collection.

Figure 3.2: Aqueous-phase $\mathrm{pH}$, Eh, alkalinity, and sulfate $\left(\mathrm{SO}_{4}{ }^{2-}\right)$ depth plots for trench 1 (left), trench 2 (middle), and trench 3 (right).

Figure 3.3: Aqueous-phase sodium ( $\mathrm{Na})$, potassium $(\mathrm{K})$, calcium $(\mathrm{Ca})$, and magnesium ( $\mathrm{Mg}$ ) depth plots for trench 1 (left), trench 2 (middle), and trench 3 (right).

Figure 3.4: Aqueous-phase iron ( $\mathrm{Fe})$, copper $(\mathrm{Cu})$, zinc $(\mathrm{Zn})$, and lead $(\mathrm{Pb})$ depth plots for trench 1 (left), trench 2 (middle), and trench 3 (right). 77

Figure 3.5: Aqueous-phase manganese (Mn), cadmium (Cd), arsenic (As), and antimony $(\mathrm{Sb})$ depth plots for trench 1 (left), trench 2 (middle), and trench 3 (right).

Figure 3.6: Aqueous-phase titanium ( $\mathrm{Ti})$, chromium ( $\mathrm{Cr}$ ), cobalt (Co), and nickel (Ni) depth plots for trench 1 (left), trench 2 (middle), and trench 3 (right). 81

Figure 3.7: Aqueous-phase aluminum ( $\mathrm{Al})$, chloride $\left(\mathrm{Cl}^{-}\right)$, and phosphate $\left(\mathrm{PO}_{4}{ }^{3-}\right)$ depth plots for trench 1 (left), trench 2 (middle), and trench 3 (right). 
Figure 3.8: Calcite, dolomite, gypsum, and jarosite depth plot saturation indices for trench 1 (left), trench 2 (middle), and trench 3 (right). Dashed lines indicate SI boundary between -0.5 and +0.5

Figure 3.9: Gibbsite, boehmite, ferrihydrite, and $\mathrm{Cr}(\mathrm{OH})_{3(\mathrm{am})}$ depth plot saturation indices for trench 1 (left), trench 2 (middle), and trench 3 (right). 88

Figure 3.10: Manganite, $\mathrm{Mn}\left(\mathrm{HPO}_{4}\right)$, malachite, and otavite depth plot saturation indices for trench 1 (left), trench 2 (middle), and trench 3 (right). 89

Figure 3.11: Cerussite, $\mathrm{Pb}(\mathrm{OH})_{2}$, smithsonite monohydrate, and $\mathrm{Zn}(\mathrm{OH})_{2}$ depth plot saturation indices for trench 1 (left), trench 2 (middle), and trench 3 (right). 90 Figure 3.12: Ca correlation plot with Mg for trench 1 (left), trench 2 (middle), and trench 3 (right).

Figure 3.13: $\mathrm{Zn}$ correlation plots with $\mathrm{SO}_{4}{ }^{2-}, \mathrm{Ca}(\mathrm{mmol} / \mathrm{L}), \mathrm{pH}$, and $\mathrm{Cd}(\mu \mathrm{mol} / \mathrm{L})$ for trench 1 (left), trench 2 (middle), and trench 3 (right).

Figure 3.14: $\mathrm{Zn}(\mathrm{mmol} / \mathrm{L})$ correlation plots with $\mathrm{Pb}, \mathrm{Cu}, \mathrm{Co}$, and $\mathrm{Ni}(\mu \mathrm{mol} / \mathrm{L})$ for trench 1 (left), trench 2 (middle), trench 3 (right).

Figure 3.15: $\mathrm{Ca}(\mathrm{mmol} / \mathrm{L})$ correlation plot with $\mathrm{Mn}(\mu \mathrm{mol} / \mathrm{L})$ for trench 1 (left), trench 2 (middle), and trench 3 (right) 


\section{Chapter 1: Introduction}

\subsection{Mining and the Environment}

Canada's mining sector is an important part of the Canadian economy. As of the 2017 fiscal year, approximately 634,000 employment positions were created directly in or partially involved with mining (16,500 of which for indigenous people). Likewise, mining in Canada contributed $\$ 97$ billion CAD, which accounts for approximately $5 \%$ of Canada's total GDP (Marshall, 2017). Key resources that contribute to Canada's mining wealth include gold ( $\$ 8.8$ billion), coal ( $\$ 6.3$ billion), iron ore ( $\$ 4.7$ billion), and diamond ( $\$ 2.7$ billion CAD) (Natural Resources Canada, 2017), and the richness of natural resources in Canada appeals highly to prospecting and investing in the mining industry (Stedman and Green, 2019).

The treatment processes of ore material typically involve the use of different chemicals (Muhammed and Zhang, 1989). Gold, for example, is separated and purified with the help of harmful compounds such as cyanide and hydrogen peroxide (La Brooy et al., 1994). The waste material remaining from the purification process of ore bodies retains harmful chemicals and is typically unloaded nearby, as tailings. In addition, gold ore is often rich in other metals, in the form of silicate, sulfide, and oxide minerals, that are too expensive to purify and remain in the tailings after the gold is separated (Blowes et al., 2013). These minerals are more concentrated near ore bodies, but often persist throughout the subsurface within the surrounding area (Carranza and Sadeghi, 2012).

Waste rock is material that is removed to access the ore body and is different from tailings as it is left unprocessed. Although waste rock is not treated with harmful chemicals, the material itself contains metals in the form of sulfide minerals, which may reduce the quality of drainage waters under certain conditions. Waste rock tends to be lower in total sulfur (wt.\% S) content than the tailings material that is processed from the ore body (Sracek et al., 2004). However, active mining operations often impose steady removal and stockpiling of large volumes of waste- 
rock material that can be expensive to monitor (Amos et al., 2015). The rising demand for natural resources and the subsequent increasing scale in the Canadian mining industry comes with a growing importance of understanding the impact mining can have on the environment and how to properly manage minewaste material (Hudson-Edwards et al., 2011).

Mining regulations in Ontario were introduced in 1845 and mainly addressed exploration and land ownership rights and government tax requirements (MNDM, 2008). A discovery of a large silver deposit in Cobalt, Ontario, in 1903, prompted an extensive review of the Mining Act in 1906 designating a Mining and Lands Commissioner to regulate land claim practices, enforce labour health and safety measures, and mediate corporate legislative conflict (Kamerman, 2006). For example, prospectors in the early 1900's could not file for a mining patent until an ore discovery was made, which resulted in a plethora of exposed rocks at the surface from exploration. Likewise, labour disputes, engineering failures, and economic downfalls often created financial difficulties, which left a significant disregard for environmental considerations (Mackasey, 2000). It was not until the early 1990's that the Mining Act was updated to stipulate environmental reclamation upon site closure (Kamerman, 2006). As a result, the remains of historical mining activities are left scattered across Ontario among many other Canadian provinces leaving a legacy of contamination detrimental to surrounding ecosystems. Notorious examples include the Giant mine, NWT (O'Reilly, 2012), and Britannia mine, BC (Smitheringale, 2011); however, there are hundreds of smaller and lesser-known examples such as the Ore Chimney mine (the subject of this thesis) that may also pose environmental threats.

Waste-rock material piled at Earth's surface is exposed to significantly different conditions compared to its previous entrapment underground; namely, larger temperature variation and elevated oxygen concentrations. Seasonal fluctuations in temperature and precipitation accelerate chemical reactions between minerals in the waste-rock and oxidizing agents above ground surface (i.e. chemical weathering) (Akcil and Koldas, 2006). Moreover, weaker fragmented material from 
blasting coupled with the freeze-thaw dynamics of water in high-latitude climates exacerbate the effects of chemical weathering by opening conduits in surfaced material and increasing mineral reactivity with the atmosphere (Sinclair, 2014). Sulfide minerals can be classified into monosulfides such as sphalerite (ZnS) and galena $(\mathrm{PbS})$, and disulfides such as pyrite $\left(\mathrm{FeS}_{2}\right)$ and chalcopyrite $\left(\mathrm{CuFeS}_{2}\right)$. Monosulfide (1) and disulfide (2) weathering reactions under the presence of oxygen (Plumlee, 1999) can be generalized as:

$$
\begin{aligned}
X S_{(s)}+2 O_{2} & \rightarrow X^{2+}+S_{4}^{2-}(1) \\
X S_{2(s)}+\frac{7}{2} O_{2}+H_{2} O_{(l)} & \rightarrow X^{2+}+2 S_{4}^{2-}+2 H^{+}
\end{aligned}
$$

Where $X^{2+}$ represents a divalent transition metal with common examples including ferrous iron $\left(\mathrm{Fe}^{2+}\right)$, copper $\left(\mathrm{Cu}^{2+}\right)$, zinc $\left(\mathrm{Zn}^{2+}\right)$, and lead $\left(\mathrm{Pb}^{2+}\right)$. The main difference between equations 1 and 2 is that monosulfide oxidation under the presence of oxygen is a non-acid generating process. In general, metal-sulfide mineral oxidation reactions are often the main chemical weathering processes in mine wastes with the potential to release metals and acidity into the environment (Amos et al., 2015). Ferrous iron is of particular interest because it can further oxidize into ferric iron under the thermodynamic conditions at Earth's surface and precipitate as ferric hydroxide minerals. Consequently, the overall net reaction for pyrite oxidation generates two moles of acidity for every mole of sulfur (Blowes et al., 2013) (3):

$$
\mathrm{FeS}_{2(\mathrm{~s})}+\frac{15}{4} \mathrm{O}_{2}+\frac{7}{2} \mathrm{H}_{2} \mathrm{O}_{(\mathrm{l})} \rightarrow \mathrm{Fe}(\mathrm{OH})_{3(\mathrm{~s})}+2 \mathrm{SO}_{4}^{2-}+4 \mathrm{H}^{+}
$$

In the above reactions, elevated sulfate $\left(\mathrm{SO}_{4}^{2-}\right)$, dissolved metals $\left(\mathrm{X}^{2+}\right)$, and acidity may be expected; this poor-quality leachate water is referred to as acid mine drainage (AMD). When present, oxygen is the main agent for the oxidative dissolution of sulfide minerals. However, sulfide minerals, for example pyrite, can also oxidize under the presence of ferric iron (elevated in systems with $\mathrm{pH} \leq 3$ due 
to the increased solubility of ferric oxyhydroxides such as $\left.\mathrm{Fe}(\mathrm{OH})_{3}\right)$, which can contribute to the overall generation of acidity (Amos et al., 2015) (4):

$$
\mathrm{FeS}_{2(s)}+14 \mathrm{Fe}^{3+}+8 \mathrm{H}_{2} \mathrm{O}_{(l)} \rightarrow 15 \mathrm{Fe}^{2+}+2 \mathrm{SO}_{4}^{2-}+16 \mathrm{H}^{+}
$$

Depending on other minerals present in the waste-rock material, elevated acidity (i.e., equations 2, 3, and 4) can promote secondary mineral dissolution reactions that often control the geochemical weathering signatures observed in these aerobic systems. Calcium-bearing carbonate minerals most effectively buffer effluent to near-neutral levels if they are sufficiently present in the system. Calcite $\left(\mathrm{CaCO}_{3(s)}\right)$ and dolomite $\left(\mathrm{CaMg}\left(\mathrm{CO}_{3}\right)_{2(s)}\right)$ buffer acid-generating waste to an observed $\mathrm{pH}$ range of 6.2 to 8.3 (Parbhakar-Fox and Lottermoser, 2017). Moreover, calcite reacts faster than dolomite by one order of magnitude (Lapakko, 2002) and one mole of Ca-carbonate (represented by calcite) can buffer up to two moles of acidity (5):

$$
\mathrm{CaCO}_{3(s)}+2 \mathrm{H}^{+} \rightarrow \mathrm{Ca}^{2+}+\mathrm{H}_{2} \mathrm{CO}_{3} \quad \boldsymbol{p H}<\mathbf{6 . 4}
$$

In the absence of Ca-carbonates, or when these minerals have depleted from the system, continuous oxidation of sulfide minerals may further elevate the acidity and a different buffering mineral will control the $\mathrm{pH}$. One example of this is the Nickel Rim mine in Sudbury, Ontario, where the depletion of Ca-carbonate minerals in the upper portion of a tailings impoundment presented non-uniform $\mathrm{pH}$ measurements across depth (Johnson et al, 2000). If Ca-carbonates are depleted, the generalized mineral buffering sequence, in order of decreasing $\mathrm{pH}$, includes siderite $\left(\mathrm{Fe}^{2+} \mathrm{CO}_{3(s)}\right)$ (buffers at $\left.\mathrm{pH} \sim 5\right)$, aluminum hydroxide $\left(\mathrm{Al}(\mathrm{OH})_{3(s)}\right)(\mathrm{pH} \sim 4$ to 4.5 ), iron(III) (oxy)hydroxide ( $\mathrm{pH} \sim 2.5$ to 3.5 ), and aluminosilicate minerals (i.e. $\mathrm{NaAlSi}_{3} \mathrm{O}_{8}$ ) (significant at $\mathrm{pH}<2.5$ ) (Bain et al., 2001; Blowes et al., 2013; Amos et al., 2015).

Elevated concentrations of sulfate (equations 1 to 4) and dissolved calcium (equation 5) in the waste-rock porewaters, when approaching saturation in solution, can facilitate the precipitation of certain salts, such as gypsum (Blowes et 
al., 2013). This precipitation reaction proceeds independently of $\mathrm{pH}$ and limits the concentration of dissolved $\mathrm{Ca}^{2+}$ and $\mathrm{SO}_{4}^{2-}$ in solution (6).

$$
\mathrm{Ca}^{2+}+\mathrm{SO}_{4}^{2-}+2 \mathrm{H}_{2} \mathrm{O}_{(l)} \leftrightarrow \mathrm{CaSO}_{4} \cdot 2 \mathrm{H}_{2} \mathrm{O}_{(s)}
$$

Ferric iron $\left(\mathrm{Fe}^{3+}\right)$ is typically enriched over $\mathrm{Fe}^{2+}$ in aerobic systems as the final oxidation product of pyrite. Similarly, elevated ferric iron and sulfate (equation 3) and potassium (from the weathering of mica minerals) can precipitate jarosite and limit the dissolved concentration of ferric iron in porewaters (Leahy et al., 2009; Blowes et al., 2013) (7):

$$
\mathrm{K}^{+}+3 \mathrm{Fe}^{3+}+2 \mathrm{SO}_{4}^{2-}+6 \mathrm{H}_{2} \mathrm{O}_{(\mathrm{l})} \leftrightarrow \mathrm{KFe}_{3}\left(\mathrm{SO}_{4}\right)_{2}(\mathrm{OH})_{6(s)}+6 \mathrm{H}^{+}
$$

Consequent poor quality runoff waters released into the local watershed necessitates efforts to inhibit AMD processes and manage the waste material produced from mining. Traditionally, contaminated groundwater is pumped and treated at the surface (Rivett et al., 2006). However, actively treating contaminated mine waters, especially at decommissioned sites in secluded locations, is an expensive and painstaking process (Ford, 2003; Ziemkiewicz et al., 2003). Alternatively, passive treatment systems can be installed to react with drainage waters in-place and mitigate the financial burden from continuous pump-and-treat methods (Akcil and Koldas, 2006). Waste rock and tailings material deficient in Cacarbonate minerals may require an artificial Ca-carbonate supply (Hedin et al., 1994). Moreover, elevated metals and sulfate can be remediated by sulfur reducing bacteria that proliferate in anoxic wetland environments (Jameson et al., 2010).

Passively treating contaminated throughflow waters is a low-maintenance costeffective alternative for managing poor-quality mine drainage (Blowes et al., 2013). However, some chemically driven passive treatment systems still require maintenance and only remain functional along a 20- to 30-year timeline (Watzlaf et al., 2004). Alternatively, biologically driven wetland systems may have greater benefits as a long-term passive remediation option for treating mine drainage with 
a circumneutral $\mathrm{pH}$ (Hsu and Maynard, 1999). Advantages to natural wetlands include the high attenuation capacity and storage of metals as well as ecological benefits, especially when preceded by Ca-carbonate $\mathrm{pH}$ buffering (Sheoran and Sheoran, 2006; Mayes et al., 2009; Blowes et al., 2013). Recognizing the longterm weathering processes of mine waste may help understand the utility of wetland systems to naturally attenuate low-quality drainage water in contaminated sites (Machemer and Wildeman, 1992; Skousen et al., 2000).

\subsection{Ore Chimney}

Ore Chimney is a historical gold prospecting site located near the town of Harlowe, Ontario, approximately $150 \mathrm{~km}$ west of Ottawa (44 46'35" N, $77^{\circ} 9^{\prime} 10^{\prime \prime} \mathrm{W}$ ). The 500 -acre $\left(2 \mathrm{~km}^{2}\right)$ property lies within the southwest region of Frontenac County (Archibald, 2012). An abandoned 10 kiloton (kt) waste-rock pile remains from nearby underground exploration adjacent to an organic-rich fen (Kingston and Papertzian, 1982). Previous site research assessing local groundwater and surface water flow indicates drainage from the pile, downgradient into the wetland area with localized flow to the southeast. Preliminary chemical analyses of throughflow waters near the waste-rock pile indicate near-neutral $\mathrm{pH}$ with some elevated metals, particularly zinc, calcium, and magnesium (Harper et al., 2021). Seasonal water table fluctuations typically present wetland surface waters during the spring months and on-site vegetation mainly consists of spruce, poplar, and birch trees.

Ore Chimney experiences a warm-summer humid continental climate with significant seasonal variation in daylight and temperature. Records since 1981 indicate that the coldest temperatures arrive during January with an average monthly temperature of $-11.5^{\circ} \mathrm{C}$ and an elevated average temperature of $20.7^{\circ} \mathrm{C}$ during the month of July (Environment Canada, 2010). The hot summers frequently experienced around the Ottawa Valley raise humidity levels that increase the likelihood of severe storm events with strong winds and torrential downpours. The Ore Chimney property receives approximately $81 \mathrm{~cm}$ of 
precipitation per year as a combination of rain and snow (Environment Canada, 2010).

Gold findings at Ore Chimney were first made in 1902, which prompted the excavation of a $123.4 \mathrm{~m}$ vertical mineshaft and branching underground corridors from 1909 to 1917 (Harnois and Moore, 1989). Mining rights were first held by the Ore Chimney Mining Company Ltd., which funded development on the property including the construction of an ore-processing stamp mill in 1915. Subsurface development continued intermittently from 1923 to 1932, which focused on extending and reinforcing the lateral underground network. Proprietorship at Ore Chimney changed when the site was purchased by Bey Mines Ltd. in 1928. The property continued to experience changes in ownership and was subjected to various drilling, mapping, and geophysical surveys before the mineshaft was officially capped and decommissioned in 1991 (Archibald, 2012). Despite significant efforts in prospecting and underground development, no ore material was ever processed from the Ore Chimney mine; thus, is considered and referred to as a mine only in name (Moore and Morton, 1986).

The Ore Chimney property is situated within the Mazinaw Domain, which is a stretch of land approximately $25 \mathrm{~km}$ wide that extends from Madoc, Ontario, 100 km northeastwards into Quebec (McCarron, 2013). The Mazinaw Domain is distinguished from other geological terranes due to its abundance and variation of metavolcanic rocks, and structural evidence within the metamorphic lithology suggesting two deformational events (MNDM, 1994). The Mazinaw Domain is one of few geological domains and terranes that comprise the Central Metasedimentary Belt (CMB). The CMB is part of the Grenville Province that covers a significant portion of southeastern Ontario and is located near the southern boundary of the Canadian Shield (Easton, 2006).

The oldest lithological unit at Ore Chimney is the Tudor Formation, which is crystalline volcanic basement rock that formed no earlier than 1.5 billion years ago (Ga) (Moore and Thompson, 1980). The metavolcanics comprising the Tudor Formation mainly consist of tholeiitic basalt with the intermittent presence of 
amphibolite characterized by the foliation of hornblende with additional plagioclase feldspar and quartz. Minor and trace minerals attributed to the Tudor Formation include epidote, biotite, garnet, chlorite, pyrite, magnetite, tourmaline, and calcite (Harnois and Moore, 1988).

Overlying the Tudor Formation is the Ore Chimney Formation, which is a thin $(<10 \mathrm{~m})$ biotite schist unit extending across the local area but is most easily distinguished at the Ore Chimney property. Mixed into the matrix of the Ore Chimney Formation is the presence of muscovite with porphyroblasts of garnet and hornblende. Other minerals identified in minor amounts include magnetite, hematite, pyrite, chalcopyrite, apatite, tourmaline, chlorite, and titanite (Harnois and Moore, 1988). Genesis of the Ore Chimney Formation is proposed as a result from hydrothermal alteration, reconsolidation, and metamorphism of material eroded from the Tudor Formation. This unconformity and subsequent metamorphic activity led to the creation of the Ore Chimney Formation approximately $1.2 \mathrm{Ga}$ (Moore and Thompson, 1980).

The Flinton group overlies the Ore Chimney Formation and represents the youngest rocks in the area. The three main formations belonging to the Flinton group are the Myer Cave Formation, the Lessard Formation, and the Bishop Corners Formation. Surficial geology at the Ore Chimney property most commonly displays the Bishop Corners Formation, characterized by the presence of muscovite schist, quartzite, and oligomictic metaconglomerate. The minerals comprising the lithology of the Bishop Corners Formation include muscovite, quartz, plagioclase feldspar, orthoclase feldspar, and magnetite. The Flinton group was deposited in a fluvial environment resulting from continental uplift nearly 1.1 $\mathrm{Ga}$. The continental uplift was part of the Grenvillian Orogeny, which regionally deformed all the rocks in the area approximately $1 \mathrm{Ga}$ and is the most recent metamorphic activity on site (Moore and Thompson, 1980).

Major tectonic stresses exerted on the region over the course of the Grenvillian Orogeny opened fractures in the subsurface carrying fluids with solubilized mineral components from a nearby dyke intrusion that crystallized as a series of quartz 
veins hosting calcite and dolomite at average volume proportions of $5 \%$ that occasionally measured as high as $20 \%$ (Harnois and Moore, 1989). Property surveys reveal a network of 14 quartz veins on the Ore Chimney property, five of which display significant sphalerite, galena, pyrite, and chalcopyrite mineralization (Archibald, 2012). Extensive drilling through one of the quartz veins yielded gold estimates of $7 \mathrm{~g} /$ tonne $(\mathrm{Au})$, silver estimates as high as $193 \mathrm{~g} / \mathrm{tonne}(\mathrm{Ag})$ and assays of lead and zinc at 3.2 and 1.9 wt.\%, respectively (Carter 1984; Archibald, 2012). The quartz veins were the prospected ore deposit and formed $30 \mathrm{~m}$ below an unconformable contact between the Tudor Formation and the Bishop Corners Formation (Harnois and Moore, 1989).

\subsection{Thesis Structure and Objectives of Research}

Remaining at the Ore Chimney mine are the ruins of old structures, the abandoned mine shaft, and an estimated $\sim 10 \mathrm{kt}$ waste-rock pile that lies above the water table, approximately $30 \mathrm{~m}$ north of the mineshaft. Although prospecting activities continued at Ore Chimney until 1999, the $\sim 10$ kt waste-rock pile is documented to be formed from material removed to create the mineshaft and underground network from 1909 to 1932 (Archibald, 2012; Sangster et al., 2012). Aerial photography of the historical Ore Chimney mine in 1934 (Figure 1.1) combined with visual on-site inspections show little disturbance of the pile throughout time, corroborating estimations of $\sim 100$ years of subaerial exposure. Therefore, it is presumed that the waste-rock pile resembles material that was excavated as the underground network periodically expanded over an elapsed timeline of approximately 25 years. It is estimated that some of the earliest material was dumped $\sim 110$ years ago, and the most recent stockpiling of waste-rock material took place no later than $\sim 85$ years ago. The relationship between waste-rock pile strata and exposure time across the $\sim 25$-year underground tunneling phase is relatively uncertain aside from assuming that the development of the waste-rock pile follows Nicolaus Steno's principle of superposition (Winter, 1916). However, it is certain that the waste-rock pile at the Ore Chimney site, in its entirety, has been subjected to weathering above ground surface for a minimum of 85 years. 


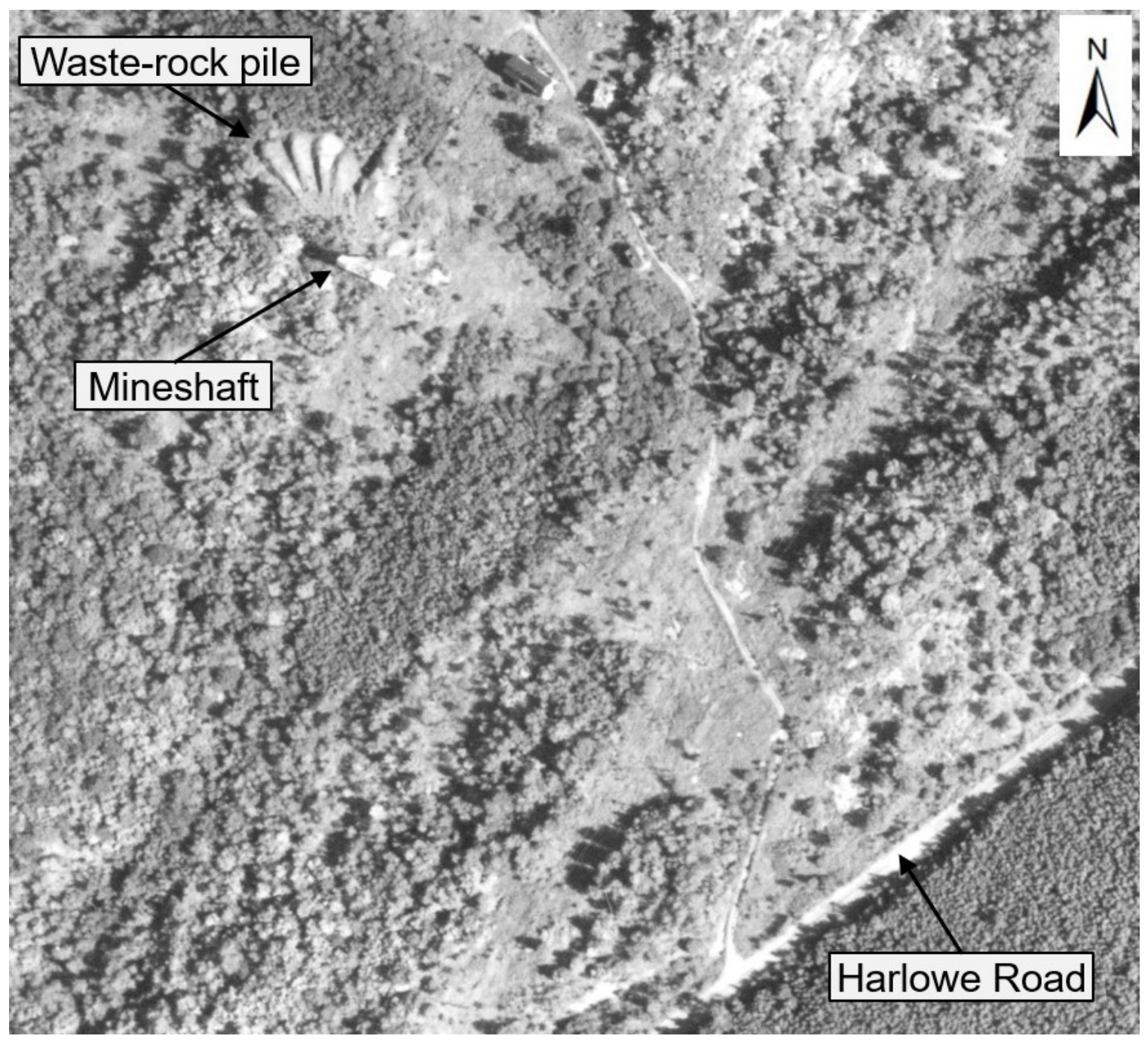

Figure 1.1: Historical imagery (1934) of Ore Chimney (Natural Resources Canada, 2016).

This study seeks to develop an improved understanding of the long-term mineral weathering in the waste-rock pile and the subsequent effects on metal transport. This has been accomplished by investigating the mineralogical and geochemical signatures that remain in this unsaturated aerobic system after $85+$ years of weathering and how these signatures change spatially. Waste-rock mineral weathering in mining environments has been studied in the past (Langman et al., 2015); however, there are limited historical mine-waste dumps that allow the possibility of collecting empirical data to investigate long-term wasterock weathering mechanisms. Likewise, few comprehensive studies have 
complemented waste-rock mineralogical investigations with detailed porewater measurements to better describe chemical pathways observed in aerobic minewaste systems (Atherton, 2017; Smith et al., 2021).

The research presented herein is divided into four chapters including the introduction, two research chapters, and the conclusion. Chapter two investigates mineral weathering processes using solid-phase mineralogical and geochemical data from optical microscopy, scanning electron microscopy with energy dispersive spectrometry (SEM-EDX), total carbon-sulfur (C/S) analysis, powdered $X$-ray diffraction (PXRD), and inductively coupled plasma atomic emission and mass spectrometry (ICP-AES/MS). Chapter three examines the porewater chemistry to complement metal-release mechanisms proposed in chapter two and investigate the overall mobility of metals throughout the pile. Results from spectrophotometry, probe measurements, anion chromatography (IC), and ICPAES/MS were interpreted with PHREEQC geochemical modeling software to evaluate secondary mechanisms controlling the porewater chemistry and changes with depth. Chapter four summarizes conclusions and outlines future research. 


\section{Chapter 2: Mineralogy and Solid-Phase Geochemistry}

\subsection{Introduction}

The increasing adaptability of modern civilization continues to accelerate the utility and extraction rate of Earth's resources, which has shaped the planet's surface dramatically since the industrial revolution (Hudson-Edwards et al., 2011). From the first recording of a streamlined iron ore smelting operation in 1737 near the St. Lawrence River, mining in Canada has remained a substantial component of the resource extraction industry (Cranstone, 2002). By volume, mining activities disturb and relocate more Earth materials than any other practice including the construction industry (ICOLD, 1996). In 2008, it was estimated that metal and nonmetal mining in Canada (i.e. excluding oilsands mining) accumulated 217 million tonnes (Mt) of mine tailings and $256 \mathrm{Mt}$ of waste rock that increased in production rate by 33\% from 2001 (Statistics Canada, 2012). Large mining operations will often reuse waste rock to strengthen tailings impoundments (Wickland et al., 2006; Gorakhki and Bareither, 2017), to reinforce roads (Amrani et al., 2021), and even as a natural fertilizer (Ramos et al., 2017). However, the majority of waste rock is typically stockpiled as large volumes of unsaturated material and may produce lowquality drainage waters from chemical weathering at Earth's surface (Akcil and Koldas, 2006; Blowes et al., 2013).

Waste-rock piles are often formed by edge dumping that extends the footprint of the pile in different lateral directions over time (Pearce et al., 2016). Dumping material off the edges of the pile fractionates particles based on grain size with coarser material accumulating towards the base (Lahmira et al., 2016). Differences in particle settling rates typically reveal stratified layers of varying grain size, which has been characterized in greater detail in various settings (Azam et al., 2007; Cash, 2014). Geochemical signatures in waste-rock piles are often reflected by physical heterogeneities (Smith et al., 2013a), and recognizing these processes to evaluate risks associated with waste-rock weathering must consider both the chemical and physical aspects of mine-waste systems (Amos et al., 2015). Waste- 
rock drainage waters affected by mineral weathering processes may percolate into neighbouring watersheds and necessitates a thorough understanding to inhibit the release of low-quality effluent and remediate contaminated waters at an industrial scale (Nordstrom and Alpers, 1999).

There have been many studies tailored to investigate mineral weathering and subsequent effects on water quality in mine tailings impoundments during the initial stages of development (Jamieson et al., 1995; Gleisner, 2005) and across multidecadal timescales (Moncur et al., 2005; Gunsinger et al., 2006a; Hayes et al., 2014; Moncur et al., 2015; Elghali et al., 2021). However, there is less emphasis in the literature on evaluating these processes in aerobic waste-rock systems (Lefebvre et al., 2001; Sracek et al., 2004; Smith et al., 2013b; Langman et al., 2014). Delineating waste-rock weathering mechanisms, which change over time and govern in situ geochemical signatures is typically accomplished by applying an array of analytical techniques that may include optical microscopy, SEM-EDX, electron microprobe analysis (EMPA), total C/S, XRD, ICP-AES/MS, and X-ray absorption spectroscopy (XAS) (Smith et al., 2013a; Langman et al., 2014; Elghali et al., 2018; Langman and Moberly, 2018; Bao et al., 2020, Bao et al., 2021). However, the research typically incorporates a smaller portion of these analyses and is often focused solely on in situ metal release mechanisms into the porewaters. Furthermore, sampling approaches may not fully encapsulate the effects of waste-rock heterogeneity and many test piles have only weathered for one or two decades. Limited studies have applied a wide range of analytical techniques and combined solid-phase and aqueous-phase geochemical data to investigate metal mobility at different scales (Smith et al., 2021). Moreover, very few mine-waste investigations have examined mineral weathering processes beyond 50 years (Jeong and Lee, 2003; Moncur et al., 2009) and a comprehensive mineralogical and geochemical study on century-old Ore Chimney waste rock may help bridge the gap in the effects between short-term and long-term weathering.

Historical mining operations had higher cut-off grades for ore material, which typically led to increased concentrations of sulfide minerals in older waste dumps 
compared to modern times (Kwong et al., 1997). Ontario's Ministry of Northern Development and Mines (2018) has documented over 5,000 abandoned mines across the province with potential environmental hazards that are not well understood. Therefore, it is important to recognize the long-term effects that wasterock weathering can impose on metal transport and how the underlying processes may change over time to make properly informed decisions and develop impactful management strategies (Berghorn and Hunzeker, 2001). This chapter aims to investigate metal release mechanisms after $\sim 100$ years of weathering at Ore Chimney while capturing the effects of waste-rock heterogeneity.

\subsection{Methods}

\subsubsection{Field Methods}

During the first week of November 2019, samples of waste-rock material were collected from three vertical transects of the $\sim 10 \mathrm{kt}$ waste-rock pile at the Ore Chimney site. Vertical trenches were spaced out approximately 10 metres from each other and from the edges of the pile. In reference to the surface of the pile, three vertical transects were dug to a depth of five metres, approximately corresponding to the total height of the pile above the original ground surface. Samples of in situ waste-rock material were collected every $0.5 \mathrm{~m}$ along an undisturbed sidewall of each trench using a trowel and 5 to $6 \mathrm{~kg}$ of material was transferred into $2721 \mathrm{~mL}$ Nasco Whirl-Pak sample bags. Waste-rock pile deconstruction was facilitated using a 4.5 tonne Bobcat E42 mini-excavator. The material sampled at each depth was subdivided into two classes, designated for hard-rock geochemistry and porewater chemistry investigations, respectively. Furthermore, two depth locations in each trench were designated for collecting duplicate samples (Figure 2.1). Samples of waste-rock material were stored in a freezer at $-22^{\circ} \mathrm{C}$ following each day of field work in preparation for subsequent laboratory analysis. 


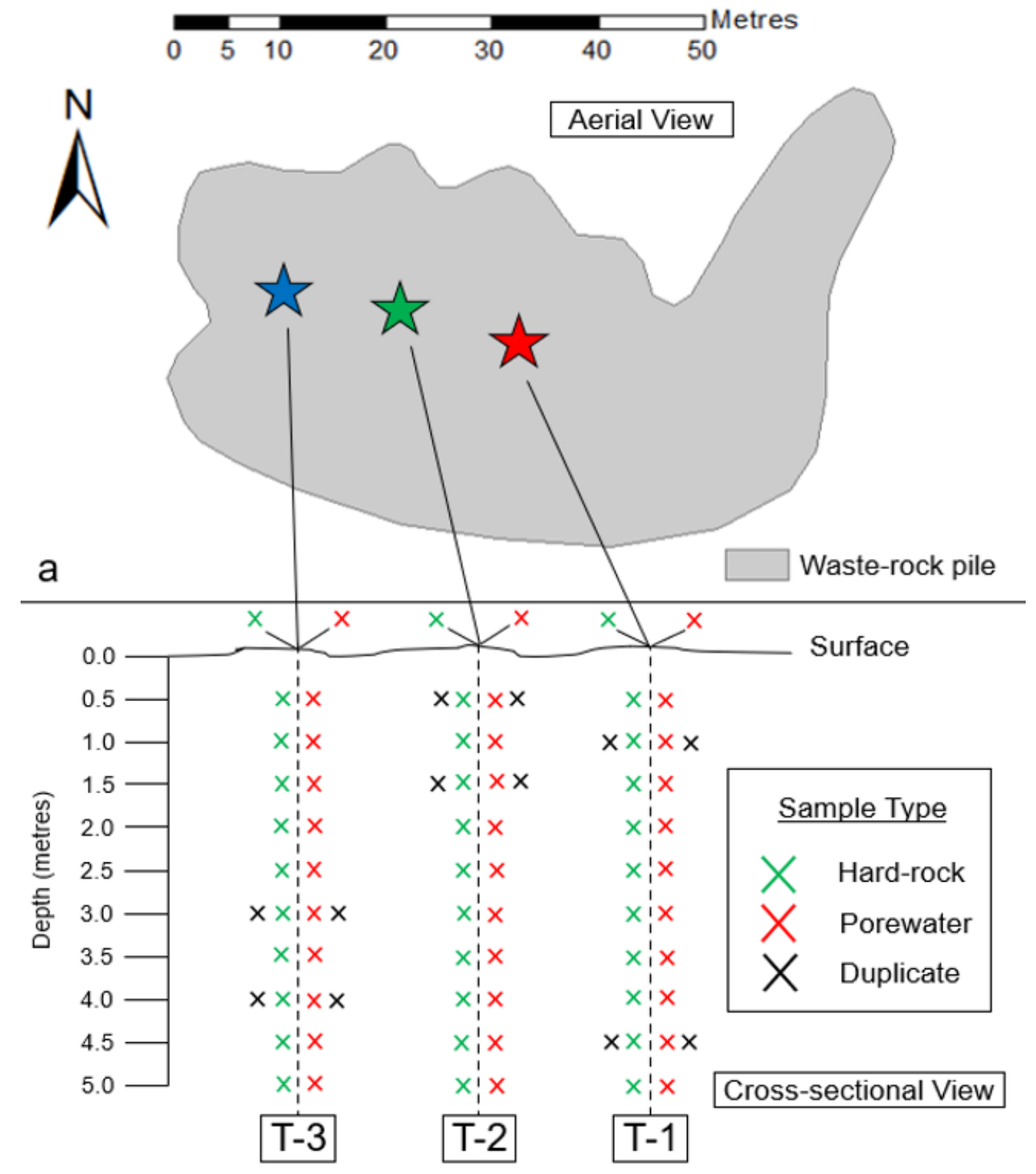

Figure 2.1: a) Aerial schematic of the waste-rock pile with location of vertical transects (stars; $T=$ trench), b) Cross-sectional view of sampling locations $(8 \times$ vertically exaggerated).

\subsubsection{Sample preparation}

Samples of waste-rock material were air-dried for 48 hours and passed through a two-millimetre sieve. The particles of waste-rock material that passed through the sieve were air dried for an additional 24 hours and the $>2.0 \mathrm{~mm}$ fraction was 
immediately returned to the freezer for future considerations. To contrast weathering on different grain size, air-dried samples less than two millimeters in diameter were passed through a second sieve with a $0.5 \mathrm{~mm}$ mesh size. Wasterock material 0.5 to $2.0 \mathrm{~mm}$ in diameter was designated as the coarse-grained fraction and material $<0.5 \mathrm{~mm}$ was designated as the fine-grained fraction. Sieved waste-rock material was passed through a Gilson Model: SP-33 stainless steel universal riffle splitter and material was split to a desired sample volume of $110 \mathrm{~mL}$ for archiving and subsample freeze-drying (ASTM C702/C702M-11, 2011).

Samples of waste-rock material were transferred into $125 \mathrm{~mL} V W R \otimes$ polypropylene wide mouth bottles and affixed with $20 \mu \mathrm{m}$ filter paper for modified lids. To ensure that sample moisture was removed, samples were freeze dried at $-87^{\circ} \mathrm{C}$ and 0.5 mbar for 24 hours using a Labconco FreeZone $2.5 L$ Benchtop Freeze Dry System with a 12-port drying manifold. A $\sim 40 \mathrm{~g}$ subsample of freezedried material for polished grain mount preparation was obtained by applying the ASTM quartering method (ASTM C702/C702M-11, 2011). The remaining sample material was crushed and homogenized for quantitative geochemical analyses. Freeze-dried $\sim 300 \mathrm{~g}$ subsamples were powdered to $<75 \mu \mathrm{m}$ using a (Rocklabs) stainless steel standard ring mill. Pulverised samples were submitted for PXRD, total $(\mathrm{C} / \mathrm{S})$ analysis, and ICP-AES/MS. Non-pulverised freeze-dried samples were prepared for optical microscopy and SEM-EDX.

\subsubsection{Analytical Methods}

Grain mounts of freeze-dried waste-rock material were prepared on glass slides ( $45 \mathrm{~mm} \times 25 \mathrm{~mm}$ ), immersed in a non-aqueous epoxy, and polished to a thickness of $60 \mu \mathrm{m}$. Grain mounts were prepared to a thickness of $60 \mu \mathrm{m}$ instead of $30 \mu \mathrm{m}$ to reduce the likelihood of obscurities and better preserve entire grains of finegrained ore minerals (Langman et al., 2015). The ore mineralogy of the polished grain mounts was characterized under reflected light using a Nikon OPTIPHOT$P O L$ polarizing microscope connected to a JENOPTIK ProgRes® microscope camera. To assess the extent of waste-rock sulfide mineral alteration from prolonged exposure above ground surface, the average condition of sulfide grains 
in coarse-grained samples was interpreted using an empirical ranking system (Table 2.1).

Table 2.1: Sulfide mineral oxidation ranking.

\begin{tabular}{cc}
\hline Rank & Description of average oxidation of sulfide grain \\
\hline 1 & Pristine rim (0 to $10 \%$ of mineral area) \\
2 & Thinly weathered rim (10 to $20 \%$ of mineral area) \\
3 & Moderately weathered rim (20 to $30 \%$ of mineral area) \\
4 & Extensively weathered rim ( $>30 \%$ mineral area) \\
\hline
\end{tabular}

With the average condition of each sulfide mineral in the coarse-grained fraction ranked, a sulfide alteration index (SAI) was developed to interpret the differences in weathering condition between the different sulfide minerals commonly found throughout the waste rock (Table 2.2). The SAl is based on similar scales in previous studies of mine-waste sulfide mineral weathering (Blowes and Jambor, 1990; Moncur et al., 2005, Moncur et al., 2009) but was tailored for the sulfide mineral assemblage ubiquitous to the Ore Chimney waste-rock pile and included pyrite $\left(\mathrm{FeS}_{2}\right)$, chalcopyrite $\left(\mathrm{CuFeS}_{2}\right)$, and sphalerite $(\mathrm{ZnS})$.

Table 2.2: Sulfide alteration index (SAI) of the Ore Chimney waste-rock pile.

\begin{tabular}{cc}
\hline Index score & Description of alteration \\
\hline \hline 4 & $\begin{array}{c}\text { Sulfide minerals near complete oxidation, traces of } \\
\text { pyrite and chalcopyrite remain, no sphalerite present } \\
\text { Sphalerite is sparse and remaining grains are } \\
\text { heavily oxidized, pyrite grains show alteration }\end{array}$ \\
2 & $\begin{array}{c}\text { Sphalerite grains show a thin oxidation rim with the } \\
\text { mineral core relatively preserved, pyrite and } \\
\text { chalcopyrite show minimal alteration }\end{array}$ \\
1 & $\begin{array}{c}\text { Sphalerite is common and relatively unweathered, } \\
\text { pyrite and chalcopyrite grains are pristine }\end{array}$ \\
\hline
\end{tabular}

Various mineral phases and subsequent regions of suspected chemical alteration in polished grain mounts representing the fine-grained fraction of sampled wasterock material were identified and prepared for SEM-EDX. Chemical analysis was performed using energy dispersive X-ray spectrometry with an Oxford silicon drift 
detector energy dispersive spectrometer (SDD-EDS) ultra-thin window detector coupled with a JSM-IT500 JEOL scanning electron microscope. Furthermore, secondary mineral formation and subsequent mineral structures were interpreted with digital back-scattered electron (BSE) high-resolution imagery.

PXRD was performed for bulk mineralogical analyses at a $(2 \theta)$ scan rate of $0.5^{\circ}$ /minute from 5 to $85^{\circ}$ at the University of Ottawa using a Rigaku Ultima IV Diffractometer. Peak data generated from PXRD was post-processed at Carleton University using @ PANalytical HighScorePlus software (version 4.7.0.24755). The primary mineral phases were identified in reference to the international centre for diffraction database (ICDD) and the amplitudes of peak data corresponded to mineral concentrations, quantified in relation to external standards developed in the ICDD. A conservative detection limit for PXRD mineral quantification and SEMEDX elemental composition was estimated at 2 wt.\% (Aguilar et al., 2019).

The total $\mathrm{C} / \mathrm{S}$ analysis was conducted at the University of Waterloo using an ELTRA CS-2000 Carbon/Sulfur analyzer with an induction furnace and infrared detector. The conservative detection limit for the ELTRA CS-2000 system was estimated at 0.02 wt.\% (Ripley et al., 2011). Inorganic carbon and sulfur content in a material sample are typically measured as a mass percentage value (wt.\%). Post-processing data from total $\mathrm{C} / \mathrm{S}$ analysis assumes that the $\mathrm{S}$ content is fixed as pyrite $\left(\mathrm{FeS}_{2(\mathrm{~s})}\right)$ and the inorganic carbon content is fixed as calcite $\left(\mathrm{CaCO}_{3(s)}\right)$. The acidification potential (AP) and neutralization potential (NP) was interpreted under the assumption that one mole of calcite (equation 5) neutralizes one mole of sulfur (equation 3). Therefore, the AP (8) and NP (9) of a sample can be estimated (Sobek, 1978; Blowes et al., 2013).

$$
\begin{gathered}
A P=\text { sulfur content of sample }(\mathrm{kg} / \text { tonne }) \times \frac{M_{w} \text { of calcite }(\mathrm{g} / \mathrm{mol})}{M_{w} \text { of sulfur }(\mathrm{g} / \mathrm{mol})} \\
N P=\text { carbon content of sample }(\mathrm{kg} / \text { tonne }) \times \frac{M_{w} \text { of calcite }(\mathrm{g} / \mathrm{mol})}{M_{w} \text { of carbon }(\mathrm{g} / \mathrm{mol})}
\end{gathered}
$$


Acidification and neutralization potential of waste-rock samples were classified according to INAC (1993). Waste-rock samples with NP:AP ratios less than 1:1 were described to have a "potential acid generating" (PAG) ability, NP:AP ratios between $1: 1$ and 3:1 were considered to have an "uncertain acid generating" (UAG) potential, and NP:AP ratios greater than 3:1 were termed "non-acid generating" (NAG) (Smith et al, 2013a).

ICP-AES/MS was performed at the Geochemistry Laboratory at the University of Ottawa. Freeze-dried and powdered waste-rock samples were subjected to a twostep acid digestion procedure. A $50 \mathrm{mg}$ subsample of sediment was weighed in a $7 \mathrm{~mL}$ Teflon vial. Ultra-pure nitric acid $(0.5 \mathrm{~mL})$ and hydrochloric acid $(1.5 \mathrm{~mL})$ (aqua regia) were added to the vial and settled for one hour. The loosely capped Teflon vials were heated at $110^{\circ} \mathrm{C}$ for 12 hours. The solution evaporated to near dryness and the residue was re-dissolved in $0.5 \mathrm{~mL}$ of nitric acid and $2 \mathrm{~mL}$ of Fisher Optima Grade and MilliQ $18.2 \Omega$ deionized water. Contents were transferred into pre-weighed $15 \mathrm{~mL}$ plastic vials and centrifuged. The clear portion of the solution containing major cations (i.e., $\mathrm{Al}, \mathrm{Ca}, \mathrm{Mg}$ ) was quantitatively transferred to another $15 \mathrm{~mL}$ vial and diluted with deionized water to a mass of $10.0 \mathrm{~g}$. Remaining residue mostly contained insoluble silicates and was transferred back into the $7 \mathrm{~mL}$ Teflon vial and digested with ultra-pure hydrofluoric acid $(0.5 \mathrm{~mL} \mathrm{HF})$ and nitric acid $(0.5$ $\mathrm{mL} \mathrm{HNO}_{3}$ ). Contents were evaporated to near dryness and residual hydrofluoric acid was removed by adding a second $0.5 \mathrm{~mL}$ portion of nitric acid and repeating the drying procedure. The residue was re-dissolved in $0.5 \mathrm{~mL}$ of nitric acid and 2 $\mathrm{mL}$ of deionized water and diluted to a mass of $10.0 \mathrm{~g}$. (N. De Silva, personal communications, 2021).

To compare metal concentrations between digestions representing more soluble solid phases (i.e. aqua regia) and less soluble silicate minerals (i.e. $\mathrm{HF}$ and $\mathrm{HNO}_{3}$ ), solutions from both steps of the acid digestion procedure were analyzed. Major cations were measured by ICP-AES using an Agilent 5110 SVDV CCD atomic emission spectrometer and trace metal concentrations were determined by ICPMS using an Agilent $8800 Q Q Q$ triple quadrupole mass spectrometer. Both ICP- 
AES and ICP-MS measurements were calibrated using external standards and all calibration standards were prepared using an ultra-pure 1\% nitric acid solution (N. De Silva, personal communications, 2021).

\subsection{Results}

Visual observations during excavation of the vertical transects at Ore Chimney revealed that the waste-rock pile (WRP) slightly exceeded five metres in depth at trench 1 . The beginning of a transitional boundary between the waste-rock pile and natural overburden material was estimated between 4.5 to 5.0 metres deep in trench 2 and between 4.0 to 4.5 metres deep in trench 3 . The subsequent geochemical depth plots indicate these non-discrete boundary estimations accordingly as "WRP boundary" and the samples located above these boundaries were referred to as the waste-rock material. Likewise, only the samples representing waste-rock material (i.e. excluding the samples below the WRP boundary) were included in statistical comparisons and the annotated results summary unless indicated otherwise.

The results presented herein compare fine-grained and coarse-grained materials, spatial differences within a given trench (i.e. vertical trends), and differences in measurements between trenches, but only trends and differences with a statistical significance are reported. Vertical trends were interpreted from a two-tailed Pearson correlation analysis with $95 \%$ confidence and compared to critical Pearson correlation $\left(R^{2}\right.$ critical) values of $0.553,0.576$, and 0.602 for trenches 1,2 , and 3, respectively (Degrees of Freedom $=n-2$ ) (Weatherington et al., 2012). Remaining statistical analyses were conducted as rank sum two-tailed t-tests calculating P-values $(\alpha)$ comparing fine- and coarse-grained samples of individual trenches $(n=$ sample size $=13$ in trench $1, n=12$ in trench 2 , and $n=11$ in trench 3). Additional t-tests that compared samples between trenches did not include data from duplicate samples and only considered samples between 0.0 to $4.0 \mathrm{~m}$ depth to account for the transition between waste rock and overburden material observed in trenches 2 and $3(n=9)$. Vertical trends with insignificant correlation coefficients $\left(R^{2}\right.$ calculated $<R^{2}$ critical) and t-test comparisons of population means $(\mu)$ with standard 
deviations $(\sigma)$ yielding no statistical difference $(\alpha>0.05)$ were interpreted as such and not reported herein.

\subsubsection{X-ray Diffraction: Phase Identification and Quantitation}

Quartz concentrations in the waste-rock material ranged from 35 to $62 \mathrm{wt} . \%$ (coarse-grained $\mu=48.1, \sigma=9.9$; fine-grained $\mu=42.9, \sigma=7.2$ ) in trench 1 , from 31 to 51 wt.\% (coarse-grained $\mu=42.2, \sigma=5.5$; fine-grained $\mu=37.3, \sigma=3.8$ ) in trench 2, and from 33 to $52 \mathrm{wt} . \%$ (coarse-grained $\mu=45.0, \sigma=5.3$; fine-grained $\mu$ $=41.6, \sigma=6.0$ ) in trench 3 (Fig. 2.2a - c). The lowest quartz concentrations of the fine-grained fraction were observed in trench 2 and were highest in trench 1 with a mean difference of $7.9 \mathrm{wt} . \%$ ( $\alpha=0.05 ; 0.0$ to $4.0 \mathrm{~m}$ depth). Quartz was the only mineral phase that consistently measured higher concentrations in the coarsegrained fraction of waste-rock samples throughout all three trenches. Quartz concentrations were statistically higher in the coarse-grained fraction than the finegrained fraction by mean differences of $5.2,4.9$, and $3.4 \mathrm{wt} . \%$ in trenches 1,2 , and 3 ( $\alpha=0.002,0.006$, and 0.03, respectively).

Oligoclase concentrations ranged from 10 to $25 \mathrm{wt} \%$ (coarse-grained $\mu=16.8, \sigma$ $=3.9$; fine-grained $\mu=17.8, \sigma=4.0$ ) in trench 1 , from 17 to 25 wt. $\%$ (coarsegrained $\mu=20.2, \sigma=2.6$; fine-grained $\mu=21.9, \sigma=2.5$ ) in trench 2 , and from 13 to $28 \mathrm{wt}$ \% (coarse-grained $\mu=17.9, \sigma=3.2$; fine-grained $\mu=21.1, \sigma=5.7$ ) in trench 3 (Fig. 2.2d - f). The lowest oligoclase concentrations of the coarse-grained fraction were observed in trench 1 and were highest in trench 2 with a mean difference of 4.6 wt. \% ( $\alpha=0.04)$. Oligoclase concentrations in the fine-grained fraction were statistically higher than the coarse-grained fraction in trenches 2 and 3 with mean differences of 1.8 and 3.2 wt. $\%(\alpha=0.05$ and 0.02 ).

Hornblende concentrations ranged from 5 to 12 wt. \% (coarse-grained $\mu=8.6, \sigma=$ 2.1; fine-grained $\mu=8.3, \sigma=2.3$ ) in trench 1 , from 7 to $16 \mathrm{wt} . \%$ (coarse-grained $\mu$ $=10.7, \sigma=2.4$; fine-grained $\mu=9.3, \sigma=1.6$ ) in trench 2 , and from 5 to $15 \mathrm{wt} . \%$ (coarse-grained $\mu=9.2, \sigma=2.3$; fine-grained $\mu=8.8, \sigma=2.5$ ) in trench 3 (Fig. $2.2 \mathrm{~g}$ - i). Hornblende concentrations within the waste-rock material were relatively consistent between trenches and did not vary statistically with depth. 
Biotite concentrations ranged from 9 to $27 \mathrm{wt} . \%$ (coarse-grained $\mu=14.6, \sigma=4.2$; fine-grained $\mu=16.7, \sigma=6.4$ ) in trench 1 , from 11 to 24 wt. $\%$ (coarse-grained $\mu=$ 14.8, $\sigma=2.5$; fine-grained $\mu=18.2, \sigma=3.6$ ) in trench 2 , and from 10 to 20 wt. $\%$ (coarse-grained $\mu=12.9, \sigma=2.3$; fine-grained $\mu=16.2, \sigma=2.9$ ) in trench 3 (Fig. 2.2j- I). The biotite mineral phase was predicted to host Ti, Mn, and $\mathrm{Zn}$ at trace atomic proportions of $0.1,0.01$, and 0.01 , respectively. Among the mineral phases identified by PXRD, biotite most consistently measured higher concentrations in the fine-grained fraction of waste-rock samples throughout all three trenches. Biotite concentrations in the fine-grained fraction were statistically higher than the coarse-grained fraction with mean differences of 2.1, 3.3, and 3.3 wt. $\%$ in trenches 1,2 , and 3 ( $\alpha=0.02,0.0003$, and 0.0004 , respectively).

Chlorite concentrations ranged from 3 to $7 \mathrm{wt} . \%$ (coarse-grained $\mu=5.3, \sigma=1.1$; fine-grained $\mu=5.5, \sigma=1.0$ ) in trench 1 , from 3 to 6 wt. $\%$ (coarse-grained $\mu=4.1$, $\sigma=0.9$; fine-grained $\mu=4.8, \sigma=0.8$ ) in trench 2, and from 3 to $7 \mathrm{wt} . \%$ (coarsegrained $\mu=4.9, \sigma=1.0$; fine-grained $\mu=4.9, \sigma=1.2$ ) in trench 3 (Fig. 2.3a - c). Chlorite concentrations within the waste-rock material were relatively consistent between trenches and did not vary statistically with depth.

PXRD analyses had a conservative detection limit of $2 \mathrm{wt} . \%$. As such, calcite often measured concentrations $<2$ wt.\% but were still incorporated in statistical calculations for simplicity, but with less emphasis in the discussion. Calcite concentrations ranged from below the detection limit to $6 \mathrm{wt} . \%$ (coarse-grained $\mu$ $=2.7, \sigma=1.0$; fine-grained $\mu=3.8, \sigma=2.0$ ) in trench 1 , from below detection to 3 wt. \% (coarse-grained $\mu=2.0, \sigma=0.4$; fine-grained $\mu=2.2, \sigma=0.6$ ) in trench 2, and below detection of $2 \mathrm{wt} . \%$ (coarse-grained $\mu=1.3, \sigma=0.5$; fine-grained $\mu=$ $1.5, \sigma=0.5$ ) in trench 3 (Fig. 2.3d - f). Although often measuring below detection, calcite concentrations in the coarse-grained fraction were highest in trench 1 and lower in trenches 2 and 3 by mean differences of 0.6 and 1.3 wt. \% ( $\alpha=0.05$ and 0.04). The same trends were observed in the fine-grained fraction with mean differences of 1.5 and 2.2 wt. $\%(\alpha=0.02$ and 0.04 ). Calcite concentrations in the 
fine-grained fraction were higher than the coarse-grained fraction in trench 1 with a mean difference of $1.1 \mathrm{wt} . \%(\alpha=0.003)$.

Dolomite concentrations ranged from below detection to $6 \mathrm{wt} . \%$ (coarse-grained $\mu$ $=2.9, \sigma=1.4$; fine-grained $\mu=2.3, \sigma=1.4$ ) in trench 1 , from 2 to 8 wt. $\%$ (coarsegrained $\mu=4.6, \sigma=1.5$; fine-grained $\mu=4.0,1.1$ ) in trench 2 , and from 3 to 13 wt. $\%$ (coarse-grained $\mu=7.0, \sigma=3.2$; fine-grained $\mu=4.6, \sigma=1.2$ ) in trench 3 (Fig. $2.3 \mathrm{~g}-\mathrm{i})$. Dolomite concentrations in the coarse-grained fraction were observed to be lowest in trench 1 and statistically higher in trenches 2 and 3 by mean differences of 2.1 and 4.4 wt. $\%$ ( $\alpha=0.004$ and 0.007 ). The same trend was observed for the fine-grained fraction with mean differences of 1.9 and $2.5 \mathrm{wt} . \%$ ( $\alpha$ $=0.01$ and 0.002). Dolomite concentrations in the coarse-grained fraction were higher than the fine-grained fraction in trench 3 by a mean difference of $2.4 \mathrm{wt} . \%$ $(\alpha=0.01)$.

Pyrite, ferroan sphalerite, and galena were the only sulfide phases identified from PXRD measurements. Due to their trace abundance, individual sulfide phases were difficult to quantify. Therefore, the sulfide mineral phases were presented herein as the summation of pyrite, ferroan sphalerite, and galena measurements. The sulfide mineral content typically measured below detection of $2 \mathrm{wt} . \%$ and ranged from 0 to $3 \mathrm{wt}$ \% in trench 1, from 1 to $4 \mathrm{wt} . \%$ in trench 2 , and from 1 to 4 wt.\% in trench 3 (Fig. 2.3j - I). There was no relationship between concentration and depth for any grain fraction of the cumulative sulfide mineral phases identified by PXRD.

The analytical sensitivity of PXRD analysis was estimated at $\sim 2 \mathrm{wt} . \%$ (Aguilar et al., 2019), which creates difficulties in reporting the presence of trace mineral phases with sufficient confidence. However, estimations of carbonate (i.e. calcite and dolomite) and sulfide mineral wt.\% from PXRD analysis was comparable to ranges observed from total C/S analysis (Fig. 10a - C). Any sulfide depth trends, differences in content between trenches, and differences between coarse and finegrained samples in the same trench were better interpreted from total [C] and [S] 
readings due to the higher sensitivity and no cumulative error associated with the reported measurements.

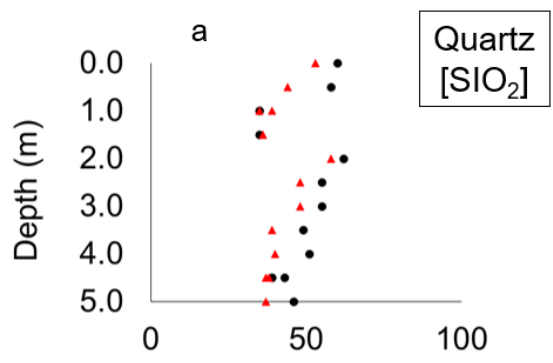

wt. \%

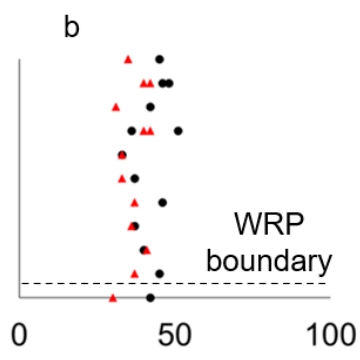

wt. \%

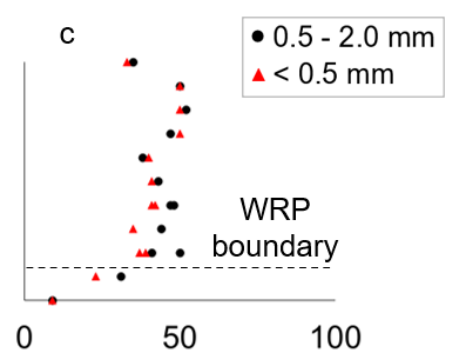

wt. \%
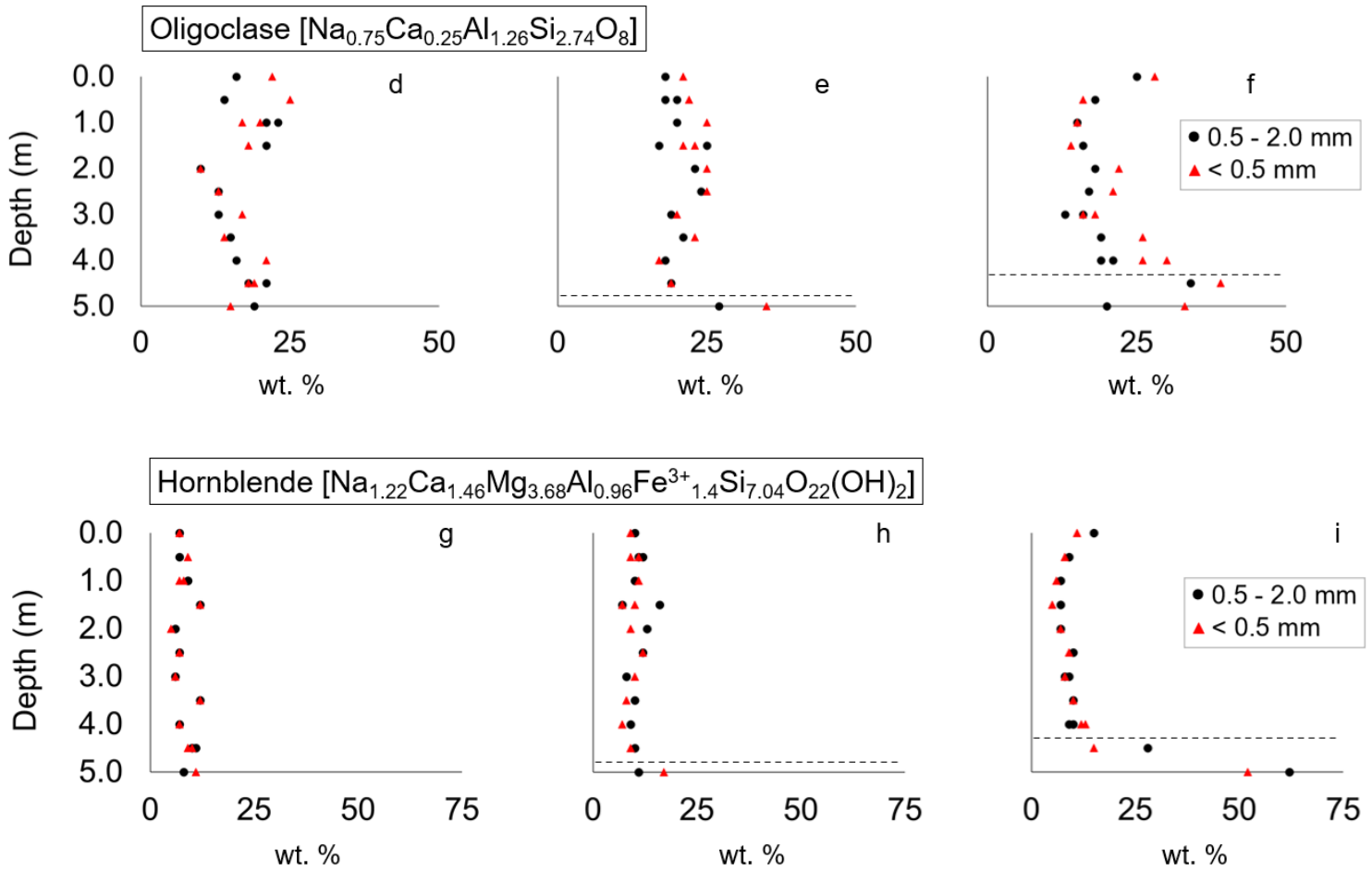

Biotite $\left[\mathrm{K}_{0.81} \mathrm{Mg}_{0.92} \mathrm{Na}_{0.04} \mathrm{Ti}_{0.1} \mathrm{Mn}_{0.01} \mathrm{Zn}_{0.01} \mathrm{Fe}^{2+}{ }_{1.4} \mathrm{Al}_{1.77} \mathrm{Si}_{2.7} \mathrm{O}_{10.14}(\mathrm{OH})_{1.77} \mathrm{~F}_{0.09}\right]$
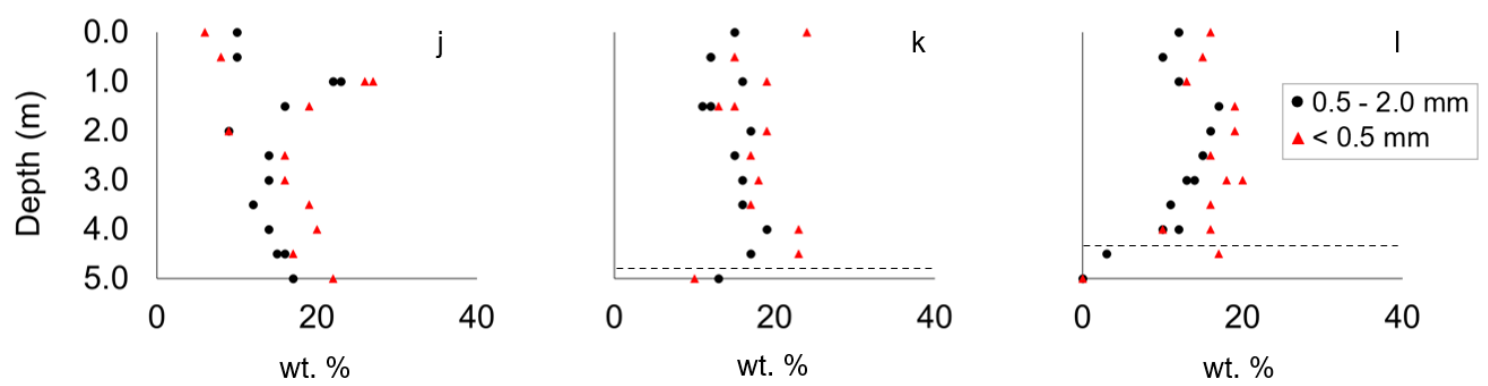

Figure 2.2: Major mineral phase depth plots for trench 1 (left), trench 2 (middle), and trench 3 (right). 

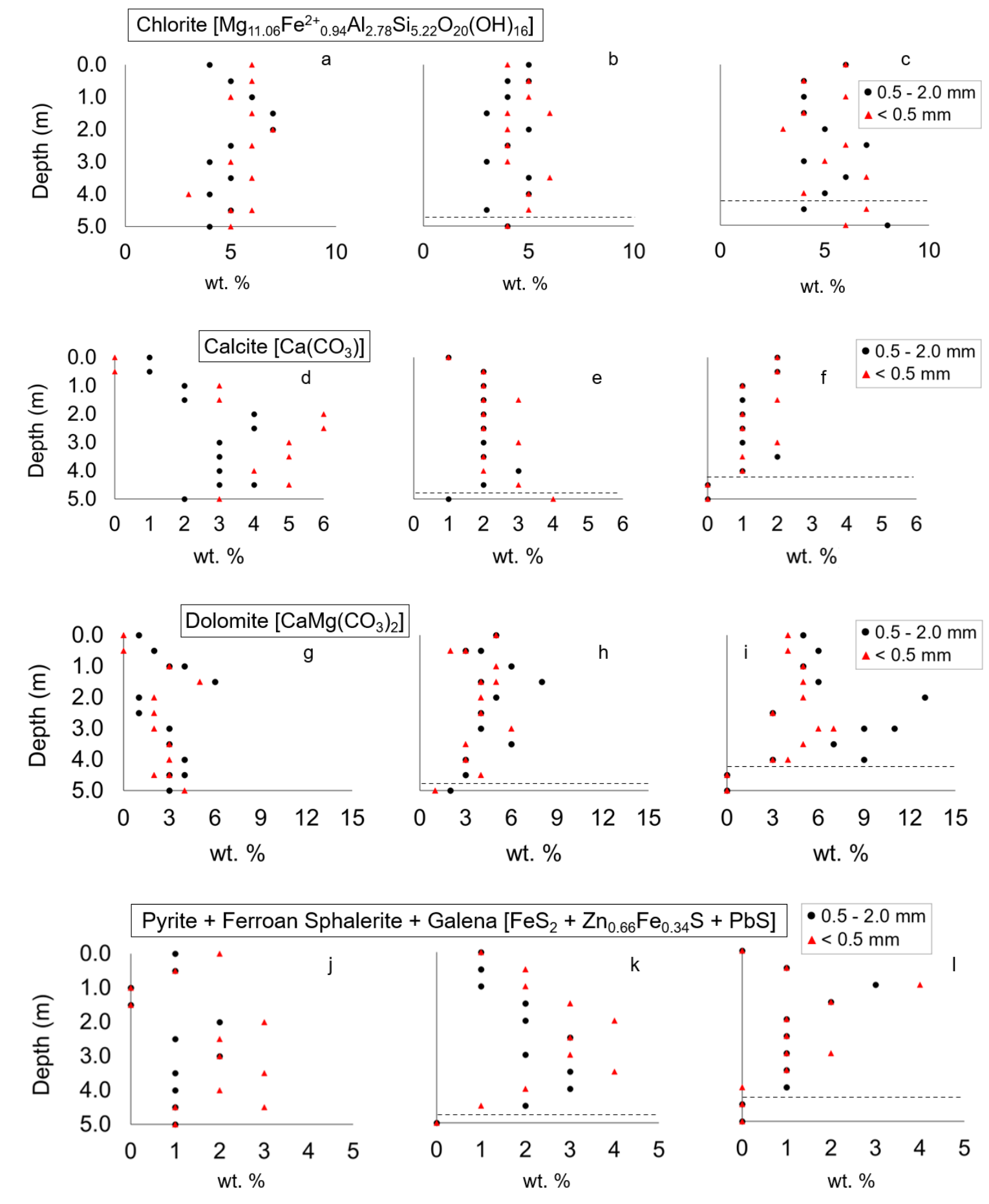

Figure 2.3: Minor mineral phase depth plots for trench 1 (left), trench 2 (middle), and trench 3 (right). 


\subsubsection{Ore Petrography}

The four most common sulfide minerals from high to low relative abundance in the polished grain mounts were sphalerite $(\mathrm{ZnS})>$ galena $(\mathrm{PbS})>$ pyrite $\left(\mathrm{FeS}_{2}\right)$ $>$ chalcopyrite $\left(\mathrm{CuFeS}_{2}\right)$ and were analyzed for the degree of oxidation based on the empirical ranking scheme presented in Table 2.1. Each polished grain mount (representing a sample of waste-rock material) contained approximately 3 to 8 pyrite and chalcopyrite grains (each) and 5 to 12 sphalerite and galena grains (each). Sulfide mineral grains within the same grain mount often showed a slight range in weathering and results are presented as an average rank for each sulfide mineral for each sample (one sample for each depth location in each trench; $n=13$ for trench $1, n=12$ for trench 2 , and $n=11$ for trench 3 ). All four sulfide minerals showed some indication of weathering (Fig. 2.4a - I). The average degree of weathering for the four common sulfide minerals was relatively consistent between trenches and did not vary significantly with depth. Chalcopyrite displayed the lowest average degree of weathering with mineral grains typically assigned a rank of 1 , indicating a very thin zone of alteration. In many instances, pyrite grains showed a similar alteration range to chalcopyrite; however, displayed a slightly higher average degree of weathering (i.e. a higher proportion of samples assigned an average rank of 2). In general, galena grains weathered to a similar extent as pyrite; however, exhibited a higher average range in weathering throughout each trench with more samples assigned a rank of 3 . Sphalerite mineral grains were observed to be weathered to the highest extent with all samples given an average rank of 2 or 3. 

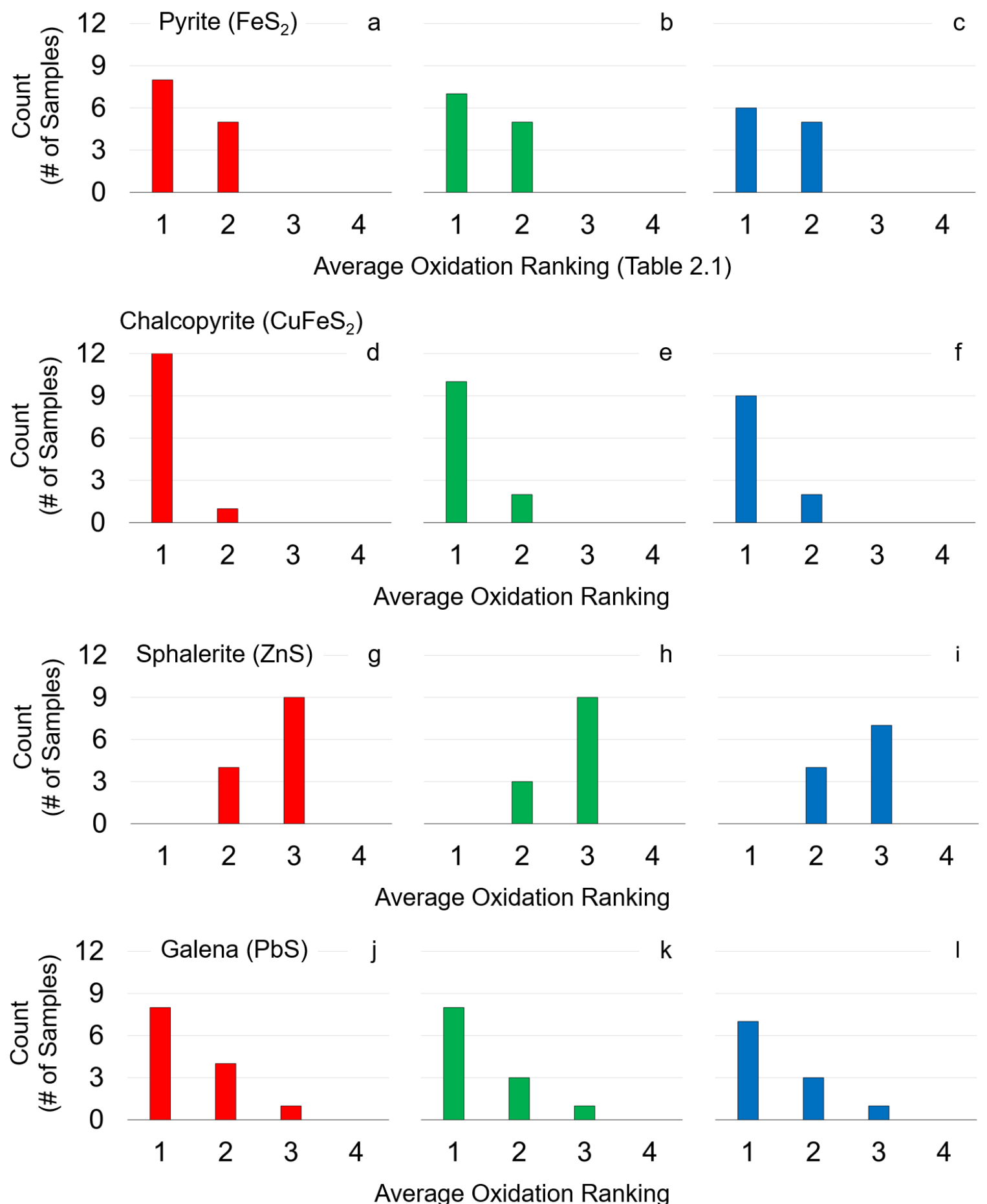

Figure 2.4: Average pyrite, chalcopyrite, sphalerite, and galena oxidation ranking for each waste-rock sample location for trench 1 (left), trench 2 (middle), and trench 3 (right). 
The variation in the degree of sulfide mineral weathering of individual grains within the same sample reflected the overall variation in the average ranks distributed between sample locations. For example, the sample representing $4.5 \mathrm{~m}$ depth in trench 1 revealed pyrite grains that were oxidized $<10 \%$ of the mineral area (rank of 1; Fig. 2.5a) and 10 to $20 \%$ of the mineral area (rank of 2; Fig. 2.5b). Likewise, pyrite grains with an oxidation rank of 1 (Fig. 2.5e) and a rank of 2 (Fig. 2.5c, d, and f) were observed from samples representing different depths in different trenches. Chalcopyrite mineral grain oxidation ranks also ranged from 1 (Fig.2.5h, $\mathrm{i}, \mathrm{k}$, and I) to 2 (Fig. $2.5 \mathrm{~g}$ and j); however, most grains had an average condition of 1. Sphalerite mineral grain condition ranged from 2 (Fig. $2.5 \mathrm{~m}$, p and r) to 3 (Fig. $2.5 \mathrm{n}, \mathrm{o}$, and q) and the average galena grain condition varied at 1 (Fig. 2.5s and u), 2 (Fig. 2.5t, v, and w), and 3 (Fig. 2.5x).

Sulfide Alteration Index (SAI) scores were assigned based on the overall degree of weathering, taking into account the suite of sulfide minerals, their abundance, and their average oxidation rank (Table 2.2). Galena was omitted from SAI interpretations due to a "persistence effect" described by Moncur et al (2009). The overall magnitude of weathering of the Ore Chimney waste-rock material was defined primarily by the prevalence and condition of sphalerite grains, which exhibited a combination of thinly weathered, moderately weathered, and extensively weathered rims. In addition, other sulfide minerals such as pyrite and chalcopyrite were noticeably less weathered than sphalerite. In general, the SAI scores for each sample ranged from 2 to 3 and showed no significant change with depth nor between trenches.

Systematic ranking of sulfide mineral weathering as described above was completed on the coarse-grained fraction of waste-rock samples. However, the average extent of sulfide mineral oxidation in the fine-grained fraction was also observed to be highest in sphalerite grains (Fig. $2.6 \mathrm{~m}$ - r) and lowest in chalcopyrite grains (Fig. $2.6 \mathrm{~g}-\mathrm{I}$ ). In addition, individual sphalerite, pyrite (Fig. 2.6a - f), and galena (Fig. 2.6s - x) grains also displayed a range in alteration within the same samples and between sample locations. Intricacies in the preparation of polished 
grain mounts and the inherent weathering variability of sulfides made it difficult to assess any distinct difference in mineral reactivity between coarse and finegrained fractions. Pyrite, chalcopyrite, sphalerite, and galena were common in both grain fractions and the corresponding condition of mineral alteration rims between grain size ranges was similar in most cases. On average, the number of individual sulfide mineral grains were higher in the fine-grained fraction and sometimes presented a greater intra-sample variability in mineral alteration. Furthermore, pyrite fracturing was more apparent in the fine-grained fraction and pyrite mineral cores were often observed to be smaller (Fig. 2.6d and e).

In addition to pyrite, chalcopyrite, sphalerite, and galena, the Ore Chimney wasterock material contained additional ore minerals that were found only in a few sample locations. These mineral phases included a $(\mathrm{Cu}, \mathrm{Sb}) \mathrm{S}$ phase (potentially famatinite), a (Cu,Sb,Ag)S phase (potentially freibergite), arsenopyrite (FeAsS), magnetite $\left(\mathrm{Fe}_{3} \mathrm{O}_{4}\right)$, ilmenite $\left(\mathrm{FeTiO}_{3}\right)$, rutile $\left(\mathrm{TiO}_{2}\right)$, and titanite $(\mathrm{CaTiSiO})$ (Fig. 2.7a - f). Although below the detection limit, arsenopyrite, magnetite, and ilmenite measured trace concentrations of Co $(<1 \mathrm{wt} . \%)$. Each of these trace ore mineral phases were observed to be altered to some extent; however, they were not abundant enough throughout the pile to accurately supplement assessments of overall sulfide mineral alteration.

Sulfide mineral investigations of the fine-grained fraction of waste-rock material under SEM-EDX revealed that unweathered pyrite predominantly consisted of $\mathrm{Fe}$ and $S$ with concentrations below detection $(<1.0 \mathrm{wt} . \%)$ of mercury $(\mathrm{Hg})$, cobalt (Co), and nickel (Ni). Alteration zones of pyrite grains were observed as a Fe-oxide phase containing $\mathrm{Pb}, \mathrm{Zn}$, and sometimes $\mathrm{Cu}$ (Fig. 2.8a and b). Pyrite mineral grains also exhibited various degrees of fracturing, which revealed increased zones of alteration and were increasingly apparent with smaller grain size. Unweathered chalcopyrite grains were composed of $\mathrm{Cu}, \mathrm{Fe}$, and $\mathrm{S}$ with no detectable trace concentrations of other metals. Alteration zones of chalcopyrite were mostly comprised of a Fe-oxide phase with detectable concentrations of $\mathrm{Pb}$, $\mathrm{Zn}$, and $\mathrm{Cu}$. Measured concentrations of $\mathrm{Cu}$ in unweathered chalcopyrite cores 
ranged from 30 to $36 \mathrm{wt} . \%$ and were significantly lower within the alteration zones ranging from 5 to $15 \mathrm{wt}$ \% (Fig. 2.8c and d).
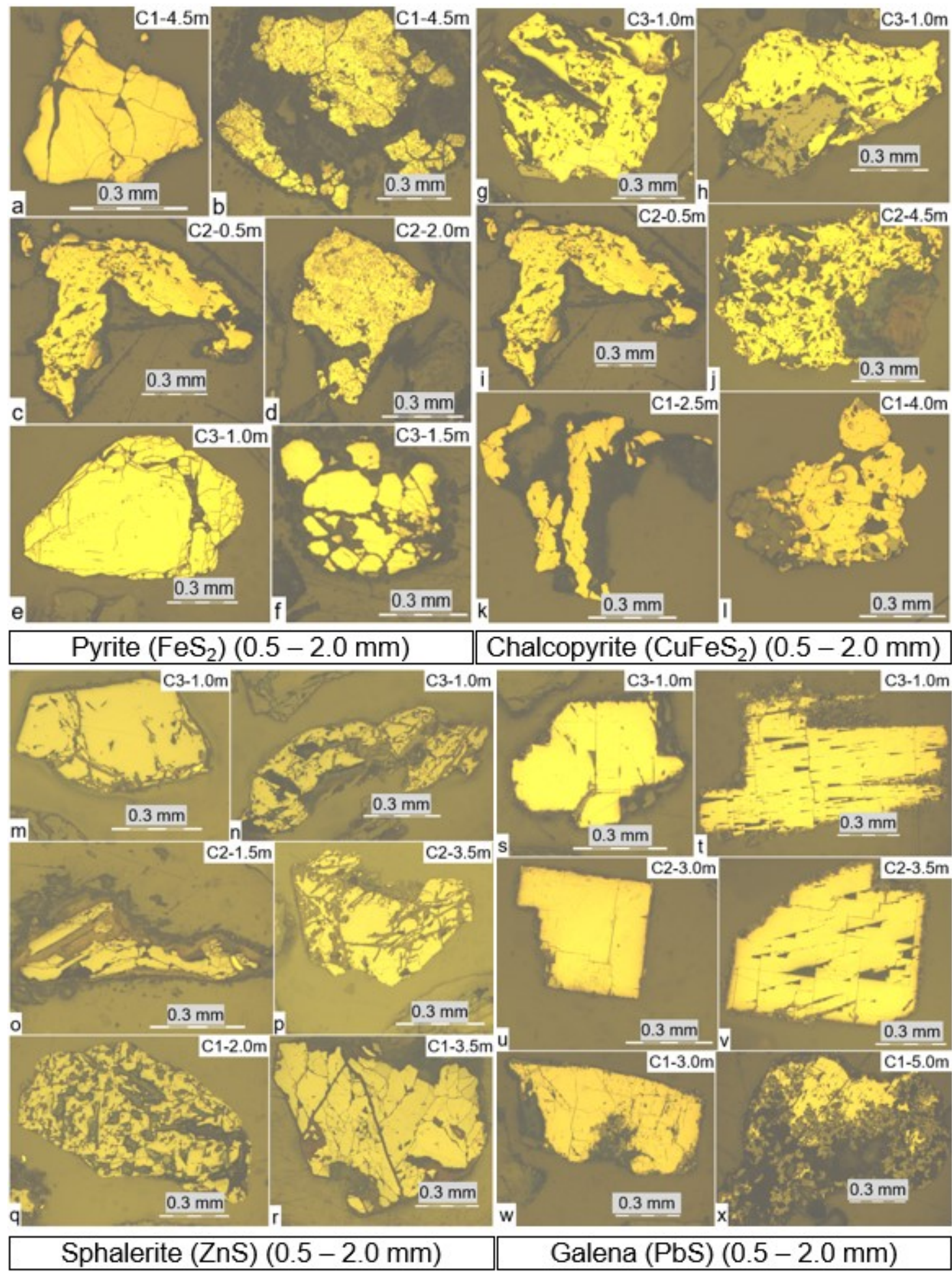

Figure 2.5: Common ore minerals under reflected light $(0.5$ to $2.0 \mathrm{~mm}$ grain size) (i.e. $\mathrm{C} 1$ refers to coarse grain fraction at trench 1). 


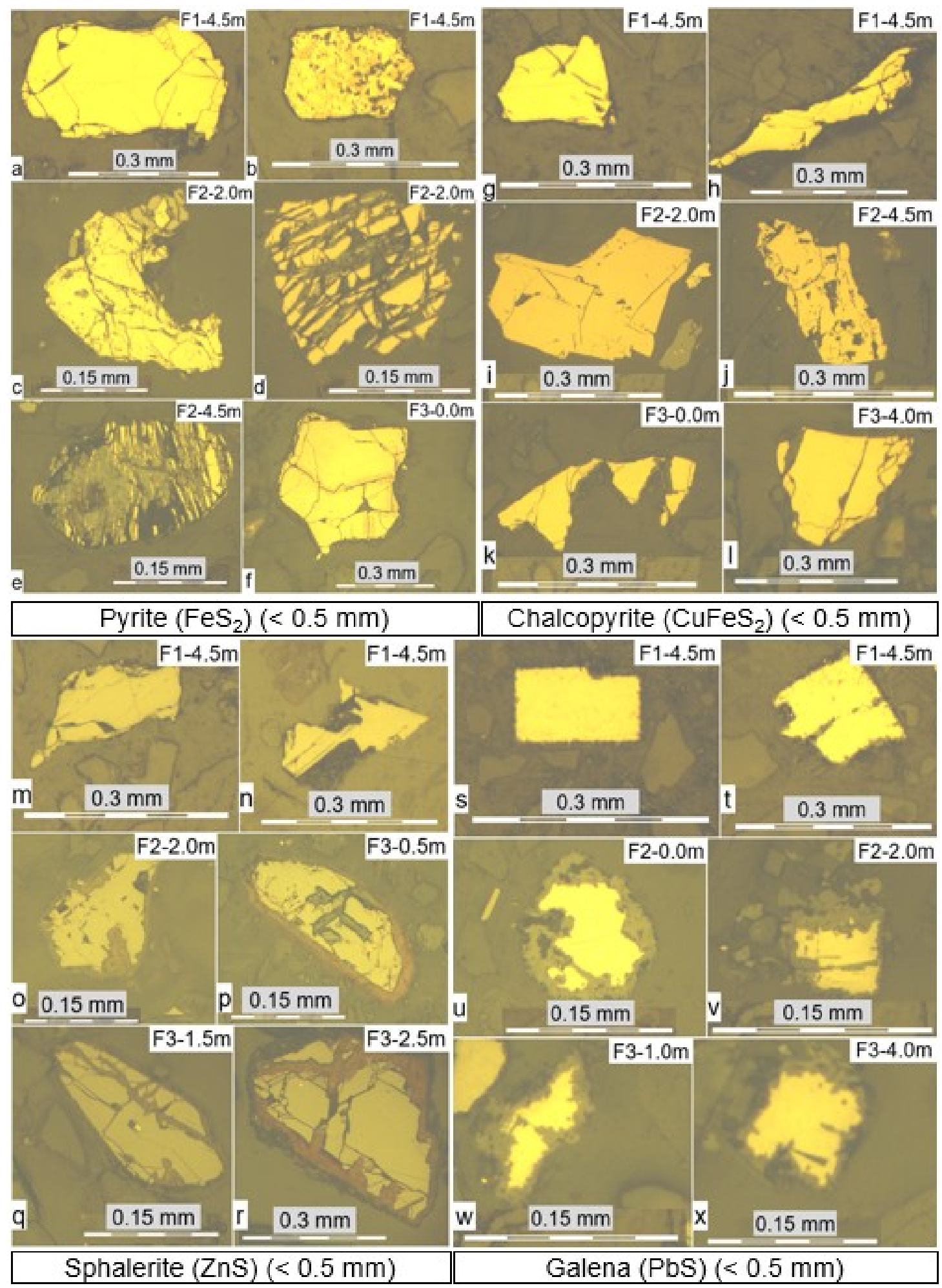

Figure 2.6: Common ore minerals under reflected light ( $<0.5 \mathrm{~mm}$ grain size) (i.e. F3 refers to fine grain fraction at trench 3 ). 


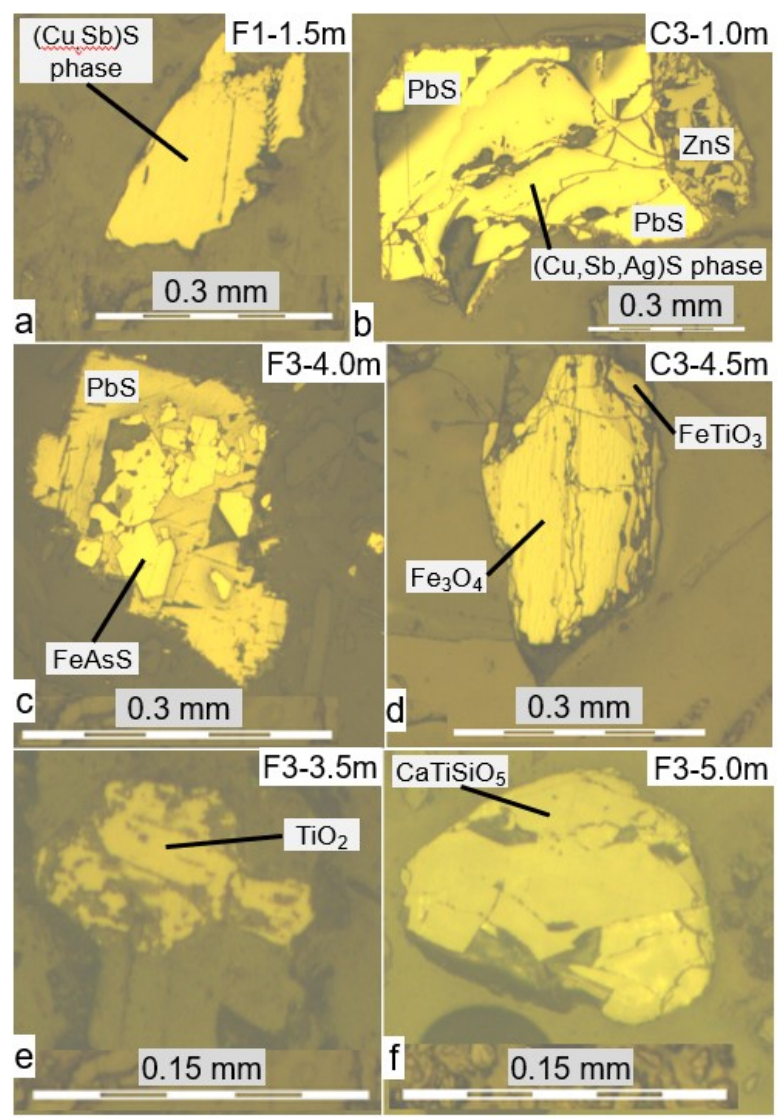

Figure 2.7: Trace ore minerals under reflected light ( $F:<0.5 \mathrm{~mm}, \mathrm{C}: 0.5$ to $2.0 \mathrm{~mm}$ grain size).

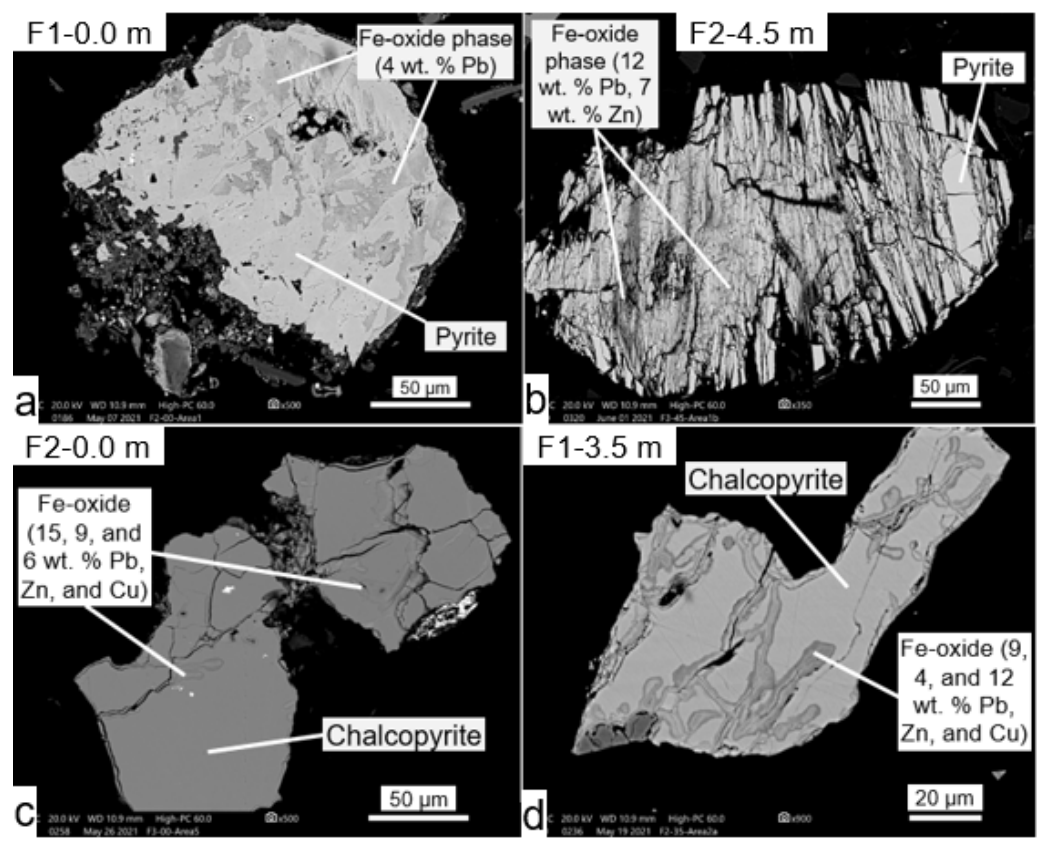

Figure 2.8: BSE images of pyrite ( $a$ and $b$ ) and chalcopyrite (c and d) weathering phases under SEM ( $<0.5 \mathrm{~mm}$ grain size). 
Unaltered sphalerite mineral cores were primarily composed of $\mathrm{Zn}$ and $\mathrm{S}$ with 7 to 10 wt.\% Fe, under range Cd (1 to $2 \mathrm{wt} . \%$ ), and $<1$ wt.\% Ni. Sphalerite alteration zones were typically comprised of a $\mathrm{ZnCO}_{3}$ phase (hereafter referred to as smithsonite) and 15 to $19 \mathrm{wt}$.\% Fe potentially as an accessory Fe-oxide phase with detectable concentrations of $\mathrm{Pb}$ and sometimes $\mathrm{Cu}$ (<5.0 wt.\%) (Fig. 2.9a and b). There was no detection of $\mathrm{Cd}$ in the alteration zones of any sphalerite grains. Pristine galena mineral cores were composed entirely of $\mathrm{Pb}$ and $\mathrm{S}$ with no presence of other trace metals. Galena alteration zones were mainly composed of a cerussite $\left(\mathrm{PbCO}_{3}\right)$ phase with detectable concentrations of $\mathrm{Zn}$ and sometimes $\mathrm{Cu}$ (<5.0 wt.\%) (Fig. 2.9c and d). Calcite measured Mg concentrations up to 2 wt. \%, and although below detection, both calcite and dolomite occasionally hosted trace concentrations of $\mathrm{Mn}(<1 \mathrm{wt} . \%)$. Calcite and dolomite were observed both as loose grains and within sulfide minerals such as pyrite (Fig. 2.10a and b).

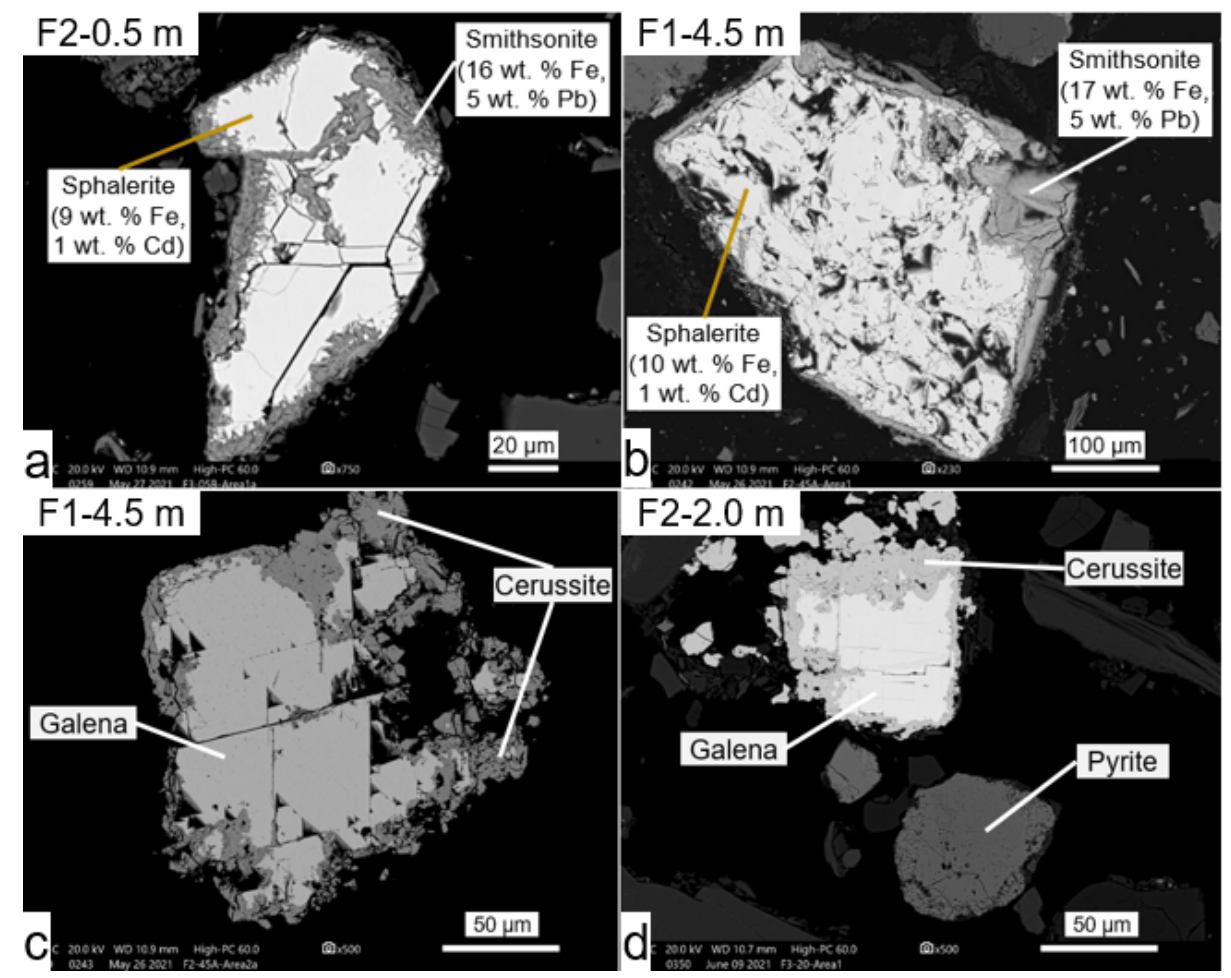

Figure 2.9: BSE images of sphalerite ( $a$ and $b$ ) and galena (c and $d$ ) weathering phases under SEM ( $<0.5 \mathrm{~mm}$ grain size). 


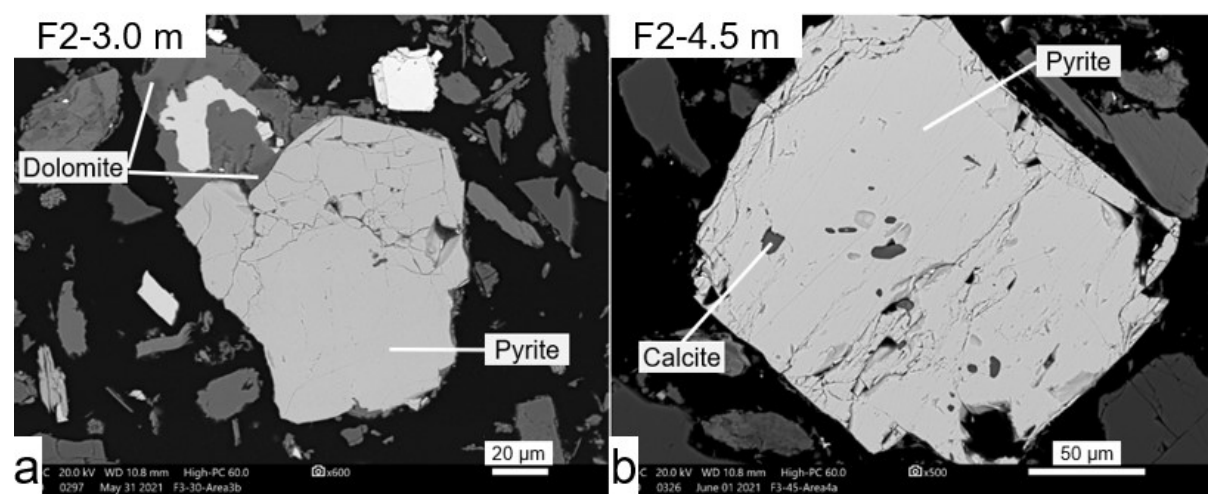

Figure 2.10: BSE images of pyrite and Ca-carbonate phases under SEM $(<0.5 \mathrm{~mm}$ grain size) .

Although trace concentrations of certain metals (i.e. Co, $\mathrm{Ni}, \mathrm{Cd}, \mathrm{Mg}$, and $\mathrm{Mn}$ ) were measured below the detection limit of $\sim 2 \mathrm{wt} . \%$, the presence of these trace metals from the proposed mineral sources remains likely due to metal concentrations confirmed via solid-phase ICP-AES/MS (section 2.4.3).

\subsubsection{Total Inorganic Carbon and Sulfur (C/S) Analysis}

Sulfur concentrations in the waste-rock material ranged from 0.6 to $4.3 \mathrm{wt} . \%$ (coarse-grained $\mu=2.4, \sigma=1.1$; fine-grained $\mu=2.3, \sigma=1.1$ ) in trench 1 , from 1.1 to 4.1 wt. $\%$ (coarse-grained $\mu=2.0, \sigma=0.8$; fine-grained $\mu=2.0, \sigma=0.6$ ) in trench 2 , and from 0.3 to $4.0 \mathrm{wt} . \%$. (coarse-grained $\mu=1.8, \sigma=1.0$; fine-grained $\mu=1.6$, $\sigma=0.9$ ) in trench 3 . Inorganic carbon measurements ranged from 0.2 to $2.2 \mathrm{wt} . \%$ (coarse-grained $\mu=1.3, \sigma=0.6$; fine-grained $\mu=1.4, \sigma=0.6$ ) in trench 1, from 0.9 to $1.5 \mathrm{wt}$ \% (coarse-grained $\mu=1.3, \sigma=0.1$; fine-grained $\mu=1.3, \sigma=0.1$ ) in trench 2 , and from 0.8 to $2.2 \mathrm{wt} . \%$ (coarse-grained $\mu=1.5, \sigma=0.3$; fine-grained $\mu=1.5$, $\sigma=0.4)$ in trench 3. Error bars were generated based on the standard deviation $(\sigma)$ of three consecutive sample measurements (Fig. 2.11a - c). The variation in S and $\mathrm{C}$ measurements corresponded to different depth locations in each trench and showed no indications of depth dependency. However, the range in total $\mathrm{S}$ and $\mathrm{C}$ content between trenches was similar and total inorganic carbon concentrations showed an inverse relationship to the total sulfur content across all depths within each trench. Furthermore, the average $S$ content was statistically higher in the coarse-grained fraction than the fine-grained fraction in trench 3 by a mean difference of $0.3 w t . \%(\alpha=0.003)$. 

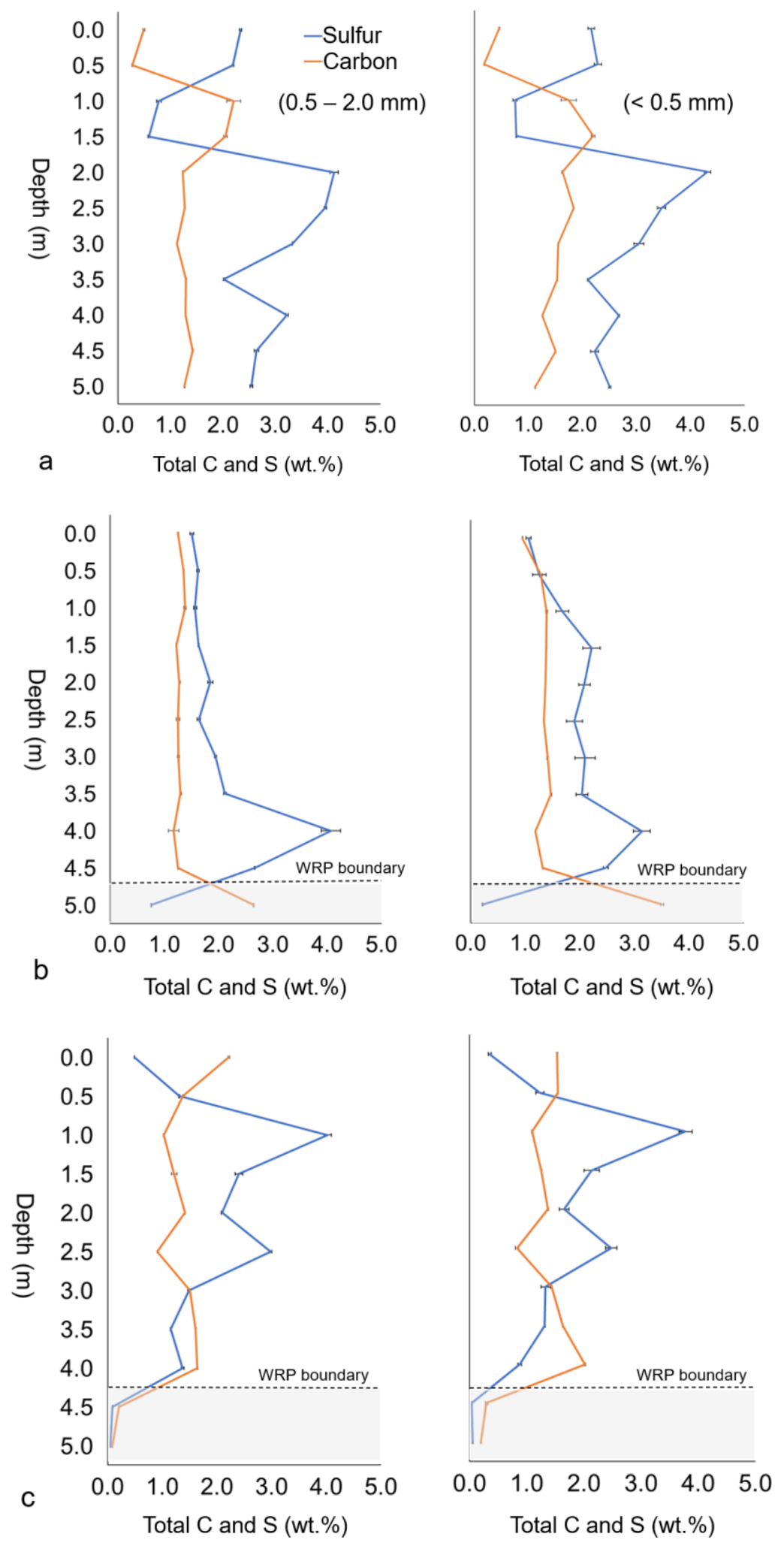

Figure 2.11: Total $C$ and $S$ content (wt.\%) for coarse (left) and fine (right) grain fractions for a) trench 1, b) trench 2, c) trench 3. Error bars show the standard deviation from three consecutive measurements 
NP:AP ratios (NPR values) for coarse- and fine-grained waste-rock samples ranged from 0.21 to 9.29 (coarse-grained $\mu=2.7, \sigma=3.2$; fine-grained $\mu=2.5, \sigma$ $=2.5$ ) in trench 1 , from 0.76 to 2.83 (coarse-grained $\mu=1.9, \sigma=0.5$; fine-grained $\mu=1.9, \sigma=0.5$ ) in trench 2 , and from 0.68 to 12.06 (coarse-grained $\mu=3.2, \sigma=$ 3.1; fine-grained $\mu=3.9, \sigma=3.3$ ) in trench 3 (Fig. 2.12a - c). Most waste-rock samples, both coarse- and fine-grained, across each trench, had a UAG potential. Trench 2 showed the least variability in NPR values with only the coarse-grained fraction of one sample falling into the PAG region; the remainder observed to be uncertain. Trench 1 and trench 3 showed greater variability with multiple samples of both grain size fractions in the PAG and NAG regions. 

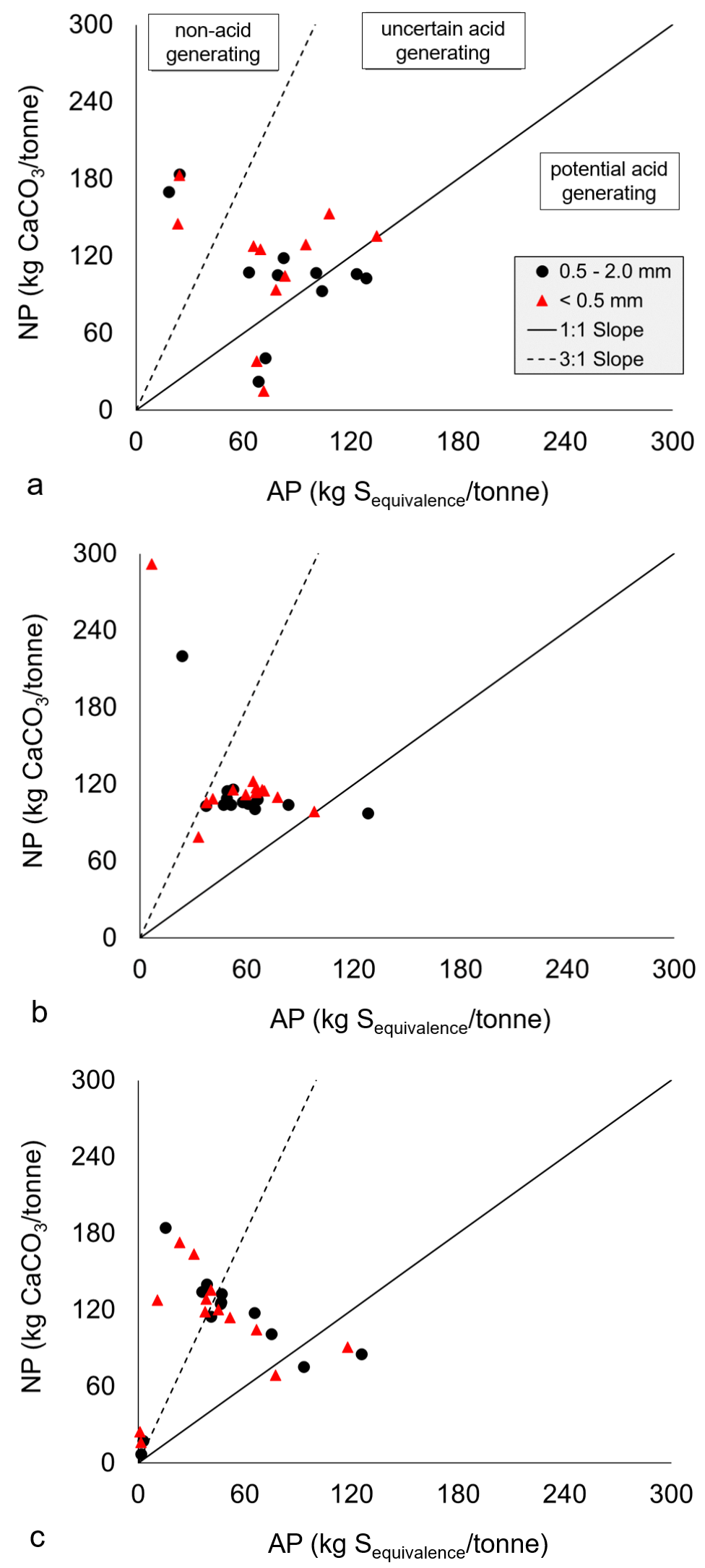

Figure 2.12: Acid generation potential for a) trench 1, b) trench 2, c) trench 3 . 


\subsubsection{Solid Phase Chemistry}

Iron $(\mathrm{Fe})$ concentrations in the waste-rock material ranged from 65126 to 117275 ppm (coarse-grained $\mu=74107, \sigma=5466$; fine-grained $\mu=80030, \sigma=16113$ ) in trench 1, from 64693 to 91735 ppm (coarse-grained $\mu=72077$, $\sigma=7109$; finegrained $\mu=77206, \sigma=6339$ ) in trench 2 , and from 61406 to $93794 \mathrm{ppm}$ (coarsegrained $\mu=70600, \sigma=7117$; fine-grained $\mu=77499, \sigma=7230$ ) in trench 3 (Fig. 2.13a - c). Iron concentrations in the fine-grained fraction were statistically higher than the coarse-grained fraction in trenches 2 and 3 with mean differences of 5129 and $6899 \mathrm{ppm}\left(\alpha=6 \times 10^{-4}\right.$ and $\left.4 \times 10^{-4}\right)$.

Copper $(\mathrm{Cu})$ concentrations ranged from 376 to $4098 \mathrm{ppm}$ (coarse-grained $\mu=$ 1657, $\sigma=752$; fine-grained $\mu=2536, \sigma=1206$ ) in trench 1 , from 1224 to 7544 ppm (coarse-grained $\mu=2047, \sigma=1220$; fine-grained $\mu=3286, \sigma=1544$ ) in trench 2 , and from 348 to $3853 \mathrm{ppm}$ (coarse-grained $\mu=1146, \sigma=714$; fine-grained $\mu=$ 1781, $\sigma=991$ ) in trench 3 (Fig. 2.13d - f). Copper concentrations in the fine-grained fraction were statistically higher than the coarse-grained fraction in trenches 1,2 , and 3 with mean differences of 878,1240 , and $635 \mathrm{ppm}\left(\alpha=5 \times 10^{-5}, 4 \times 10^{-7}\right.$, and $2 \times 10^{-4}$, respectively).

Zinc $(\mathrm{Zn})$ concentrations ranged from 6416 to $25709 \mathrm{ppm}$ (coarse-grained $\mu=$ 10357, $\sigma=3538$; fine-grained $\mu=15223, \sigma=5227$ ) in trench 1 , from 14138 to $28567 \mathrm{ppm}$ (coarse-grained $\mu=16673, \sigma=2493$; fine-grained $\mu=23198, \sigma=$ 3978 ) in trench 2, and from 4007 to $38899 \mathrm{ppm}$ (coarse-grained $\mu=11270, \sigma=$ 6026; fine-grained $\mu=17252, \sigma=9164$ ) in trench 3 (Fig. 2.13g - i). Zinc concentrations in the fine-grained fraction were statistically higher than the coarsegrained fraction in trenches 1,2 , and 3 with mean differences of 4867, 6525, and $5982 \mathrm{ppm}$ ( $\alpha=8 \times 10^{-6}, 1 \times 10^{-6}$, and $2 \times 10^{-4}$, respectively). Furthermore, $\mathrm{Zn}$ concentrations in the coarse-grained fraction were observed to be highest in trench 2 and statistically lower in trench 1 by a mean difference of $6111 \mathrm{ppm}$ $\left(\alpha=2 \times 10^{-4}\right)$. The same trend was observed in the fine-grained fraction with a mean difference of $7590 \mathrm{ppm}\left(\alpha=2 \times 10^{-3}\right)$. 
Lead $(\mathrm{Pb})$ concentrations ranged from 3781 to $30373 \mathrm{ppm}$ (coarse-grained $\mu=$ 10624, $\sigma=5071$; fine-grained $\mu=15926, \sigma=7510$ ) in trench 1, from 8122 to 20971 ppm (coarse-grained $\mu=12243, \sigma=2270$; fine-grained $\mu=16042, \sigma=3184$ ) in trench 2, and from 4478 to $45582 \mathrm{ppm}$ (coarse-grained $\mu=12244, \sigma=6916$; finegrained $\mu=15551, \sigma=11201)$ in trench 3 (Fig.2.13j - I). Lead concentrations in the fine-grained fraction were statistically higher than the coarse-grained fraction in trenches 1 and 2 with mean differences of 5302 and 3799 ppm $\left(\alpha=9 \times 10^{-4}\right.$ and $\left.5 \times 10^{-5}\right)$.

Manganese $(\mathrm{Mn})$ concentrations ranged from 504 to $1674 \mathrm{ppm}$ (coarse-grained $\mu$ = 1099, $\sigma=288$; fine-grained $\mu=1305, \sigma=255$ ) in trench 1 , from 1049 to 1677 ppm (coarse-grained $\mu=1210, \sigma=99$; fine-grained $\mu=1234, \sigma=155$ ) in trench 2 , and from 972 to $1790 \mathrm{ppm}$ (coarse-grained $\mu=1241, \sigma=181$; fine-grained $\mu=$ $1379, \sigma=253$ ) in trench 3 (Fig. 2.14a - c). Manganese concentrations in the finegrained fraction were statistically higher than the coarse-grained fraction in trenches 1 and 3 with mean differences of 205 and 138 ppm $\left(\alpha=3 \times 10^{-4}\right.$ and $6 \times$ $\left.10^{-3}\right)$.

Cadmium (Cd) concentrations ranged from 35 to $229 \mathrm{ppm}$ (coarse-grained $\mu=$ $107, \sigma=35$; fine-grained $\mu=134, \sigma=50$ ) in trench 1 , from 127 to 284 ppm (coarsegrained $\mu=173, \sigma=25$; fine-grained $\mu=210, \sigma=49$ ) in trench 2, and from 46 to 340 ppm (coarse-grained $\mu=115, \sigma=56$; fine-grained $\mu=149, \sigma=77$ ) in trench 3 (Fig. 2.14d - f). Cadmium concentrations in the fine-grained fraction were statistically higher than the coarse-grained fraction in trenches 1,2 , and 3 with mean differences of 27, 37, and $34 \mathrm{ppm}\left(\alpha=1 \times 10^{-3}, 8 \times 10^{-3}\right.$, and $9 \times 10^{-4}$, respectively). Furthermore, $\mathrm{Cd}$ concentrations in the coarse-grained fraction were observed to be lowest in trench 1 and statistically higher in trench 2 by a mean difference of $65 \mathrm{ppm}\left(\alpha=5 \times 10^{-4}\right)$. The same trend was observed in the finegrained fraction with a mean difference of $74 \mathrm{ppm}\left(\alpha=1 \times 10^{-3}\right)$.

Arsenic (As) concentrations ranged from 86 to $1106 \mathrm{ppm}$ (coarse-grained $\mu=178$, $\sigma=123$; fine-grained $\mu=463, \sigma=282$ ) in trench 1 , from 119 to 1607 ppm (coarsegrained $\mu=396, \sigma=137$; fine-grained $\mu=1160, \sigma=316$ ) in trench 2 , and from 
106 to $1078 \mathrm{ppm}$ (coarse-grained $\mu=205, \sigma=88$; fine-grained $\mu=550, \sigma=293$ ) in trench 3 (Fig. $2.14 \mathrm{~g}-\mathrm{i}$ ). Arsenic concentrations in the fine-grained fraction were statistically higher than the coarse-grained fraction in trenches 1,2 , and 3 with mean differences of 313,764 , and $345 \mathrm{ppm}\left(\alpha=1 \times 10^{-4}, 6 \times 10^{-7}\right.$, and $8 \times 10^{-4}$, respectively). Furthermore, As concentrations in the coarse-grained fraction were observed to be lowest in trench 1 and statistically higher in trench 2 by a mean difference of $214 \mathrm{ppm}(\alpha=0.01)$. The same trend was observed in the fine-grained fraction with a mean difference of $657 \mathrm{ppm}\left(\alpha=7 \times 10^{-4}\right)$.

Antimony $(\mathrm{Sb})$ concentrations ranged from 155 to $1313 \mathrm{ppm}$ (coarse-grained $\mu=$ $301, \sigma=122$; fine-grained $\mu=610, \sigma=344$ ) in trench 1 , from 312 to $1560 \mathrm{ppm}$ (coarse-grained $\mu=560, \sigma=176$; fine-grained $\mu=1050, \sigma=280$ ) in trench 2, and from 43 to $1318 \mathrm{ppm}$ (coarse-grained $\mu=279, \sigma=239$; fine-grained $\mu=532, \sigma=$ 412 ) in trench 3 (Fig. 2.14j - I). Antimony concentrations in the fine-grained fraction were statistically higher than the coarse-grained fraction in trenches 1,2 , and 3 with mean differences of 308,490 , and $252 \mathrm{ppm}\left(\alpha=4 \times 10^{-4}, 1 \times 10^{-7}\right.$, and $8 \times$ $10^{-3}$, respectively). Furthermore, $\mathrm{Sb}$ concentrations in the coarse-grained fraction were highest in trench 2 and statistically lower in trenches 1 and 3 by mean differences of 287 and $284 \mathrm{ppm}\left(\alpha=5 \times 10^{-3}\right.$ and 0.04$)$. The same trend was observed in the fine-grained fraction with mean differences of 477 and $460 \mathrm{ppm}$ $(\alpha=0.02$ and 0.03 ).

Titanium ( $\mathrm{Ti}$ ) concentrations ranged from 2013 to $4274 \mathrm{ppm}$ (coarse-grained $\mu=$ 3153, $\sigma=744$; fine-grained $\mu=3376, \sigma=589$ ) in trench 1 , from 3606 to $4312 \mathrm{ppm}$ (coarse-grained $\mu=3784, \sigma=244$; fine-grained $\mu=4052, \sigma=178$ ) in trench 2, and from 3064 to $4418 \mathrm{ppm}$ (coarse-grained $\mu=3497, \sigma=365$; fine-grained $\mu=$ $3825, \sigma=368)$ in trench 3 (Fig. $2.15 a-c)$. Titanium concentrations in the finegrained fraction were statistically higher than the coarse-grained fraction in trenches 1, 2, and 3 with mean differences of 223,268 , and 328 ppm ( $\alpha=0.03$, $1 \times 10^{-3}$, and $7 \times 10^{-3}$, respectively). Furthermore, Ti concentrations in the coarsegrained fraction were lowest in trench 1 and statistically higher in trench 2 by a 
mean difference of $757 \mathrm{ppm}(\alpha=0.04)$. The same trend was observed for the finegrained fraction with a mean difference of $753 \mathrm{ppm}(\alpha=0.01)$.

Chromium ( $\mathrm{Cr}$ ) concentrations ranged from 152 to $294 \mathrm{ppm}$ (coarse-grained $\mu=$ 217, $\sigma=42$; fine-grained $\mu=176, \sigma=15$ ) in trench 1 , from 145 to 249 ppm (coarsegrained $\mu=208, \sigma=18$; fine-grained $\mu=166, \sigma=14$ ) in trench 2 , and from 158 to 264 ppm (coarse-grained $\mu=225, \sigma=26$; fine-grained $\mu=179, \sigma=15$ ) in trench 3 (Fig. $2.15 d-$ f). Chromium concentrations in the coarse-grained fraction were statistically higher than the fine-grained fraction in trenches 1,2 , and 3 with mean differences of 42,43 , and $46 \mathrm{ppm}$ ( $\alpha=3 \times 10^{-4}, 2 \times 10^{-6}$, and $7 \times 10^{-6}$, respectively). Furthermore, $\mathrm{Cr}$ concentrations in the fine-grained fraction were highest in trench 1 and statistically lower in trench 2 with a mean difference of $13 \mathrm{ppm}$ $\left(\alpha=6 \times 10^{-3}\right)$.

Cobalt (Co) concentrations ranged from 17 to $45 \mathrm{ppm}$ (coarse-grained $\mu=23$, $\sigma=4$; fine-grained $\mu=35, \sigma=6$ ) in trench 1 , from 20 to $44 \mathrm{ppm}$ (coarse-grained $\mu=22, \sigma=1$; fine-grained $\mu=34, \sigma=3$ ) in trench 2, and from 18 to $46 \mathrm{ppm}$ (coarsegrained $\mu=23, \sigma=3$; fine-grained $\mu=35, \sigma=6$ ) in trench 3 (Fig. 2.15g - i). Cobalt concentrations in the fine-grained fraction were statistically higher than the coarsegrained fraction in trenches 1,2 , and 3 each with a mean difference of $12 \mathrm{ppm}$ $\left(\alpha=2 \times 10^{-6}, 1 \times 10^{-7}\right.$, and $5 \times 10^{-5}$, respectively).

Nickel $(\mathrm{Ni})$ concentrations ranged from 23 to $81 \mathrm{ppm}$ (coarse-grained $\mu=44$, $\sigma=10$; fine-grained $\mu=58, \sigma=12$ ) in trench 1 , from 34 to $96 \mathrm{ppm}$ (coarse-grained $\mu=48, \sigma=13$; fine-grained $\mu=66, \sigma=12$ ) in trench 2 , and from 40 to $73 \mathrm{ppm}$ (coarse-grained $\mu=47, \sigma=6$; fine-grained $\mu=62, \sigma=7$ ) in trench 3 (Fig. $2.15 \mathrm{j}-\mathrm{I}$ ). Nickel concentrations in the fine-grained fraction were statistically higher than the coarse-grained fraction in trenches 1,2 , and 3 by 14, 18, and 15 ppm ( $\alpha=1 \times 10^{-6}, 2 \times 10^{-7}$, and $1 \times 10^{-5}$, respectively). Furthermore, $\mathrm{Ni}$ concentrations in the fine-grained fraction were highest in trench 2 and statistically lower in trench 1 by a mean difference of 9 ppm $(\alpha=0.02)$. 

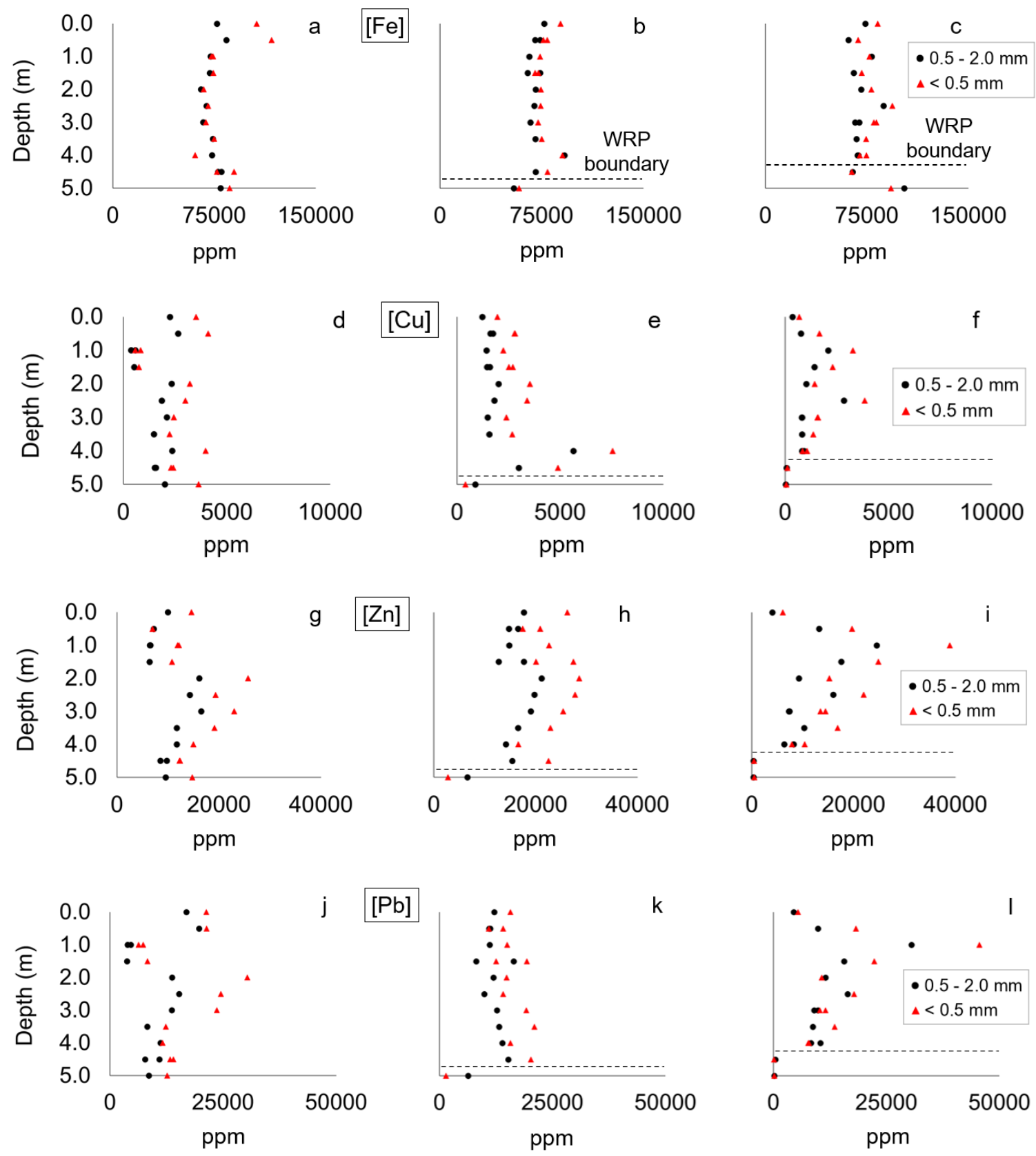

Figure 2.13: Solid-phase iron ( $\mathrm{Fe})$, copper $(\mathrm{Cu})$, zinc $(\mathrm{Zn})$, and lead $(\mathrm{Pb})$ depth plots for trench 1 (left), trench 2 (middle), and trench 3 (right). 

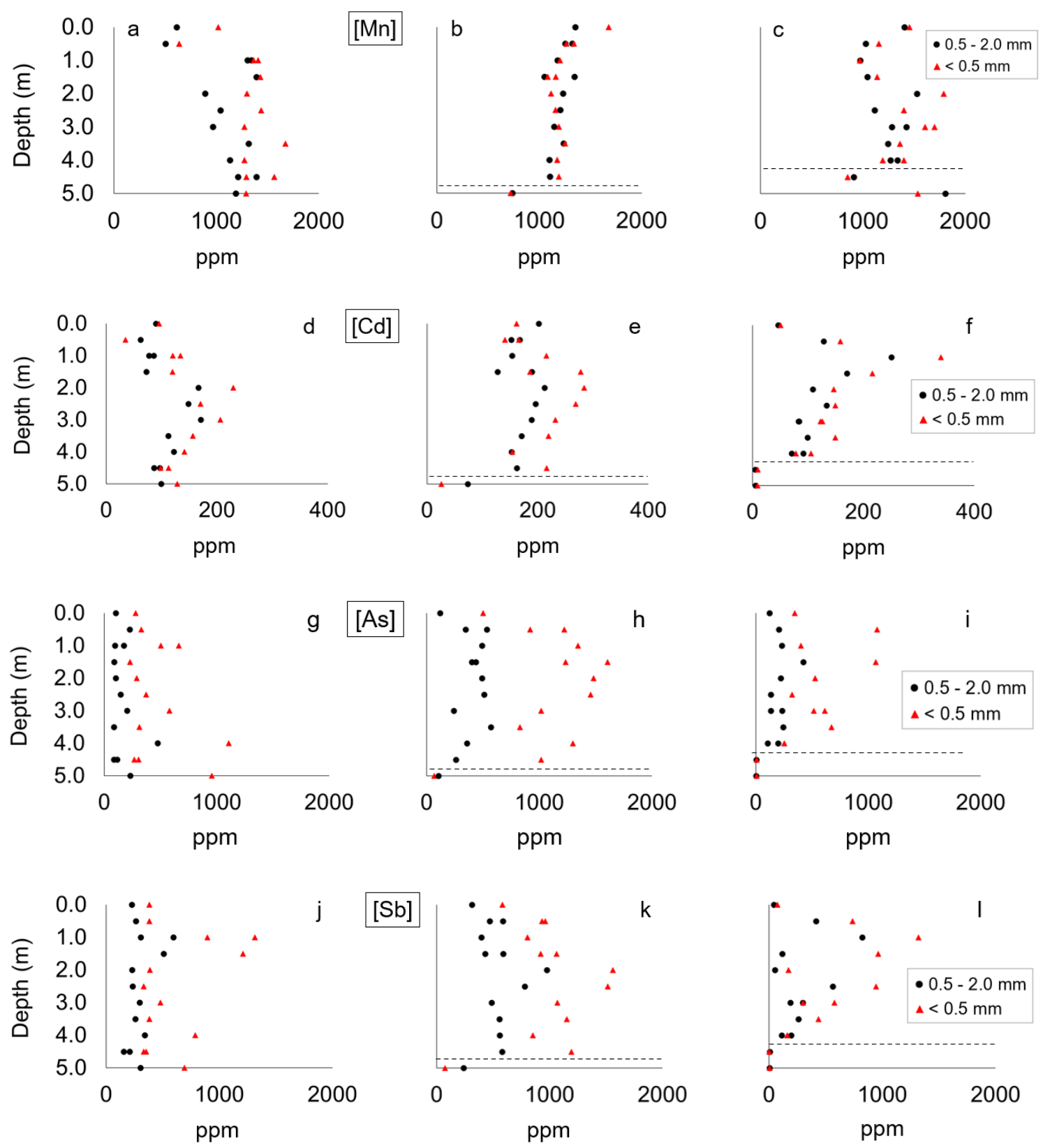

Figure 2.14: Solid-phase manganese (Mn), cadmium (Cd), arsenic (As), and antimony $(\mathrm{Sb})$ depth plots for trench 1 (left), trench 2 (middle), and trench 3 (right). 

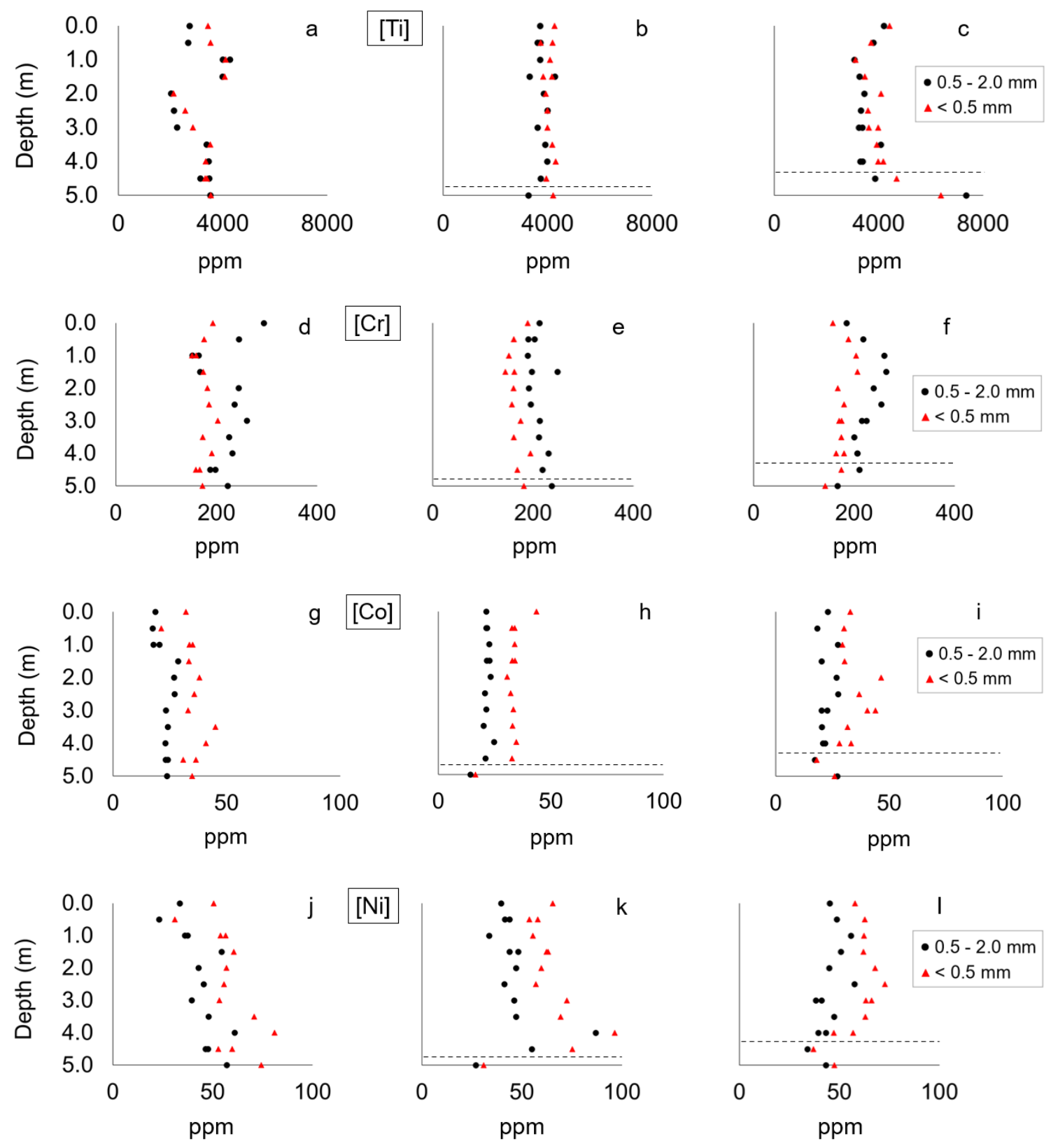

Figure 2.15: Solid-phase titanium ( $\mathrm{Ti}$ ), chromium ( $\mathrm{Cr}$ ), cobalt $(\mathrm{Co})$, and nickel (Ni) depth plots for trench 1 (left), trench 2 (middle), and trench 3 (right).

In summary, there was no statistically significant relationship between concentration and depth in any trench for either grain fraction of the reported metals identified by ICP-AES/MS. Chromium was the only metal that measured higher concentrations in the coarse-grained fraction than the fine-grained fraction of waste-rock material. In order of appearance, the fine-grained fraction measured 
higher relative concentrations of $\mathrm{Cu}$ (57\% increase), $\mathrm{Zn} \mathrm{(45 \% ),} \mathrm{Pb}(36 \%), \mathrm{Cd}$ (25\%), As (186\%), Sb (92\%), Co (53\%), and $\mathrm{Ni}(34 \%)$ than the coarse-grained fraction. In trench $1, \mathrm{Zn}, \mathrm{Cd}, \mathrm{As}, \mathrm{Sb}, \mathrm{Ti}$, and $\mathrm{Ni}$ in fine and/or coarse-grained fractions measured statistically higher average concentrations than trench 2 . Furthermore, concentrations of $\mathrm{Zn}, \mathrm{Pb}$, and $\mathrm{Cd}$ showed very similar depth patterns spiking at $1.0 \mathrm{~m}$ depth in trench 3 and deficient at $1.0 \mathrm{~m}$ depth in trench 1.

\subsection{Discussion}

\subsubsection{General Lithology and Mineralogy}

The primary waste-rock mineral phases at Ore Chimney included quartz, oligoclase, hornblende, and biotite and accounted for 80 to $90 \mathrm{wt} \%$ of the bulk mineralogy. The minor mineral phases identified throughout the waste-rock pile accounted for the remaining 10 to $20 \mathrm{wt}$ \% and included chlorite, calcite, dolomite, and sulfide minerals mainly represented by chalcopyrite, pyrite, sphalerite, and galena. Wheeler (2017) conducted a detailed petrographic study in one $4.0 \mathrm{~m}$ deep trench in the waste-rock pile at Ore Chimney and characterized the mineralogy to mainly consist of quartz, biotite, and hornblende with traces of calcite, galena, sphalerite, pyrite, and chalcopyrite. Moore and Thompson (1980) and Harnois and Moore (1989) identified these phases from thin section analyses from fresh in situ samples of the Ore Chimney Formation, Tudor Formation, and neighbouring quartz vein lithologies from bore holes that intersected the underground workings that generated the Ore Chimney waste-rock pile and described in detail the additional presence of plagioclase feldspar, chlorite, and dolomite.

Distribution of major mineral phases (including chlorite) was relatively uniform throughout all three vertical transects and showed only minor changes with depth. However, variation in mineral abundance with depth was different in each vertical transect and showcases the heterogeneity of blasted waste-rock material and nonuniform pile formation from underground development at Ore Chimney. The wasterock material at Ore Chimney was stockpiled as six elongated "fingers" that overlapped and extended away from the direction of the mineshaft (Kingston, 
1980; Archibald, 2012). The fingers represent stretches of geological material that were blasted and stockpiled during different stages of underground development. Vertical trenches 1,2 , and 3 were dug at fingers 3,4 , and 5 , respectively, and Wheeler (2017) sampled to $4.0 \mathrm{~m}$ depth in a trench corresponding to finger 2 (Fig. 2.16). Two of the six elongated sections of stockpiled material (1 and 6) were masked by vegetation, yielding four distinct piling stages from aerial photography (Fig. 1.1).

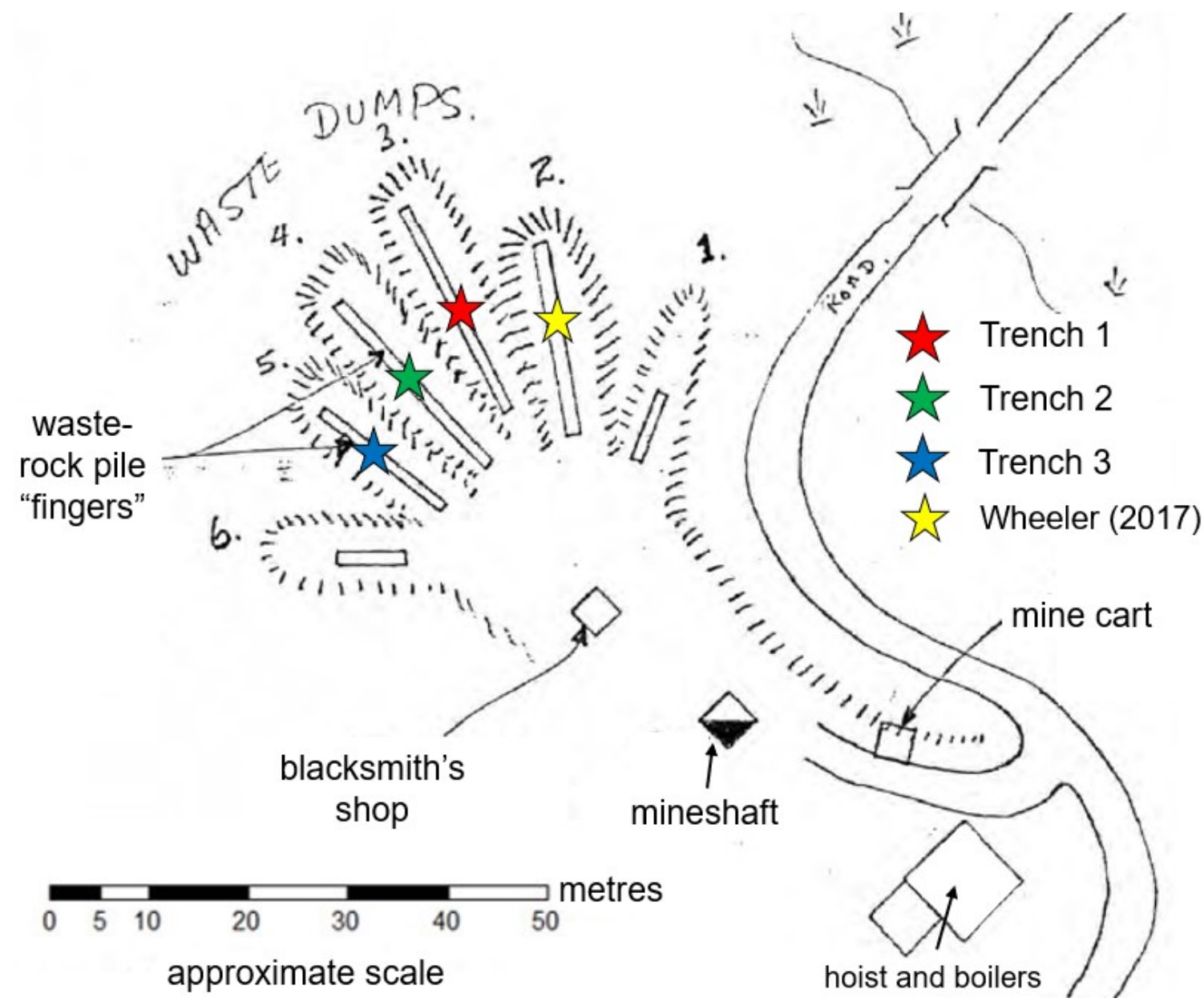

Figure 2.16: Historical sketch of the Ore Chimney waste-rock pile updated with study sampling locations (modified from Kingston, 1980).

The entrance of the vertical mineshaft at the Ore Chimney property was confined within the Tudor Formation and underground workings extended laterally at various levels targeting carbonate-rich quartz veins surrounding the Ore Chimney 
Formation (Dillon, 1985; Harnois and Moore, 1989). The variation in waste-rock mineral abundance with depth along each vertical transect was not considerable enough to distinguish the different lithologies encountered during underground development. Therefore, the waste-rock pile on the property was most likely comprised of blasted rock fragments originating from the Tudor Formation, Ore Chimney Formation, and intrusive quartz veins. There are no records indicating a systematic formation of the waste-rock pile (Archibald, 2012); however, it is most likely that the waste-rock "fingers" developed in succession and represent slightly different distributions of the Tudor Formation, Ore Chimney Formation, and quartz veins, which was directly reflected in the similar bulk mineralogy and minor variation in mineral abundance from PXRD and total $C / S$ measurements.

Quartz was observed as the dominant mineral phase in the waste-rock material, ranging from 40 to $60 \mathrm{wt} . \%$. It is highly unlikely for the quartz content to originate from quartzite and/or siliceous metaconglomerate (Flinton group) since these geological units were spatially located away from underground workings and were observed to contain minimal sulfur ( $<0.01 \mathrm{wt} . \%)$ and carbonate $(0.2 \mathrm{wt} . \%)$ content (Harnois and Moore, 1988). The metamorphosed tholeiitic basalt comprising the Tudor Formation is mainly composed of hornblende and plagioclase feldspar but may contribute minor proportions (5 to $15 \mathrm{wt} . \%$ ) of the quartz concentrations measured in the waste-rock material (Harnois and Moore, 1988). Measurements of oligoclase (10 to $30 \mathrm{wt}$ \%) dispersed throughout the waste-rock samples can be explained by the presence of the Tudor Formation and elevated quartz measurements therefore must have been contributed by another type of lithology, likely quartz veins.

Concentrations of biotite are mainly hosted within biotite schist and provide the strongest evidence that blasted material from the Ore Chimney Formation was mixed throughout the waste-rock pile. Measurable concentrations (> $5 \mathrm{wt} . \%$ ) were ubiquitous throughout the pile suggesting that the Ore Chimney Formation was actively targeted throughout most of the mining operations. Furthermore, apatite and titanite were trace mineral phases most commonly associated with the Ore 
Chimney Formation and were identified in some instances under SEM-EDX; thus, providing additional evidence that the Ore Chimney Formation constitutes an appreciable portion of the waste-rock material (Harnois and Moore, 1988).

Hornblende has been identified as a mineral component of the Tudor Formation; however, it has also been observed to persist in the Ore Chimney Formation near the contact between the two units (Moore and Thompson, 1980). Investigations of the Ore Chimney Formation from detailed geological mapping surveys identified a variation in mineral assemblage including garnet-biotite, muscovite-biotite, and hornblende-biotite schist. The Ore Chimney Formation that was targeted underground mainly consisted of biotite schist or hornblende-biotite schist due to the absence of garnet and muscovite mineral phases in the waste rock (Harnois and Moore, 1988). Therefore, it is likely that the hornblende concentrations were contributed by both the Tudor Formation and the Ore Chimney Formation. Likewise, the Tudor Formation and the Ore Chimney Formation have both been observed to host chlorite, which may also be contributed by both formations (Harnois and Moore, 1988).

Although sometimes measured below detection, average concentrations of calcite (2.2 wt.\%) and dolomite (4.1 wt.\%) throughout the waste-rock pile from both grain fractions estimated by PXRD was confirmed with optical microscopy and subsequent SEM-EDX. Harnois and Moore (1988) observed carbonate minerals in the Tudor Formation at Ore Chimney; however, they were typically associated as small veinlets less than $2 \mathrm{~cm}$ in diameter and are mainly composed of calcite. Calcite has been observed in metasedimentary rocks and some sections of biotite schist that are located on the property; although, these localities do not intersect with the underground workings that created the waste-rock pile (Moore and Thompson, 1980; Harnois and Moore, 1988). Furthermore, dolomite was measured as a dominant carbonate phase throughout the waste-rock pile but was not observed in the Tudor, Ore Chimney, or Bishop Corners Formation (Moore and Thompson, 1980). The presence of calcite and dolomite in relatively high abundance most likely originated from the blasting of carbonate-rich quartz veins 
located throughout a shear zone directly intersecting the underground workings (Archibald, 2012).

The relatively high detection limit of 2 wt. $\%$ for PXRD analyses made it difficult to compare certain mineral quantities with sufficient confidence. However, in coarsegrained samples, dolomite may be more abundant than calcite by 2.5 and $4.8 \mathrm{wt} . \%$ in trenches 2 and 3, respectively. Fine-grained samples in trenches 2 and 3 may also contain more dolomite than calcite by 1.5 and $2.7 \mathrm{wt} . \%$, respectively. Harnois and Moore (1989) observed calcite and dolomite as the two carbonate phases hosted by the quartz vein system that was targeted at Ore Chimney and estimated that calcite and dolomite were each concentrated in the quartz veins by an average of $5 \%$ (by volume) but ranged as high as $20 \%$. In addition, Harnois and Moore (1989) observed a higher proportion of calcite than dolomite, which is contrary to measurements of the waste-rock material herein that suggest higher average concentrations of dolomite. Compared to dolomite, calcite has a higher solubility (Langmuir, 1997) and has been observed to buffer low pH waters at a rate approximately one order of magnitude higher, which explains the potential depletion of calcite in the waste-rock material (Lapakko, 2002). However, measurable calcite is still present in the waste rock and has not been completely exhausted even after $\sim 100$ years of sulfide mineral weathering. The quartz vein system is likely the main contributor for the concentrations of calcite and dolomite observed throughout the pile. Likewise, the quartz vein system is the only geological body that hosted the assemblage of sulfide minerals most comparable to concentrations observed in the pile and therefore must be a significant component of the waste-rock bulk mineralogy (Archibald, 2012).

The grain size of waste-rock material varied considerably throughout the pile from $<0.5 \mathrm{~mm}$ particles to $20 \mathrm{~cm}$ diameter rock fragments. Material blasting and weathering processes may fractionate different minerals into different grain size categories depending on mineral hardness and reactivity at the surface. For example, quartz is a robust mineral with a low chemical reactivity and therefore remains relatively inert (Nesbitt et al., 1997), which explains why higher 
concentrations of quartz were observed in the coarse-grained fraction than the fine-grained fraction in all three trenches. Conversely, biotite has a lower mineral hardness and is more reactive than quartz due to the oxidation of ferrous iron and inherently weaker mineral structure (Fordham, 1990), which corroborates PXRD results of higher concentrations of biotite measured in the fine-grained fraction of sampled waste-rock material.

\subsubsection{Mineral-Derived Metals in the Waste Rock}

Mineralogical data from PXRD indicated that solid-phase Fe concentrations in the waste rock originated from hornblende, biotite, chlorite, pyrite, and ferroan sphalerite minerals. Furthermore, ICP-AES measured higher Fe concentrations in the fine-grained fraction of waste-rock material compared to the coarse-grained fraction in trenches 2 and 3 . Hornblende accounts for 5 to $15 \mathrm{wt} \%$ of the bulk mineralogy; however, PXRD results did not show a difference in hornblende concentration with grain size. Biotite was slightly enriched in the fine-grained fraction of the waste rock and accounted for 10 to $25 \mathrm{wt} . \%$ of the bulk mineralogy, which is the highest of the Fe-bearing mineral phases. Wilson (1970) studied the weathering of a soil profile developed from a biotite-hornblende parent rock and observed enrichment of biotite-derived clay minerals in the upper soil profile where hornblende was less weathered and concentrated in closer proximity to the parent material. Therefore, elevated Fe measurements observed in the fine-grained fraction of the waste rock compared to the coarse-grained fraction in trenches 2 and 3 suggest that biotite weathers more easily than hornblende and is likely the primary source of $\mathrm{Fe}$ in the waste-rock material (Wilson, 1970; Wilson and Farmer, 1970).

Although often measured below the detection limit, PXRD analysis identified the presence of galena and Fe-bearing sphalerite, which are likely the main sources of $\mathrm{Pb}$ and $\mathrm{Zn}$ in the waste rock. Low ICP-AES/MS $\mathrm{Zn}$ and $\mathrm{Pb}$ concentrations observed at 1.0 and $1.5 \mathrm{~m}$ depth in trench 1 correlate with low total $\mathrm{S}$ measurements in addition to a decreased presence of sulfide minerals in the $\mathrm{PXRD}$ data. Likewise, elevated $\mathrm{Zn}$ and $\mathrm{Pb}$ measurements at $1.0 \mathrm{~m}$ depth in trench 
3 correlate with elevated total S concentration and increased concentrations of sulfides. Decreased Cu signatures at 1.0 and $1.5 \mathrm{~m}$ depth in trench 1 also correlate with a low sulfide mineral concentration; however, $\mathrm{Cu}$ concentrations rarely exceeded $5000 \mathrm{ppm}(0.5 \mathrm{wt} . \%)$ and were too dilute to detect a Cu-bearing sulfide phase from PXRD. Using reflected light microscopy, galena and sphalerite grains and lower levels of chalcopyrite and pyrite were identified in every fine- and coarsegrained waste-rock sample, which is consistent with the sulfide mineral assemblage identified from underground workings at Ore Chimney from past studies (Dillon, 1985; Harnois and Moore, 1988, Harnois and Moore, 1989; Archibald, 2012). Solid-phase ICP-AES/MS analyses of $\mathrm{Cu}, \mathrm{Zn}$, and $\mathrm{Pb}$ all measured higher relative concentrations in the fine-grained fraction. Compared to quartz, which has a mineral hardness of 7 , galena, sphalerite, and chalcopyrite all have relatively lower mineral hardness of $2.5,3.5$ to 4 , and 3.5 to 4 , respectively (Petrescu, 1999). Therefore, blasting activities and century-long weathering may partition sulfides into smaller grain sizes, which was statistically insignificant with PXRD and total C/S measurements, but apparent in the solid-phase ICP-AES/MS results.

The biotite mineral phase identified from PXRD analysis contained $\mathrm{Mn}$ at a mole fraction of $1 \%$ (atomic proportion of 0.01 ; Fig. $2.2 \mathrm{j}-\mathrm{I}$ ). Comparing both grain fractions from all three trenches, the average biotite concentration in the wasterock pile at Ore Chimney is approximately $16 \mathrm{wt} . \%$. Therefore, the relative mass fraction of $\mathrm{Mn}$ in biotite $(0.0012 \mathrm{~g} \mathrm{Mn} / \mathrm{g}$ biotite) identified by PXRD yields an average $\mathrm{Mn}$ contribution of $0.02 \mathrm{wt} . \%$, which is sixfold lower than the average total Mn concentration of $1200 \mathrm{ppm}(0.12 \mathrm{wt} . \%)$ in the waste-rock pile determined from ICP-AES. PXRD has a much lower resolution than ICP-AES and the discrepancy between average $\mathrm{Mn}$ concentration suggests that $\mathrm{Mn}$ was underestimated as a component of biotite and/or additional Mn-bearing minerals are contributing to the signatures measured in the waste rock.

Polished grain mounts of $60 \mu \mathrm{m}$ were tailored for the preservation and investigation of ore minerals (Langman et al., 2015); thus, Mn content in biotite grains was not 
verified using SEM-EDX. Although below the detection limit, SEM-EDX consistently detected $\mathrm{Mn}$ in calcite and dolomite grains ( $\mathrm{n}=4$ calcite and 1 dolomite) ranging from 0.33 to $0.86 \mathrm{wt} . \%(\mu=0.51, \sigma=0.22)$. In addition, $\mathrm{Mn}$ concentrations were consistently detected in ilmenite grains under SEM-EDX $(n=21)$ ranging from 0.37 to $4.73 w t . \%(\mu=1.81, \sigma=1.12)$. Llera et al (2019) identified ilmenite with an average $\mathrm{Mn}$ concentration of $4.6 \mathrm{wt} \%$ in biotitemuscovite schist that underwent similar shearing and metasomatic processes as the mineralized Ore Chimney Formation (Harnois and Moore, 1988). In addition, the average Mn content of biotite was observed to increase from $0.18 \mathrm{wt} . \%$ in nonmetasomatized schist samples to $0.28 \mathrm{wt}$.\% in metasomatized samples (Llera et al., 2019) suggesting that biotite, ilmenite, and calcite in the mineralized Ore Chimney Formation may substantially contribute to waste-rock Mn concentrations measured by ICP-AES.

Waste-rock $\mathrm{Cd}$, As, and $\mathrm{Sb}$ concentrations measured by ICP-MS were not reflected in the mineralogy identified from PXRD. Low Cd concentrations observed at 1.0 and $1.5 \mathrm{~m}$ depth in trench 1 correlate with low total $S$ measurements and a decreased abundance of sulfides in the mineralogical data. Likewise, an elevated $\mathrm{Cd}$ measurement at $1.0 \mathrm{~m}$ depth in trench 3 correlates with elevated $\mathrm{S}$ content and an increased concentration of sulfides. SEM-EDX analysis identified $\mathrm{Cd}$ at 1 to 2 wt.\% exclusively in sphalerite grains, which is below the detection limit, but consistent with measurements from other studies (Koski et al., 2008; Cook et al., 2009; Ye et al., 2011). Like other sulfide-derived metals ( $\mathrm{Pb}, \mathrm{Zn}$, and $\mathrm{Cu}$ ), $\mathrm{Cd}$ concentrations measured by ICP-MS were higher in the fine-grained fraction of waste-rock samples. Furthermore, the relationship between $\mathrm{Cd}$ concentrations and depth was similarly observed with $\mathrm{Zn}$ indicating that sphalerite is likely the principal source of $\mathrm{Cd}$ concentrations in the waste rock.

Reflected light microscopy and SEM-EDX analysis on polished grain mounts identified the presence of arsenopyrite, which was the only mineral observed to host measurable quantities of As. In aerobic environments, arsenopyrite has a mineral durability and alteration resistance that is proposed to be lower than pyrite 
and chalcopyrite but greater than sphalerite (Moncur et al., 2009). Likewise, As concentrations were higher in the fine-grained fraction of waste-rock samples, which is consistent with measurements of other sulfide-bearing metals and suggests that arsenopyrite is the predominant source for As concentrations in the waste rock. Petrographic investigations also identified the presence of a ( $\mathrm{Cu}, \mathrm{Sb}, \mathrm{Ag}$ )-bearing sulfide mineral that has been previously observed (in addition to arsenopyrite) in the mineralized zone of the Ore Chimney Formation and is described as freibergite (Harnois and Moore, 1989). In other settings, galena has been observed to substitute $\mathrm{Pb}$ for $\mathrm{Sb}$ at concentrations as high as $0.3 \mathrm{wt} . \%$ (George et al., 2015; Hamzeh et al., 2020) and contain inclusions with Sb concentrations as high as 4.0 wt.\% (Sharp and Buseck, 1993). However, SEMEDX measurements of galena at Ore Chimney revealed no trace of $\mathrm{Sb}$ and it is likely that freibergite is the primary source of $\mathrm{Sb}$ (and $\mathrm{Ag}$ ) concentrations in the waste rock.

PXRD analysis estimated biotite to host $\mathrm{Ti}$ at an atomic proportion of 0.1 (mass fraction of 0.01 ). An average biotite concentration of $16 \mathrm{wt} . \%$ contributes a relative Ti proportion of $0.16 \mathrm{wt}$ \%. Solid-phase ICP-AES/MS measurements of Ti in the waste rock averaged a concentration of $3600 \mathrm{ppm}(0.36 \mathrm{wt} . \%)$, which is twofold higher than Ti estimations in biotite predicted by PXRD. Reflected light microscopy and subsequent SEM-EDX analysis identified one grain of titanite ( $\left.\mathrm{CaTiSiO}_{5}\right)$ at $5.0 \mathrm{~m}$ depth in trench 3 (Fig. 2.7f) and the occasional presence of ilmenite $\left(\mathrm{FeTiO}_{3}\right)$ and rutile $\left(\mathrm{TiO}_{2}\right)$ as additional Ti-bearing mineral phases throughout the waste-rock pile $(2.17 a-d)$. Grey and Reid (1975) proposed that rutile may be a natural weathering product of ilmenite through ferrous iron oxidation and subsequent $\mathrm{Fe}$ removal by leaching. However, Fe oxidation is expected to form secondary hematite $\left(\mathrm{Fe}_{2} \mathrm{O}_{3}\right)$ and goethite $[\mathrm{FeO}(\mathrm{OH})]$ along ilmenite grain boundaries (Dawson and Smith, 1977; Schroeder et al., 2002) and the presence of Fe-oxides or Feoxyhydroxides were not detected as an alteration phase of ilmenite in the Ore Chimney waste rock (Fig. 18a - d). Fu et al (2010) observed rutile as a stable ilmenite oxidation product under a temperature range of 500 to $800^{\circ} \mathrm{C}$, which overlaps with regional metamorphic temperature estimates of 420 to $530^{\circ} \mathrm{C}$ at Ore 
Chimney (Harnois and Moore, 1989). Therefore, it is likely that rutile and ilmenite crystallized within an underground intrusion and subsequent metamorphism under oxidizing conditions, rather than subaerial weathering and are relatively more stable above ground surface than sulfide minerals (Dawson and Smith, 1977).

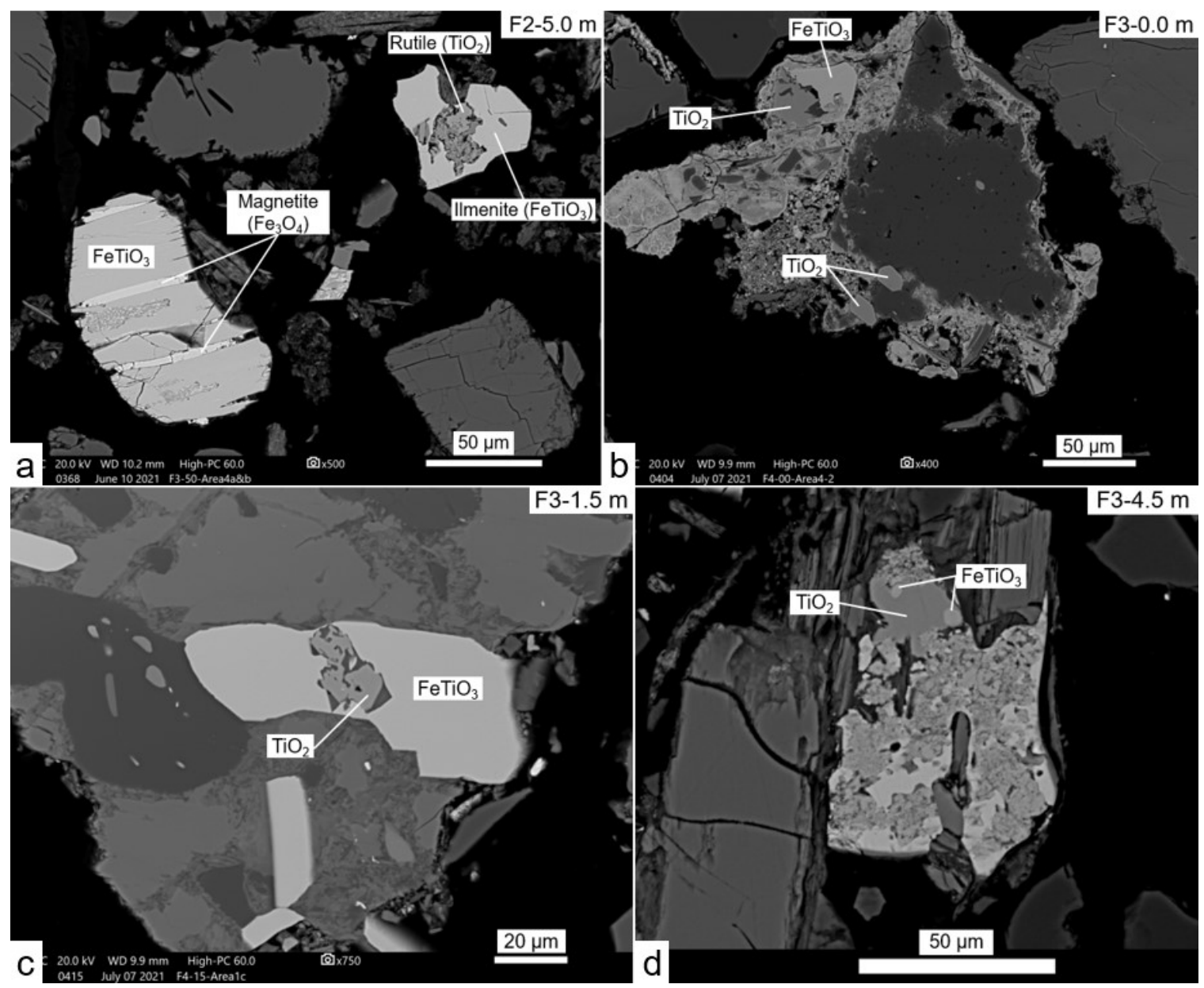

Figure 2.17: BSE images of Fe- and Ti-oxide phases in the Ore Chimney waste rock.

The average solid-phase $\mathrm{Cr}$ concentrations in the waste rock at Ore Chimney measured $200 \mathrm{ppm}(0.02 \mathrm{wt} . \%)$ and were too low to be reflected as a stoichiometric component of mineral phases identified with PXRD. Furthermore, SEM-EDX analysis did not detect $\mathrm{Cr}$ as a component of any ore mineral phase except for one instance where $\mathrm{Cr}$ was measured (below the detection limit) in magnetite at 0.1 wt.\%. In other mine-waste studies, $\mathrm{Cr}$ has been observed as a trace component of 
chlorite, biotite, amphibole, and pyroxene minerals (Tischendorf et al., 2001; Jambor et al., 2002; Moncur et al., 2009). However, subsequent porewater $\mathrm{Cr}$ signatures are typically derived from the weathering of $\mathrm{Cr}$-bearing magnetite in mine wastes (Moncur et al., 2005; Gunsinger et al., 2006b; Moncur et al., 2009). Chromium concentrations in the Ore Chimney waste rock were too low to be attributed to any common rock-forming or trace mineral phases. However, magnetite is a relatively robust mineral (Petrescu, 1999) and higher measurements of $\mathrm{Cr}$ in the coarse-grained fraction of waste rock measured by ICP-AES/MS suggests that magnetite may be the primary source of $\mathrm{Cr}$ in the waste rock. Solidphase concentrations of $\mathrm{Co}$ and $\mathrm{Ni}$ throughout the waste-rock pile were lower than $\mathrm{Cr}$ and averaged 54 and $28 \mathrm{ppm}$ (0.005 and $0.003 \mathrm{wt} . \%$, respectively). Although below the SEM-EDX detection limit, spot analyses on polished grain mounts detected trace levels of $\mathrm{Co}(<0.6 \mathrm{wt} . \%)$ and $\mathrm{Ni}(<0.9 \mathrm{wt} . \%)$ in several pyrite, magnetite, and ilmenite grains but these metals seldomly existed together. Pyrite was observed to host trace $\mathrm{Co}$ and $\mathrm{Ni}$ concentrations more frequently than magnetite and ilmenite. In addition, pyrite is more reactive than Fe-oxides in aerobic environments (Moncur et al., 2009) and ICP-AES/MS measured higher concentrations of $\mathrm{Co}$ and $\mathrm{Ni}$ in the fine-grained fraction of waste-rock material further suggesting that pyrite is the primary source of $\mathrm{Co}$ and $\mathrm{Ni}$ at Ore Chimney.

\subsubsection{Sulfide Mineral Weathering}

The primary sulfide mineral assemblage identified in almost every waste-rock sample using reflected light microscopy in order of decreasing relative abundance included sphalerite $>$ galena $>$ pyrite $>$ chalcopyrite. In addition, observations of arsenopyrite and a (Cu,Sb,Ag)S mineral phase (potentially freibergite) were identified as additional sulfide minerals in few samples in trace amounts. IImenite represented the most abundant oxide mineral phase that was detected in few samples at trace levels and all the identified ore minerals were previously observed by Harnois and Moore (1989). The average extent of weathering observed in the waste-rock material was variable between the different primary sulfide minerals indicating differences in mineral durability. The comparative weathering rates of 
sulfide minerals are summarized by Nordstrom and Alpers (1999) and corroborated by empirical field studies (Blowes and Jambor, 1990; Plumlee, 1999; Moncur et al., 2005; Gunsinger et al., 2006a; Koski et al., 2008; Moncur et al., 2009). Considering only the primary sulfide mineral phases observed at Ore Chimney, the abovementioned field studies proposed a relative resistance to oxidation that typically increased in the order: sphalerite < galena < pyrite $<$ chalcopyrite, which was consistent with the mineral weathering variability observed at Ore Chimney.

Chalcopyrite was observed as the most robust sulfide mineral, with average oxidation rankings of 1 and indicated by SEM-EDX measurements as the primary source for $\mathrm{Cu}$ concentrations in the waste rock. Alteration rims of chalcopyrite consisted of a Fe-oxyhydroxide phase that can suppress further oxidation and increase mineral durability in oxidizing environments (Moncur et al., 2009), which is consistent with observations of minimal alteration and low variation in oxidation ranking. Concentrations of $\mathrm{Pb}, \mathrm{Zn}$, and $\mathrm{Cu}$ were also detected along chalcopyrite alteration zones, which have likely co-precipitated and/or adsorbed to the Feoxyhydroxide surfaces (Koski et al., 2008). Alteration zones of pyrite were interpreted as a similar $\mathrm{Fe}$-oxyhydroxide phase bearing $\mathrm{Pb}, \mathrm{Zn}$, and $\mathrm{Cu}$ from coprecipitation/adsorption reactions. Pyrite was assigned average oxidation rankings of 1.5 and alteration levels varied slightly more than chalcopyrite even though the alteration zones of both minerals were likely composed of a similar $\mathrm{Fe}$ oxyhydroxide phase. However, assessing the alteration extent of sulfide minerals required an observational and semi-quantitative tactic, which provides important context on overall weathering, but restricts the ability to discriminate between minerals of similar alteration extent, such as pyrite and chalcopyrite (Moncur et al., 2005).

Harnois and Moore (1989) identified traces of pyrrhotite (FeS) within the in situ quartz veins at Ore Chimney at a lower abundance than chalcopyrite, pyrite, sphalerite, and galena. There was no pyrrhotite observed in any of the polished grain mounts of waste-rock material, which suggests that any pre-existing 
pyrrhotite in the pile at Ore Chimney has been completely weathered (Moncur et al., 2009). In oxidizing environments, pyrrhotite can alter to secondary marcasite $\left(\mathrm{FeS}_{2}\right)$, which is a polymorph of pyrite (Blowes and Jambor, 1990). Marcasite has been observed to have a higher reactivity than pyrite (Plumlee, 1999), and the SEM-EDX technique applied herein could not differentiate between polymorphic $\mathrm{FeS}_{2}$ minerals. Instead, it is likely that the SEM results potentially grouped pyrite and marcasite as the same $\mathrm{FeS}_{2}$ phase, which may help explain why average pyrite alteration was observed to be higher and vary slightly more than chalcopyrite.

Of the primary sulfide mineral phases observed at Ore Chimney, galena showed the greatest range in alteration extent. In sulfate-laden systems developed from sulfide oxidation, a rim of anglesite $\left(\mathrm{PbSO}_{4}\right)$ often forms on galena grains, which significantly reduces galena solubility; thus, maintaining its persistence even in sphalerite-depleted aerobic environments (Moncur et al., 2009). Likewise, carbonate-rich systems with near-neutral $\mathrm{pH}$ may favour the formation of cerussite $\left(\mathrm{PbCO}_{3}\right)$ along the grain exterior, which is a less soluble phase than anglesite, thereby enhancing galena persistence under the appropriate conditions (Keim and Markl, 2015). Sphalerite oxidation in carbonate-rich environments may favour the precipitation of smithsonite $\left(\mathrm{ZnCO}_{3}\right)$ along the grain exterior and serve to control porewater Zn concentrations (Bain et al., 2001). However, smithsonite has a higher solubility than cerussite by two orders of magnitude; therefore, galena may have a higher persistence than sphalerite in carbonate-rich oxidizing systems (Takahashi, 1960; Keim and Markl, 2015). SEM-EDX detected cerussite as an abundant phase along alteration zones of galena and lower proportions of smithsonite along sphalerite rims suggesting that high concentrations of dissolved carbonate may have a stronger control on galena weathering, and $\mathrm{Zn}$ is likely being released to a greater extent than $\mathrm{Pb}$. The susceptibility of galena to weathering is recognized to be highly dependent on dissolved sulfate and carbonate, which is difficult to compare across different case studies and therefore omitted from the SAI developed herein and in other settings (Jeong and Lee, 2003; Moncur et al., 2009). 
Sphalerite grains were observed as the principal source of waste-rock $\mathrm{Zn}$ and $\mathrm{Cd}$ concentrations. Moreover, the average molar Fe/Zn ratio determined via SEMEDX was 0.18 ( $\sigma=0.03 ; n=57$ grains) yielding an average sphalerite mineral formula of $\sim \mathrm{Zn}_{0.85} \mathrm{Fe}_{0.15} \mathrm{~S}$. SEM-EDX spot analyses were measured directly on mineral surfaces and the high reproducibility provides greater confidence than PXRD estimations based on lower sensitivity and limited selections from the ICDD ( $\left.\mathrm{Zn}_{0.66} \mathrm{Fe}_{0.34} \mathrm{~S}\right)$. SEM-EDX measurements of sphalerite alteration rims typically revealed the presence of smithsonite and/or Zn,Fe-oxyhydroxide phases. Smithsonite may be more concentrated along the outer-most boundary of some sphalerite rims with minor Fe-oxyhydroxide formation favoured near the alteration rim interior (Boulet and Larocque, 1998; Mondillo et al., 2018). However, SEMEDX was not a sensitive enough technique to accurately distinguish these secondary mineral phases along nm-scale spatial gradients and reported the alteration rim composition as a combination of both.

Similar to pyrite and chalcopyrite, Fe oxidation in ferroan sphalerite can form $\mathrm{Fe}-$ oxyhydroxide phases that increase in prevalence with increasing Fe content and slow weathering rates over time (Fanfani, et al., 1996). Jeong and Lee (2003) investigated the oxidation of Fe-bearing sphalerite $\left(\mathrm{Zn}_{0.84} \mathrm{Fe}_{0.15} \mathrm{Mn}_{0.01} \mathrm{~S}\right)$ under a $\mathrm{pH}$ range of 5.6 to 6.7 and identified Fe-oxyhydroxides as the main weathering phase. However, sphalerite was still observed to be less resistant than pyrite, which is consistent with findings at Ore Chimney. Therefore, ferroan sphalerite can remain a useful proxy for evaluating the alteration extent of weathered waste-rock systems if the influence of Fe content is understood. Average SAI values ranged from 2 to 3 characterizing minor to moderate weathering of pyrite and chalcopyrite grains and moderate to extensive weathering of sphalerite. Overall, there was minimal variation in sulfide mineral weathering with depth and between trenches at Ore Chimney signifying that weathering processes are occurring at similar rates throughout the waste-rock material irrespective of depth or location.

The precise formulas of Fe-oxyhydroxide phases identified as the alteration product of weathered chalcopyrite, pyrite, and Fe-bearing sphalerite could not be 
accurately determined due to a lower chemical sensitivity and spatial resolution of SEM-EDX than other non-destructive X-ray techniques such as electron microprobe analysis (EMPA) (Bao et al., 2021). However, the relative abundances of $\mathrm{Fe}$ and $\mathrm{O}$ in the alteration zones measured by SEM closely resembled goethite, which is consistent with observations from other studies of mine-waste Fe-sulfide oxidation (Jeong and Lee, 2003; Moncur et al., 2005; Moncur et al., 2009). Likewise, $\mathrm{Cu}, \mathrm{Pb}$, and $\mathrm{Zn}$ have relatively high adsorption affinities to goethite at a temperature of $10^{\circ} \mathrm{C}$ and neutral $\mathrm{pH}$, which closely resembles the conditions at Ore Chimney, and corroborates measurements of $\mathrm{Cu}, \mathrm{Pb}$, and $\mathrm{Zn}$ on alteration zones using SEM-EDX (Rodda et al., 1993).

\subsubsection{Total Carbon and Sulfur}

Data calculations from total $\mathrm{C} / \mathrm{S}$ analysis assumes that the total $\mathrm{C}$ concentration corresponds to the inorganic carbonate mineral content represented by calcite. Likewise, it is assumed that the total $\mathrm{S}$ concentration is directly proportional to the concentration of pyrite. Concentrations of $S$ and $C$ in the waste-rock material showed no depth dependencies and instances of elevated or reduced $\mathrm{S}$ and $\mathrm{C}$ measurements reflects the indiscriminate distribution of quartz vein fragments associated with the development of the waste-rock pile (Fig. 2.16).

Total C/S measurements revealed an inverse relationship along each trench and elevated $S$ measurements corresponded to lower $C$ concentrations (Fig. 2.11) potentially as a result from carbonate mineral dissolution that buffers sulfide mineral oxidation. Likewise, lower $\mathrm{S}$ concentrations corresponded to higher $\mathrm{C}$ content, potentially due to the reduced acid generation from less sulfides, and the subsequently lower demand for carbonate dissolution (Blowes et al., 2013). This explanation assumes that primary $\mathrm{C} / \mathrm{S}$ ratios in the quartz veins proximal to the mineralized ore body were relatively consistent. Although, there is no information in the literature that describes the relative proportions between sulfide and carbonate content prior to weathering (Harnois and Moore, 1989; Archibald, 2012).

Concentrations of $S$ in the coarse-grained fraction were statistically higher than the fine-grained fraction in trench 3 , but only by a mean difference of $0.3 \mathrm{wt} \%$. 
Inorganic $\mathrm{C}$ measurements showed no difference in concentration between coarse and fine-grained samples along any trench. Therefore, the similar total $\mathrm{C} / \mathrm{S}$ measurements between coarse- and fine-grained material indicated no discernible partitioning of sulfide and carbonate mineral phases into the coarse- or finegrained fractions. Accelerated sulfide mineral weathering assumed for the finegrained fraction due to the higher surface area to volume ratio did not induce a noticeable difference in $S$ concentration compared to the coarse-grained fraction (Smith et al., 2013a). Likewise, carbonate mineral content was not depleted to a greater extent in the fine-grained fraction as a possible result from buffering potentially accelerated sulfide mineral oxidation (Gleisner, 2005).

Smith et al (2013a) compared the total S and C content of waste-rock material (using an ELTRA CS-2000 Carbon/Sulfur analyzer) across a range of grain sizes between two test piles constructed at the Diavik diamond mine that had been weathering for less than one year. Sulfur at Diavik was hosted predominantly in biotite schist and the test piles were segregated based on $S$ content with higher $S$ concentrations corresponding to a higher proportion of biotite schist in the waste rock (C content was consistent between test piles). The test pile with lower $\mathrm{S}$ content ( $\mu=0.035$ wt. $\%$ for $<50 \mathrm{~mm}$ fraction) measured higher average [S] in $<0.625 \mathrm{~mm}$ material than 0.625 to $2.50 \mathrm{~mm}$ material by $0.01 \mathrm{wt}$ \%. Comparisons of the same grain size ranges in the test pile with higher $S$ content $(\mu=0.053 \mathrm{wt} . \%)$ measured $0.04 \mathrm{wt} . \%$ higher $[\mathrm{S}]$ in the finer grain fraction suggesting that $\mathrm{S}$ content increases with decreasing grain size, which may occur to a greater extent when the average $S$ concentration (i.e. biotite schist content) in the test pile is higher.

Harnois and Moore (1989) measured average $\mathrm{Zn}, \mathrm{Pb}, \mathrm{S}$, and $\mathrm{C}$ concentrations (wt.\%) of 0.30 [Zn], $0.001[\mathrm{~Pb}], 0.26$ [S] and 0.89 [C] in bulk samples of the fresh mineralized zone of the Ore Chimney Formation. From combining both grain fractions, concentrations (wt.\%) of $\mathrm{Zn}, \mathrm{Pb}, \mathrm{S}$, and $\mathrm{C}$ in the Ore Chimney wasterock pile averaged 1.56 [Zn], 1.38 [Pb], 2.02 [S], and 1.38 [C]. Measurements from the waste rock are all significantly higher than findings by Harnois and Moore (1989) and this discrepancy may be partially explained by sulfide and carbonate 
mineral partitioning in $<2.0 \mathrm{~mm}$ sieved fractions from blasting and weathering processes. However, carbonate-bearing quartz veins containing $\mathrm{Zn}$ and $\mathrm{Pb}$ concentrations (derived from sphalerite and galena) ranging from 1.90 to $6.35 \mathrm{wt} . \%$ and 1.60 to 3.73 wt.\%, respectively (Archibald, 2012), were determined to comprise a considerable portion of the Ore Chimney waste-rock mineralogy based on quartz concentrations as high as $62(\mu=43)$ wt.\% measured by PXRD (Fig. 2.2a - C). SEM-EDX infrequently identified sulfide minerals associated with apatite, which is a mineral more commonly observed in the Ore Chimney Formation (biotite schist). Conversely, sulfides associated with quartz grains was a more often occurrence and likely accounted for the higher $S$ concentrations measured in the waste rock compared to observations by Harnois and Moore (1989) (Fig. 2.18a - f).

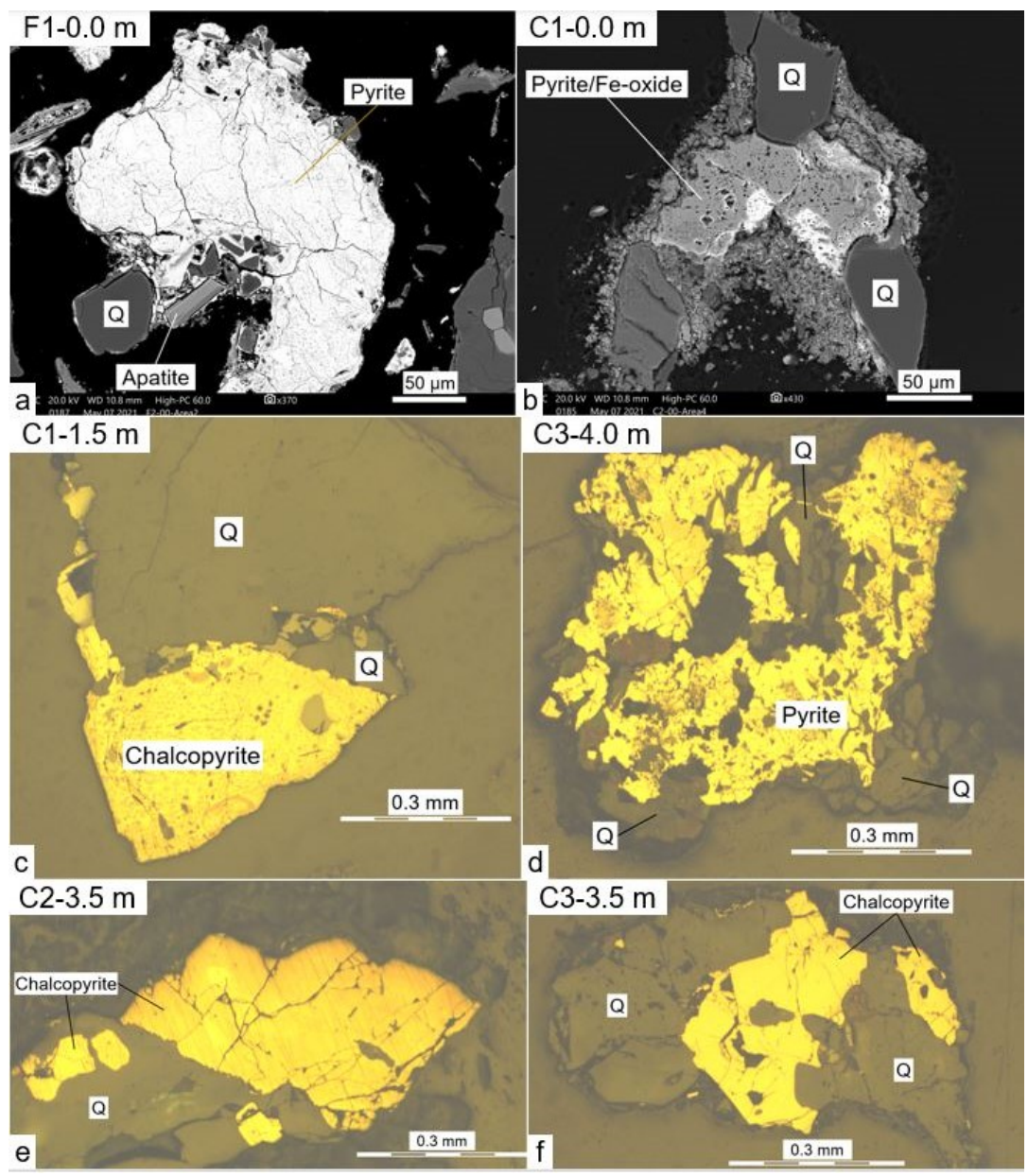

Figure 2.18: BSE images $(a$ and $b)$ and reflected light images $(c-f)$ of sulfide minerals bound with quartz $(\mathrm{Q})$. 
Average $S$ concentrations in the Ore Chimney waste rock were significantly higher than the Diavik test piles investigated by Smith et al (2013a). In addition, S concentrations at Ore Chimney were measured to be $0.3 \mathrm{wt} . \%$ higher in the coarse-grained fraction $(0.5$ to $2.0 \mathrm{~mm})$ than the fine-grained fraction $(<0.5 \mathrm{~mm})$ in trench 3 with no measurable differences in trenches 1 and 2 even after $\sim 100$ years of exposure. This suggests that sulfides in waste rock sourced from quartz veins have a different resistance to blasting and weathering processes than sulfide minerals hosted in biotite schist. However, ICP-AES/MS measured an increase in $\mathrm{Zn}$ and $\mathrm{Pb}$ concentrations (in addition to $\mathrm{Cu}, \mathrm{Cd}, \mathrm{Co}$, and $\mathrm{Ni}$ ) in the fine-grained fraction of the Ore Chimney waste-rock material by 0.58 and 0.42 wt.\%, respectively, suggesting that the partitioning of sphalerite and galena into finer grain sizes was occurring to a smaller extent than what can be resolved with total $\mathrm{C} / \mathrm{S}$ analysis and emphasizes the importance of incorporating high-resolution solid-phase ICP-AES/MS analyses into geochemical investigations of waste rock. It is likely that a proportion of sulfide minerals are encapsulated within quartz fragments, which are more resistant to blasting and subaerial weathering processes than biotite schist and the lower extent of grain size fractionation of sulfide minerals mainly derived from quartz can be interpreted from ICP-AES/MS but not from total $\mathrm{C} / \mathrm{S}$ data. It is also important to consider that the proposed "encapsulation effect" may also entrap carbonate minerals, which may inhibit carbonate mineral buffering to some extent and can explain why total $\mathrm{C} / \mathrm{S}$ analysis did not measure higher $\mathrm{C}$ concentrations in the fine-grained fraction of waste-rock material at Ore Chimney.

NPR calculations from total C/S data indicated that grain size has a negligible effect on acid generating capacity and registered most fine- and coarse-grained samples in the UAG $(1<\mathrm{NPR}<3)$ and NAG (NPR > 3) regions. Only two sample locations (surface and $0.5 \mathrm{~m}$ depth in trench 1 ) measured NPR values $<0.6$ and were attributed to relatively low neutralization potentials in the waste rock. Samples with the lowest measurements of both neutralization (NP) and acidification potentials (AP) were observed in trench 3 and situated below the WRP boundary at 4.5 and $5.0 \mathrm{~m}$ depth. AP calculations from total $\mathrm{C} / \mathrm{S}$ analysis assumes that $\mathrm{S}$ 
measurements are represented by the sulfide (pyrite) content in the waste rock; however, sulfide mineral oxidation generates sulfate, which can achieve saturation in the porewaters and precipitate as common secondary minerals such as gypsum, which is not a pH dependent process and can overestimate AP values if left unquantified (Nordstrom and Alpers, 1999; Atherton, 2017). The solid-phase sulfide and sulfate content was not distinguished herein; however, several analytical methods to quantify sulfate content exist and are described by Pillai et al, (2007) and Mussa et al, (2009).

AP calculations also assume that the $S$ concentrations are derived exclusively from pyrite where both ferrous iron and sulfide are oxidized to produce two moles of acidity per mole of sulfur (Jambor et al., 2002; Blowes et al., 2013). At Ore Chimney, sphalerite and galena grains were observed by reflected light microscopy and SEM-EDX to comprise a substantial component of the sulfide mineral assemblage (Fig. 2.9a - d). Sphalerite and galena can generate eight moles of acidity per mole of sulfur when oxidized by ferric iron; however, only sulfide undergoes oxidation and oxidative dissolution in the presence of oxygen $\left(\mathrm{O}_{2}\right)$ is a non-acid generating process (equation 1) (Plumlee, 1999; Seal and Foley, 2002; Moncur et al., 2009; Heidel et al., 2013). The aerobic conditions at Ore Chimney likely favour oxygen as the primary oxidant, which may result in overexaggerated AP estimations. Likewise, NPR calculations assume that the entire $S$ and $C$ content is available to be utilized, which may not be the case for $S$ and $C$ content derived from quartz vein material due to potential embedment of sulfide and carbonate grains within the robust mineral structure of quartz (Sobek et al., 1978).

Pedretti et al (2017) performed reactive transport simulations with the modeling software MIN3P (Mayer et al., 2002) to investigate how different spatial distributions of acid-generating and acid-neutralizing minerals of the same proportions can influence the $\mathrm{pH}$ of drainage waters. Results indicated that effluent $\mathrm{pH}$ had a stronger dependence on the random spatial distribution of acid-producing and acid-consuming minerals than bulk NPR values, and subtle reconfigurations 
of throughflow media in some instances predicted the likelihood of systems with NPR values of 2 to produce AMD after $\sim 100$ years. The spatial distribution of total $\mathrm{C} / \mathrm{S}$ concentrations at Ore Chimney was considerably different between the three trenches (Fig. 2.11a - c) implying that NPR predictions are rather uncertain. However, abundant inorganic carbon detected in the waste rock from total $\mathrm{C} / \mathrm{S}$ analysis and PXRD suggests that it is unlikely for Ore Chimney to generate AMD in the near future.

\subsubsection{Implications}

The solid-phase geochemical signatures that remain in the waste-rock pile after $\sim 100$ years of weathering indicate that different sulfide minerals altered to different extents with pyrite and chalcopyrite showing minimal alteration and sphalerite showing the highest degrees of weathering. Galena weathering was highly variable, which may be attributed to inconsistencies in secondary cerussite formation due to variable carbonate content and the absence of pyrrhotite may suggest complete removal from the waste-rock pile. All the sulfide minerals showed evidence of weathering that was consistent with depth and between sampling locations indicating that aerobic conditions are consistent throughout the entire waste-rock pile, which may be a function of coarser grain size accumulation at the base of the pile from edge dumping coupled with long-term subaerial exposure (Lahmira et al., 2016).

The rich carbonate content (1.38 wt.\% C) at Ore Chimney has been observed to counteract the aerobic oxidation of high concentrations of sulfur (2.02 wt.\% S) and subjected the waste-rock pile to neutral mine drainage for $\sim 100$ years. Comprehensive studies on young waste rock (i.e. $<1$ year of exposure above ground surface), such as the Diavik mine (Smith et al., 2013a; Smith et al., 2013b) contain much lower carbon ( $0.02 \mathrm{wt} . \%)$ and sulfur (0.16 wt.\%) content that was observed to generate acidic drainage waters after as early as five years (Langman et al., 2014). Results indicate that significantly higher carbonate concentrations are required to prevent potential acid generation after $\sim 100$ years of weathering as observed at Ore Chimney. 
Moncur et al (2009) observed the entire removal of low Fe-bearing sphalerite [Zno.96Fe ${ }_{0.04 S}$; (Moncur et al., 2005)] from the upper portion of a tailings profile that was associated with low pH and 70 years of oxidation. In contrast, Jeong and Lee (2003) investigated carbonate-rich waste rock that was subjected to 50 years of weathering under circumneutral $\mathrm{pH}$ and observed that Fe-bearing sphalerite $\left(\mathrm{Zn}_{0.84} \mathrm{Fe}_{0.15} \mathrm{Mn}_{0.01} \mathrm{~S}\right)$ was extensively weathered but still abundant in the upper portions of the pile indicating that sphalerite mineral resistance increases with increasing Fe content and may weather at slower rates when $\mathrm{pH}$ is maintained at circumneutral levels. Likewise, sphalerite $\left(\sim \mathrm{Zn}_{0.85} \mathrm{Fe} 0.15 \mathrm{~S}\right)$ in the $\sim 100$-year-old Ore Chimney waste-rock pile was moderately to extensively weathered but persisted throughout the entire pile including the upper portions. The extent of sphalerite oxidation at Ore Chimney was similar to observations by Jeong and Lee (2003) indicating that $\mathrm{Fe}$ content in sphalerite coupled with a high carbonate content in the waste rock can significantly slow weathering rates over time especially between 50 to 100 years of exposure above ground surface.

The remaining presence of moderately to extensively weathered sphalerite throughout the waste-rock pile, especially in the fine-grained fraction of waste rock indicates continual weathering after $\sim 100$ years and predicts sphalerite to deplete before chalcopyrite, pyrite, and galena. The relatively high carbonate content comprised of calcite and dolomite has prevented the generation of AMD and will continue to buffer acidity until calcite is depleted where dolomite is expected to become the primary mineral buffering phase and may elevate dissolved concentrations of $\mathrm{Mg}$ and maintain near-neutral $\mathrm{pH}$ over an extended period. Total sulfur concentrations were consistent between grain size fractions, but ICPAES/MS detected a slight enrichment of $\mathrm{Zn}$ and $\mathrm{Pb}$ in the fine-grained fraction of waste-rock material providing some indication that blasting and weathering processes partitions sulfides into finer grain sizes. However, the partitioning of sulfur into finer grain sizes is more evident for sulfide minerals derived from biotite schist (Smith et al., 2013a) compared to sulfidic quartz veins at Ore Chimney, suggesting that the source lithology for sulfide minerals plays an important role in sulfide weathering. 


\section{Chapter 3: Porewater Chemistry}

\subsection{Introduction}

The oxidation of sulfide minerals is thermodynamically favourable in ambient aerobic settings and predicts the release of metals and acidity into proximate porewaters, which has long been recognized and described as "acid mine drainage" (AMD) (Nordstrom, 1982; Akcil and Koldas, 2006). However, waste rock piles are multi-component systems that often host carbonate minerals with an affinity to counteract the release of acidity through neutralization reactions that maintain near-neutral $\mathrm{pH}$, with the most common examples being calcite and dolomite (Parbhakar-Fox and Lottermoser, 2017; Bao et al., 2020). As such, carbonate-rich waste-rock piles have been observed to maintain near-neutral $\mathrm{pH}$ throughflow waters, which is appropriately described as "neutral mine drainage" (NMD) (Jeong and Lee, 2003; Nordstrom et al., 2015). However, carbonate buffering minerals persist in mine-waste systems in finite amounts and acid generation from the continual weathering of sulfides can deplete carbonate minerals entirely (Moncur et al., 2005). The neutralization potential of mine-waste systems is both a function of buffering availability (i.e. abundance) and exposure time (Blowes et al., 2013). Under longer exposure times or in systems with carbonate deficiency, $\mathrm{pH}$ levels may be regulated by the availability of less reactive primary and secondary carbonate, hydroxide, and aluminosilicate minerals in a succession summarized by Johnson et al (2000) and Bain et al (2001).

Transition metals dissolved in waste-rock porewaters are primarily derived by the oxidative dissolution of sulfide minerals, which is often generalized as "weathering" (Amos et al., 2015). Iron-bearing sulfide oxidation typically favours the formation of Fe-oxyhydroxide phases and the adsorption of metals onto these alteration surfaces has been observed as a common sink in a variety of mine-waste settings (Zhixun, 1996; Balistrieri et al., 2008; Demers et al., 2013; Skierszkan et al., 2016). In many cases, amorphous ferrihydrite is the expected Fe-oxyhydroxide phase above a $\mathrm{pH}$ of 4 and conditions in aerobic subaerial systems favour the 
recrystallization and transformation of ferrihydrite into goethite over time (Lee et al., 2002; Stipp et al., 2002). Likewise, the adsorption of transition metals onto the surface of goethite has been observed as a $\mathrm{pH}$-dependent equilibrium process where metal adsorption affinities decrease at lower $\mathrm{pH}$ due to competition with hydronium ions (Kooner, 1993; Rodda et al., 1993; Rose and Bianchi-Mosquera, 1993; Abdus-Salam and Adekola, 2005). The relationship between goethite adsorption affinity and $\mathrm{pH}$ usually differs among divalent transition metals where a reduction in $\mathrm{pH}$ from alkaline to acidic levels generally desorbs metals into solution in the order $\mathrm{Ni} \geq \mathrm{Co}>\mathrm{Cd}>\mathrm{Zn}>\mathrm{Pb} \geq \mathrm{Cu}$ (Blowes and Jambor, 1990; Rose and Bianchi-Mosquera, 1993; Jurjovec et al., 2002; Swedlund et al., 2009; Mohapatra et al., 2011; Komárek et al., 2018).

Progressive research involving seasonal and yearly monitoring of drainage quality comprises a substantial component of the mine-waste literature with examples including Diavik (Neuner et al., 2013; Pham et al., 2013; Smith et al., 2013b), Faro (Lewkowicz and Bonnaventure, 2011; Mead, 2011; Bao et al., 2020), and Meadowbank (Borgne et al., 2018; Boulanger-Martel et al., 2021; Yi, 2021) mine. However, these mining operations are situated in high-latitude regions influenced by permafrost and lower levels of precipitation, which can mitigate the transport of contaminants (Pham et al., 2015). Vriens et al (2019) investigated the changing geochemical signatures of five waste-rock test piles of varying lithologies that weathered over a ten-year time frame at an average annual temperature of $6^{\circ} \mathrm{C}$ at the Antamina mine. Results indicated that dissolved metals in the porewaters at the base of the waste-rock piles were controlled by secondary minerals such as gypsum, Cu,Zn-hydroxysulfate, -hydroxycarbonate, and Fe-oxyhydroxides and adsorption to Fe-oxyhydroxide surfaces during the incipient stages of weathering (i.e. $<1$ year), which remained relatively consistent throughout the ten-year study. Vriens et al (2019) discovered that evaluating weathering mechanisms over multiyear timescales was difficult to interpret by monitoring only the basal porewaters, which can be influenced by overlying geochemical signatures. Furthermore, unique climatic conditions at Antamina and mineralogical heterogeneities between 
test piles made it difficult to compare results in a broader context without investigating in situ porewater chemistry at different pile depths.

Smith et al (2021) collected porewaters from in situ waste-rock samples along the surface, middle, and base of a deconstructed $15 \mathrm{~m}$ deep waste-rock pile at the Detour Lake mine that had weathered for approximately 30 years. Porewaters were observed to maintain near-neutral $\mathrm{pH}$ throughout the entire depth profile suggesting that carbonate mineral buffering had been an active process over the past 30 years. However, NPR estimations predicted samples to be potentially acid generating or have uncertain acid generation capacity suggesting that the Cacarbonate content was depleting from the waste-rock pile. A 30-year timescale is long for waste-rock mineral weathering studies in the literature but is still quite short in comparison to actual timeframes of weathering for real waste-rock piles, especially those from abandoned mine sites. This chapter aims to supplement solid-phase metal release mechanisms at high spatial resolution $(0.5 \mathrm{~m})$ examined in chapter 2 by investigating relationships in the porewaters to better understand the overall mobility of metals after $\sim 100$ years of weathering.

\subsection{Methods}

\subsubsection{Sample Preparation}

For a description of sample locations of the waste-rock site at Ore Chimney and methods for waste-rock sampling for porewater extractions, refer to section 2.2.1 in Chapter 2. Samples of raw waste-rock material (i.e. undried and unsieved) were transferred into modified Falcon ${ }^{\mathrm{TM}}$ tubes for porewater extraction (Atherton, 2017; Smith et al., 2021). Conical $50 \mathrm{~mL}$ Falcon ${ }^{\mathrm{TM}}$ centrifuge tubes were shortened to 45 $\mathrm{mL}$ and a $2 \mathrm{~mm}$ hole was drilled at the base and lined with glass wool (SigmaAldrich, product number: 18421). An additional set of Falcon ${ }^{\mathrm{TM}}$ centrifuge tubes were shortened to $10 \mathrm{~mL}$ and placed underneath the modified $45 \mathrm{~mL}$ tubes in the centrifuge holder to collect the separated porewaters (Fig. 3.1a and b). Porewater

samples were separated from waste-rock material using a Hettich Rotofix $32 \mathrm{~A}$ benchtop centrifuge rotating at 4000 RPM for five minutes. Centrifuging the same 
sample for another five minutes did not separate any additional volume of porewater, which justified five minutes as an appropriate time for centrifugation. All sample vials and porewater sampling vessels were thoroughly washed in a $2 \%$ ultra-pure nitric acid and deionized water solution. A minimum volume of $25 \mathrm{~mL}$ of porewater sample for chemical analyses was obtained from 16-24 aliquots of waste-rock material weighing approximately $100 \mathrm{~g}$ ( 1 aliquot $=1$ modified Falcon ${ }^{\mathrm{TM}}$ tube filled with $40 \mathrm{~mL}$ of sample material; Fig. 3.1a). All porewater samples for ion analyses were filtered to $0.45 \mu \mathrm{m}$. Porewater samples were transferred into unacidified $15 \mathrm{~mL}$ sample vials for anion chromatography and $5 \mathrm{~mL}$ sample vials acidified with $0.1 \mathrm{~mL}$ of ultra-pure nitric acid for ICP-AES/MS measurements. Additional aliquots were collected for immediate laboratory analysis and small volumes of porewater sample and sample reagents $(0.1$ to $5.0 \mathrm{~mL})$ were measured and transferred using a VWR VE1000 micropipette.

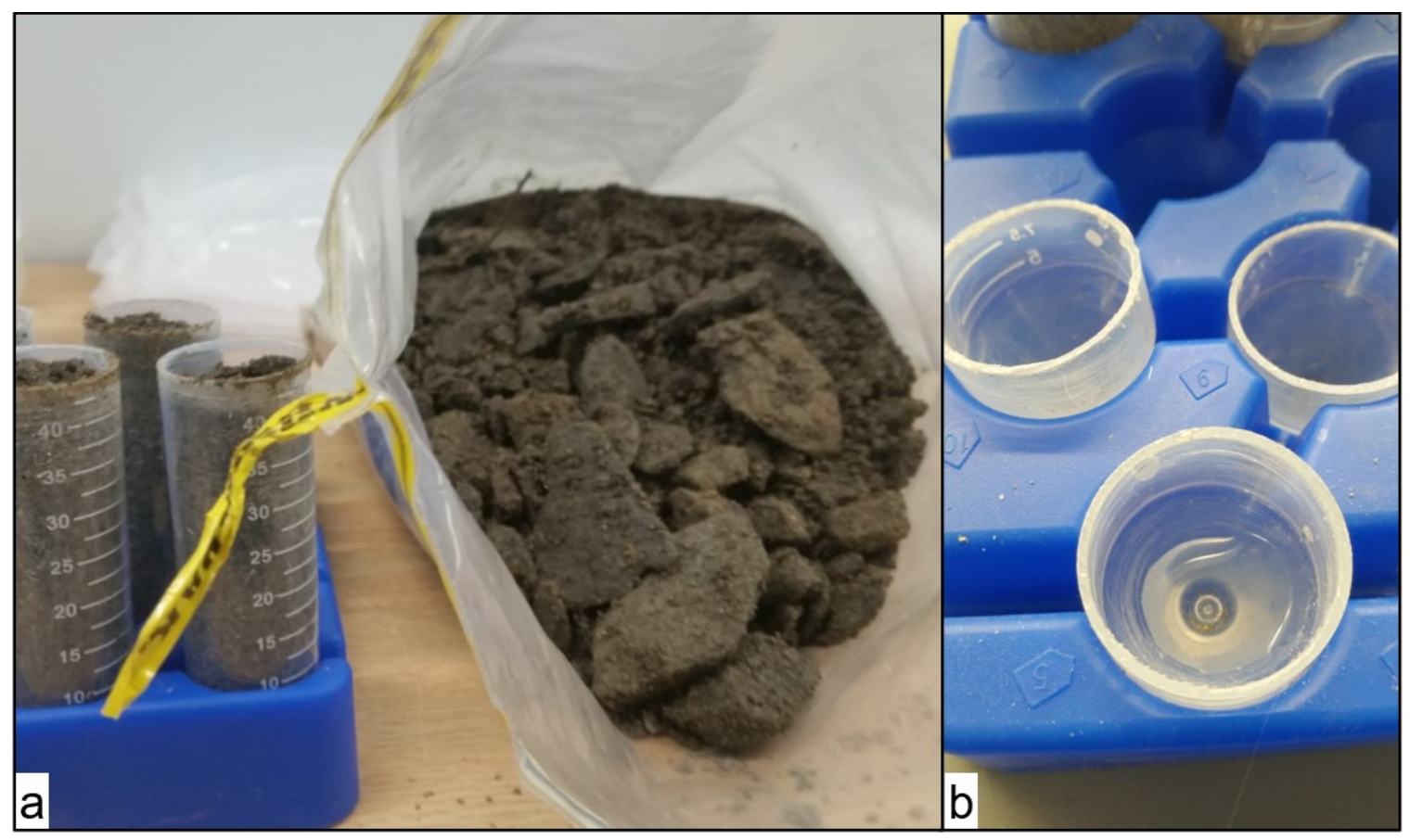

Figure 3.1: a) Falcon ${ }^{\mathrm{TM}}$ tubes shortened to $45 \mathrm{~mL}$ and filled with loose wasterock material ( $2 \mathrm{~mm}$ hole drilled at the base and lined with glass wool), b) Falcon ${ }^{\mathrm{TM}}$ tubes shortened to $10 \mathrm{~mL}$ and placed underneath for porewater collection. 


\subsubsection{Analytical Methods}

Porewater $\mathrm{pH}$ and Eh were determined using a VWR model H30PCO sympHony ${ }^{T M}$ handheld probe. A Hach DR 1900 portable spectrophotometer was used to perform immediate chemical analyses for sulfate $\left(\mathrm{SO}_{4}^{2-}\right.$ ) (Method 10248; Hach, 2013), sulfide $\left(\mathrm{HS}^{-}\right)$(Method 10254; Hach, 2014a), alkalinity $\left(\mathrm{CaCO}_{3}\right)$ (Method 10239; Hach, 2014b), and ferrous iron $\left(\mathrm{Fe}^{2+}\right)$ (Method 8146; Hach, 2014c). Porewater samples for major and trace cation analyses (ICP-AES/MS) and anion chromatography (IC) were performed at the Geochemistry Laboratory at the University of Ottawa. Porewater samples for major and trace cation analyses were diluted with deionized water to contain $1 \%$ molar concentration of ultra-pure nitric acid. Major cations were quantified by ICP-AES using an Agilent 5110 SVDV CCD spectrometer. Trace metal concentrations were determined by ICP-MS using an Agilent 8800 QQQ triple quadrupole mass spectrometer. All calibration standards for cation analyses were prepared using an ultra-pure $1 \%$ nitric acid solution. Anion concentrations were measured in un-acidified water samples via anion IC using a DIONEX ICS-2100 chromatograph and all analyses were calibrated using external standards (N. De Silva, personal communications, 2021).

Porewater chemistry data compiled from probe and spectrophotometry methods, ICP-AES/MS, and anion IC were used to generate mineral saturation indices at $10^{\circ} \mathrm{C}$ using PHREEQC software version 3.4.0-12927 with the minteq.v4 database (Parkhurst and Appelo, 1999). Depth plot saturation indices (SI) were fitted with vertical dashed lines to indicate the SI boundary between -0.5 and +0.5 and samples registering within this range were considered to be near saturation (Ettler et al., 2009; Chidambaram et al., 2012; Gawdzik et al., 2015).

\subsection{Results}

Waste-rock samples for solid-phase analyses (Chapter 2) and porewater extractions were collected in tandem. Therefore, the beginning of the estimated transitional boundary between the waste-rock pile and natural overburden material (between 4.5 to 5.0 metres deep in trench 2 and 4.0 to 4.5 metres deep in trench 
3) also applied to the samples collected for porewater extractions. The porewater chemical depth plots presented hereafter indicate these non-discrete boundary estimations accordingly as "WRP boundary" and the samples located above these boundaries were referred to as the waste-rock porewaters $(n=13$ in trench 1 , $n=12$ in trench 2, and $n=11$ in trench 3). Likewise, only the samples representing waste-rock porewaters (i.e. excluding the samples below the WRP boundary) were included in statistical comparisons and the annotated results summary unless indicated otherwise.

The results presented herein compare average concentration measurements between trenches and spatial differences within a given trench (i.e. vertical trends) but only trends and differences with a statistical significance are reported. Vertical trends were interpreted from a two-tailed Pearson linear regression analysis with $95 \%$ confidence and compared to critical Pearson correlation $\left(R^{2}\right.$ critical) values of $0.553,0.576$, and 0.602 for trenches 1,2 , and 3 , respectively (Degrees of Freedom $=\mathrm{n}-2$ ) (Weatherington et al., 2012). Rank sum two-tailed t-tests were conducted to compare samples between trenches. Two-tailed t-test comparisons did not include data from duplicate samples and only considered samples between 0.0 to $4.0 \mathrm{~m}$ depth to account for the transition between waste rock and overburden material observed in trenches 2 and $3(n=9)$. Vertical trends with statistically insignificant correlation coefficients $\left(R^{2}\right.$ calculated $<R^{2}$ critical) and t-test comparisons of population means $(\mu)$ with standard deviations $(\sigma)$ yielding no statistical difference $(\alpha>0.05)$ were interpreted as such and not reported herein.

\subsubsection{Porewater Chemistry}

Spectrophotometric analysis performed immediately after porewater extractions revealed concentrations of dissolved ferrous iron $\left(\mathrm{Fe}^{2+}\right)$ and sulfide ( $\left.\mathrm{HS}^{-}\right)$below the detection limit. Furthermore, sulfate $\left(\mathrm{SO}_{4}{ }^{2-}\right)$ measurements were conducted both immediately after porewater extractions via spectrophotometry and subsequently thereafter by anion IC. Sulfate concentrations from anion IC were consistently higher than spectrophotometry measurements by an average of $15 \%$ $(\sigma=9 \%)$. Spectrophotometry has a lower sensitivity than anion IC and was 
therefore omitted from the results presented below especially considering that presampled in situ waste rock was likely at equilibrium with atmospheric oxygen from under-range $\mathrm{Fe}^{2+}$ and $\mathrm{HS}^{-}$measurements and therefore not redox-sensitive.

The average $\mathrm{pH}$ in the Ore Chimney waste-rock porewaters was $7.0(\sigma=0.5), 7.3$ $(\sigma=0.4)$, and $7.5(\sigma=0.5)$ in trenches 1,2 , and 3, respectively (Fig. 3.2a - c). The lower average $\mathrm{pH}$ values measured in trench 1 correspond to $\mathrm{pH}$ readings of 6.5 and 6.4 at 0.5 and $4.0 \mathrm{~m}$ depth, respectively. Porewater Eh measurements averaged $434(\sigma=50), 414(\sigma=40)$, and $414(\sigma=20) \mathrm{mV}$ in trenches 1, 2, and 3, respectively (Fig. 3.2d $-f$ ). The higher average Eh reading and standard deviation observed in trench 1 were attributed to elevated readings of 547 and $486 \mathrm{mV}$ at 0.5 and $4.0 \mathrm{~m}$ depth. However, porewater $\mathrm{pH}$ and Eh measurements were not statistically different between trenches nor signified a relationship with depth in any trench.

The average porewater alkalinity concentrations were $53.7(\sigma=17.7), 52.3$ $(\sigma=23.2)$, and $76.4(\sigma=38.6) \mathrm{mg} / \mathrm{L} \mathrm{CaCO}_{3}$ in trenches 1,2 , and 3 , respectively (Fig. $3.2 \mathrm{~g}-\mathrm{i}$ ). Alkalinity concentrations were lowest in trench 2 and statistically higher in trench 3 by a mean difference of $30.6 \mathrm{mg} / \mathrm{L} \mathrm{CaCO}_{3}(\alpha=0.01)$. None of the trenches showed a statistical relationship between concentration and depth. Sulfate $\left(\mathrm{SO}_{4}{ }^{2-}\right)$ concentrations averaged 1,046.0 ( $\left.\sigma=499.0\right), 541.1(\sigma=324.7)$, and 1,111.8 $(\sigma=835.4) \mathrm{ppm}$ in trenches 1,2 , and 3, respectively (Fig. 3.2j - I). Average $\mathrm{SO}_{4}{ }^{2-}$ concentrations were lowest in trench 2 and statistically higher in trenches 1 and 3 by mean differences of 497.9 and 513.9 ppm $(\alpha=0.007$ and 0.05). Concentrations of $\mathrm{SO}_{4}{ }^{2-}$ statistically increased from 629 to 1578 (0.0 to 5.0 $\mathrm{m}$ depth), from 338 to 1293 ( 0.0 to $4.5 \mathrm{~m}$ depth), and from 140 to $1883 \mathrm{ppm}$ ( 0.0 to $4.0 \mathrm{~m}$ depth) in trenches 1,2 , and $3\left(R^{2}\right.$ calc $=0.56,0.63$, and 0.85 , respectively). 

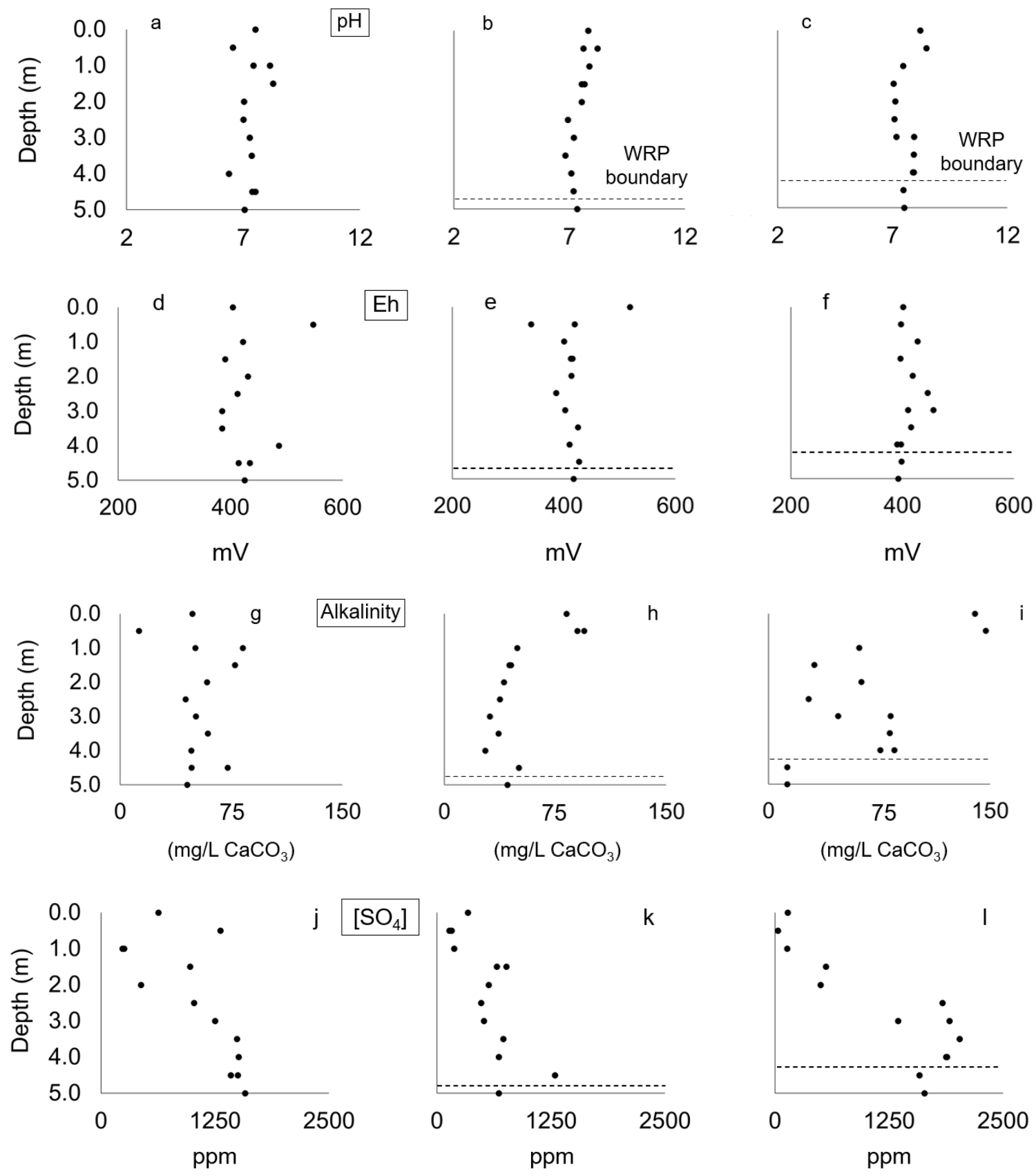

Figure 3.2: Aqueous-phase $\mathrm{pH}$, Eh, alkalinity, and sulfate $\left(\mathrm{SO}_{4}{ }^{2-}\right)$ depth plots for trench 1 (left), trench 2 (middle), and trench 3 (right). 
The average sodium ( $\mathrm{Na})$ concentrations were 28.1 $(\sigma=6.4), 22.8(\sigma=4.1)$, and $31.5(\sigma=8.7) \mathrm{ppm}$ in trenches 1,2 , and 3 , respectively (Fig. 3.3a - c). Average $\mathrm{Na}$ concentrations were lowest in trench 2 and statistically higher in trenches 1 and 3 by mean differences of 7.6 and $8.3 \mathrm{ppm}(\alpha=0.004$ and 0.05 ). Sodium concentrations were observed to statistically increase from $20.2 \mathrm{ppm}$ at the surface of the pile $(0.0 \mathrm{~m})$ to $46.1 \mathrm{ppm}$ at $4.0 \mathrm{~m}$ depth in trench $3\left(\mathrm{R}^{2}\right.$ calc $\left.=0.72\right)$. Porewater potassium $(\mathrm{K})$ concentrations averaged $32.3(\sigma=8.7), 24.6(\sigma=5.5)$, and 37.0 (21.6) ppm in trenches 1, 2, and 3, respectively (Fig. 3.3d - f). Average K concentrations were lowest in trench 2 and statistically higher in trench 1 by a mean difference of $7.5 \mathrm{ppm}(\alpha=0.02)$. Moreover, $\mathrm{K}$ concentrations statistically increased from $20.2 \mathrm{ppm}$ at the surface of the pile to $58.5 \mathrm{ppm}$ at $4.0 \mathrm{~m}$ depth in trench $3\left(R^{2}\right.$ calc $\left.=0.72\right)$.

Porewater calcium (Ca) concentrations averaged $268.4(\sigma=110.9), 159.2$ ( $\sigma=79.6)$, and $247.7(\sigma=155.2) \mathrm{ppm}$ in trenches 1,2 , and 3 , respectively (Fig. $3.3 g-i)$. Average Ca concentrations were lowest in trench 2 and statistically higher in trench 1 by a mean difference of $107.2 \mathrm{ppm}(\alpha=0.006)$. Calcium concentrations statistically increased from 176.6 to 366.3 ( 0.0 to $5.0 \mathrm{~m}$ depth), from 115.3 to 335.1 ( 0.0 to $4.5 \mathrm{~m}$ depth), and from 61.7 to $412.2 \mathrm{ppm}$ (0.0 to $4.0 \mathrm{~m}$ depth) in trenches 1,2 , and $3\left(R^{2}\right.$ calc $=0.59,0.59$, and 0.89 , respectively). The average magnesium $(\mathrm{Mg})$ concentrations were $40.0(\sigma=18.7), 14.6(\sigma=5.4)$, and $51.8(\sigma=44.4)$ ppm in trenches 1,2 , and 3, respectively (Fig. 3.3j - I). Average Mg concentrations were lowest in trench 2 and statistically higher in trenches 1 and 3 by mean differences of 25.8 and $37.6 \mathrm{ppm}(\alpha=0.002$ and 0.04 ). Porewater $\mathrm{Mg}$ concentrations may increase with depth; however, the relationship was not statistically significant $\left(R^{2}\right.$ calc $=0.50,0.35$, and 0.51 for trenches 1,2 , and 3 , respectively). 

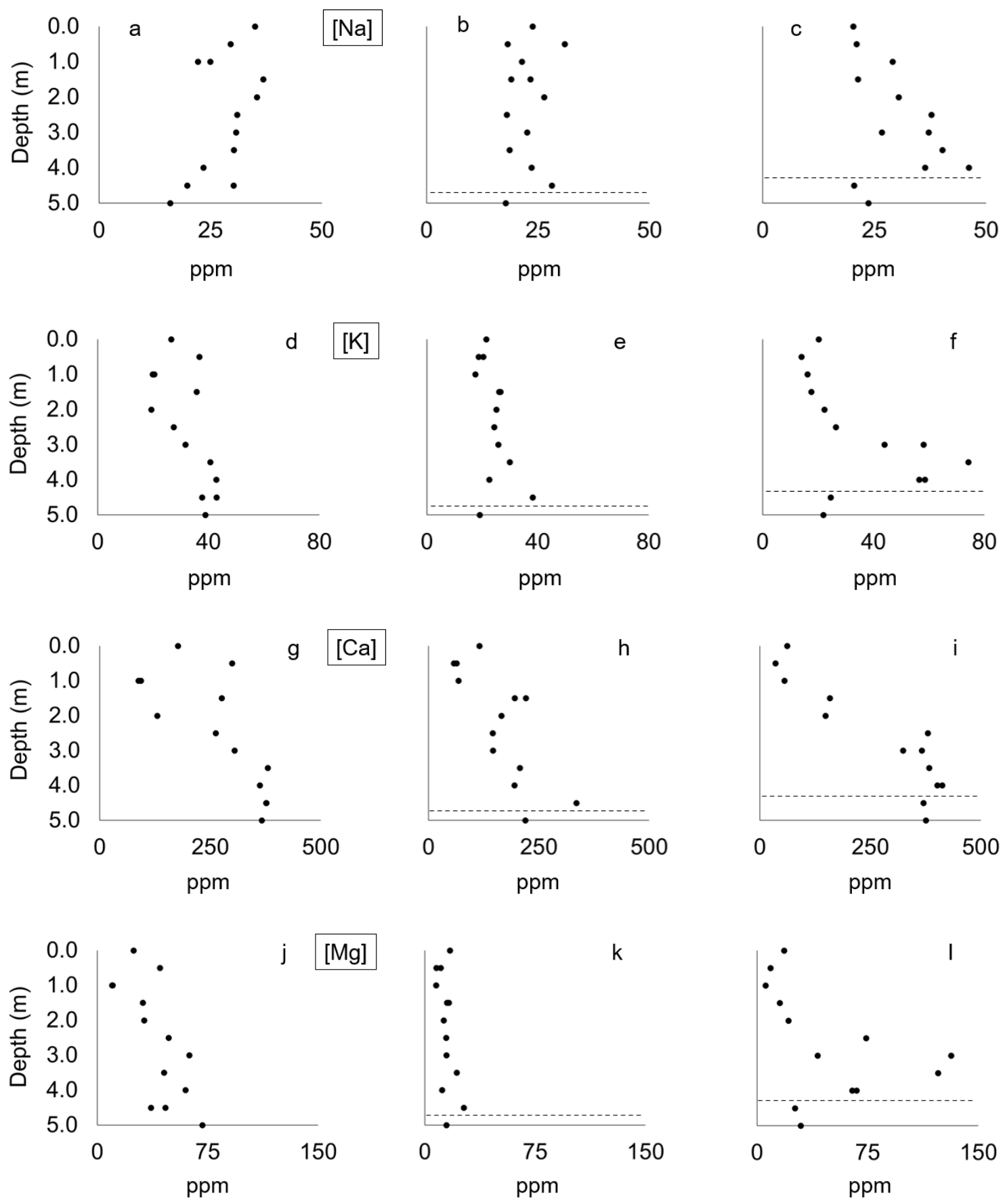

Figure 3.3: Aqueous-phase sodium ( $\mathrm{Na}$ ), potassium $(\mathrm{K})$, calcium $(\mathrm{Ca})$, and magnesium ( $\mathrm{Mg}$ ) depth plots for trench 1 (left), trench 2 (middle), and trench 3 (right). 
Iron $(\mathrm{Fe})$ concentrations in the porewaters averaged $9.2(\sigma=5.9), 5.9(\sigma=1.5)$, and $11.1(\sigma=8.1) \mathrm{ppb}$ in trenches 1,2 , and 3 , respectively (Fig. 3.4a - c). Average Fe concentrations were lowest in trench 2 and statistically higher in trenches 1 and 3 by mean differences of 2.9 and $6.1 \mathrm{ppb}$ ( $\alpha=0.04$ and 0.05 ). There was no statistically significant relationship between Fe concentration and depth in any trench. The average Copper $(\mathrm{Cu})$ concentrations measured $16.1(\sigma=20.6), 15.0$ ( $\sigma=6.8)$, and $11.7(\sigma=11.7) \mathrm{ppb}$ in trenches 1,2 , and 3 , respectively (Fig. 3.4d - f). The higher relative standard deviations measured in trenches 1 and 3 corresponded to anomalously high $\mathrm{Cu}$ readings at $0.5 \mathrm{~m}$ in trench 1 (82.6 ppb) and $2.5 \mathrm{~m}$ depth in trench 3 (45.7 ppb). A statistical increase in Cu concentrations was observed in trench 2 (7.2 ppb at the surface of the pile to $23.3 \mathrm{ppb}$ at $4.5 \mathrm{~m}$ depth; $R^{2}$ calc $\left.=0.84\right)$. No depth dependent trends were observed in trenches 1 and 3 even if the anomalies are excluded.

Porewater zinc $(Z n)$ concentrations averaged 19,400 ( $\sigma=23,300), 15,900$ $(\sigma=12,200)$, and $14,100(\sigma=22,000) \mathrm{ppb}$ in trenches 1,2 , and 3 , respectively (Fig. $3.4 \mathrm{~g}-\mathrm{i}$ ). Anomalously high $\mathrm{Zn}$ measurements at $0.5 \mathrm{~m}$ in trench $1(87,500$ $\mathrm{ppb})$ and $2.5 \mathrm{~m}$ depth in trench $3(74,900 \mathrm{ppb})$ accounted for their higher relative standard deviations. Zinc concentrations statistically increased from $700 \mathrm{ppb}$ at the surface of the pile to $31,600 \mathrm{ppb}$ at $4.5 \mathrm{~m}$ depth in trench $2\left(R^{2}\right.$ calc $\left.=0.76\right)$ but not in trenches 1 and 3 despite excluding the anomalous readings. The average lead $(\mathrm{Pb})$ concentrations measured $68.5(\sigma=79.2), 49.4(\sigma=18.7)$, and $35.4(\sigma=16.6)$ ppb in trenches 1, 2, and 3, respectively (Fig. 3.4j - I). The high relative standard deviation measured in trench 1 corresponded to an anomalously high reading at $0.5 \mathrm{~m}$ depth (322.3 ppb). Lead concentrations statistically increased in trench 2 from $31.4 \mathrm{ppb}$ at the surface of the pile to $72.3 \mathrm{ppb}$ at $4.5 \mathrm{~m}$ depth $\left(R^{2}\right.$ calc $\left.=0.79\right)$. 

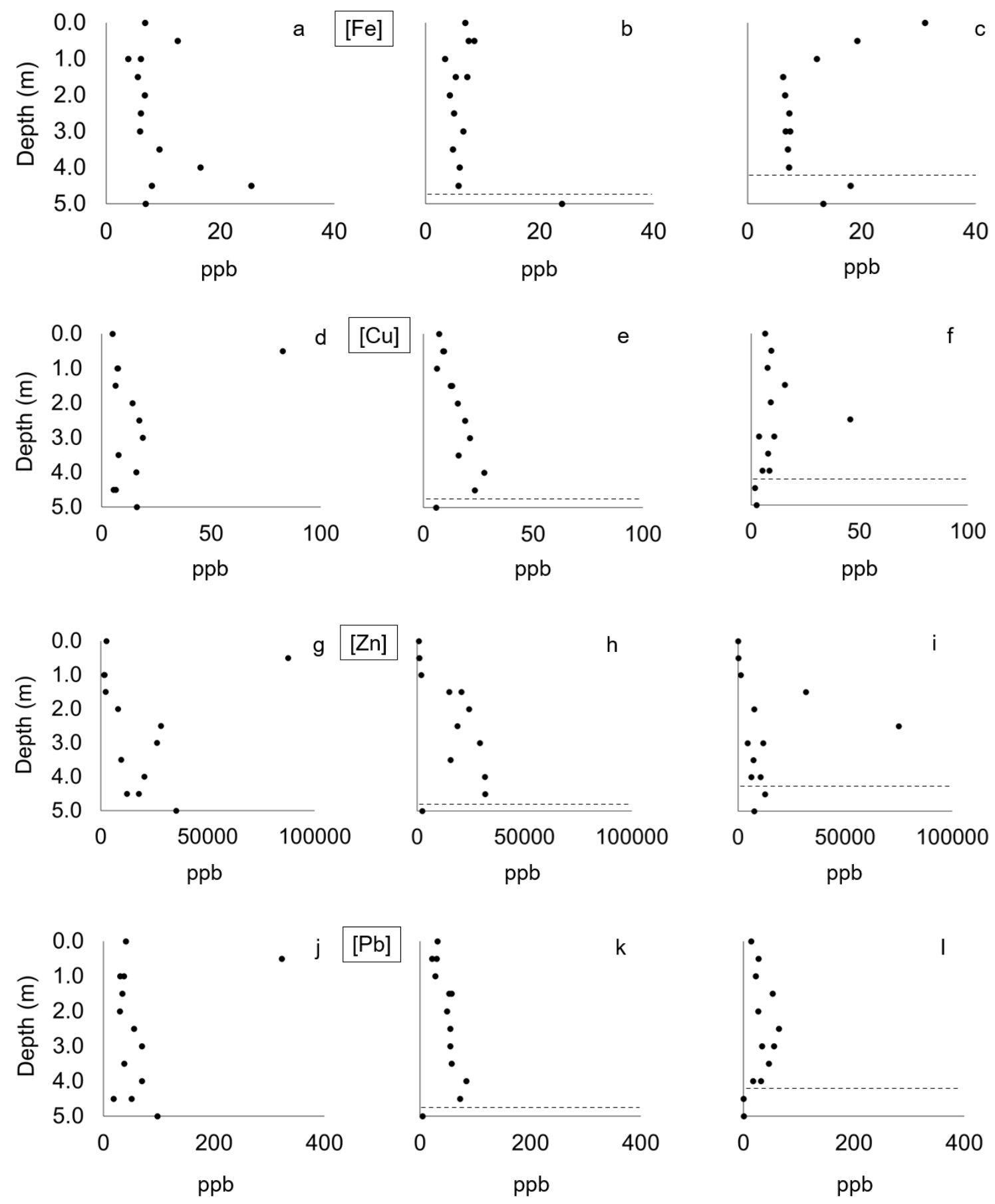

Figure 3.4: Aqueous-phase iron (Fe), copper $(\mathrm{Cu})$, zinc $(\mathrm{Zn})$, and lead $(\mathrm{Pb})$ depth plots for trench 1 (left), trench 2 (middle), and trench 3 (right). 
The average manganese $(\mathrm{Mn})$ concentrations were $348.7(\sigma=598.6), 64.5$ $(\sigma=44.1)$, and $351.0(\sigma=1,075.5) \mathrm{ppb}$ in trenches 1,2 , and 3 , respectively (Fig. 3.5a-c). The higher relative standard deviations measured in trenches 1 and 3 corresponded to anomalously high $\mathrm{Mn}$ readings at $0.5 \mathrm{~m}$ in trench $1(2,214.9$ $\mathrm{ppb})$ and $2.5 \mathrm{~m}$ depth in trench $3(3,592.2 \mathrm{ppb})$. Manganese concentrations showed no statistical relationship with depth in any trench. However, trench 1 yielded a $\mathrm{R}^{2}$ calc value of 0.544 when the anomalous measurement at $0.5 \mathrm{~m}$ depth was removed, which is statistically insignificant $(<0.553)$ but may signify that $\mathrm{Mn}$ concentrations increased from $53.2 \mathrm{ppb}$ at the surface of the pile to $679.1 \mathrm{ppb}$ at $5.0 \mathrm{~m}$ depth. Porewater cadmium ( $\mathrm{Cd}$ ) concentrations averaged $448.4(\sigma=353.5)$, 475.1 $(\sigma=330.5)$, and $339.0(\sigma=403.1) \mathrm{ppb}$ in trenches 1,2 , and 3 , respectively (Fig. 3.5d - f). Anomalously high $\mathrm{Cd}$ measurements at $0.5 \mathrm{~m}$ depth in trench 1 $(1,226.1 \mathrm{ppb})$ and $2.5 \mathrm{~m}$ depth in trench $3(1,336.2 \mathrm{ppb})$ accounted for their higher relative standard deviations. Cadmium concentrations in trench 2 statistically increased from $69.2 \mathrm{ppb}$ at the surface of the pile to $895.1 \mathrm{ppb}$ at $4.5 \mathrm{~m}$ depth $\left(R^{2}\right.$ calc $\left.=0.69\right)$. No depth dependent trends were observed in trenches 1 or 3 , even when the anomalies are excluded.

Porewater arsenic (As) concentrations averaged $1.4(\sigma=0.7), 1.5(\sigma=1.8)$, and $3.0(\sigma=3.8) \mathrm{ppb}$ in trenches 1,2 , and 3 , respectively (Fig. 3.5g - i). Average As concentrations were highest in trench 3 and statistically lower in trench 2 by a mean difference of $1.9 \mathrm{ppb}(\alpha=0.05)$. There was no statistically significant relationship between As concentration and depth in any trench. The average antimony $(\mathrm{Sb})$ concentrations measured $15.0(\sigma=13.2), 22.4(\sigma=9.3)$, and 12.0 $(\sigma=4.8) \mathrm{ppb}$ in trenches 1,2 , and 3 , respectively (Fig. 3.5j - I). Average Sb concentrations were lowest in trench 3 and statistically higher in trench 2 by a mean difference of $9.2 \mathrm{ppb}(\alpha=0.05)$. Concentrations of $\mathrm{Sb}$ were not observed to statistically change with depth in any trench. 

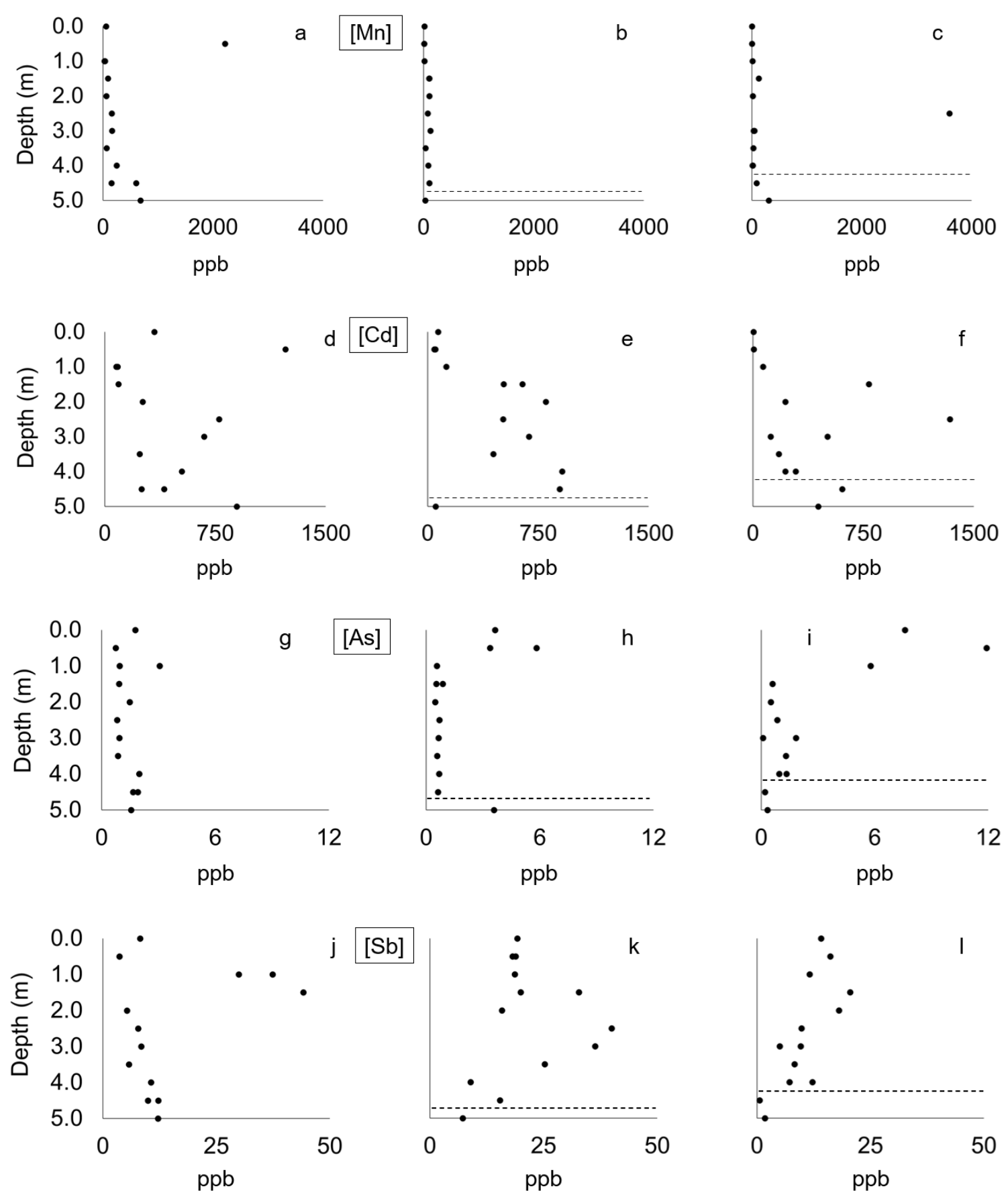

Figure 3.5: Aqueous-phase manganese (Mn), cadmium (Cd), arsenic (As), and antimony $(\mathrm{Sb})$ depth plots for trench 1 (left), trench 2 (middle), and trench 3 (right). 
The average titanium ( $\mathrm{Ti}$ ) concentrations measured 1.1 ( $\sigma=1.1), 0.2(\sigma=0.2)$, and $0.5(\sigma=0.5) \mathrm{ppb}$ in trenches 1, 2, and 3, respectively (Fig. 3.6a - c). Average Ti concentrations were observed to be lowest in trench 2 and higher in trenches 1 and 3 by mean differences of 0.7 and $0.4 \mathrm{ppb}(\alpha=0.04$ and 0.04 ). However, several Ti measurements in trenches 2 and 3 were below the detection limit of 0.13 $\mathrm{ppb}$ and created difficulties for quantitative comparisons. Titanium concentrations showed no relationship with depth in any trench. Porewater chromium $(\mathrm{Cr})$ concentrations averaged $0.3(\sigma=0.1), 0.2(\sigma=0.03)$, and $0.2(\sigma=0.05) \mathrm{ppb}$ in trenches 1, 2, and 3, respectively (Fig. 3.6d - f). Chromium concentrations were consistent with depth and showed no statistical difference in concentration between any of the trenches.

Average porewater cobalt (Co) concentrations were $16.2(\sigma=25.0), 7.1(\sigma=5.3)$, and $11.6(\sigma=27.7) \mathrm{ppb}$ in trenches 1,2 , and 3 , respectively (Fig. $3.6 \mathrm{~g}-\mathrm{i})$. The higher relative standard deviations measured in trenches 1 and 3 corresponded to anomalously high Co readings at $0.5 \mathrm{~m}$ depth in trench $1(95.9 \mathrm{ppb})$ and $2.5 \mathrm{~m}$ depth in trench 3 (94.8 ppb). Linear regression analysis of the raw data revealed no statistical relationship between concentration and depth. However, trench 1 yielded a $R^{2}$ calc value of 0.59 when the anomalous measurement at $0.5 \mathrm{~m}$ depth was removed, which may indicate an increase from $2.9 \mathrm{ppb}$ at the surface of the pile to $29.3 \mathrm{ppb}$ at $5.0 \mathrm{~m}$ depth.

The average nickel $(\mathrm{Ni})$ concentrations measured $37.1(\sigma=42.1), 17.5(\sigma=14.0)$, and $35.4(\sigma=70.1) \mathrm{ppb}$ in trenches 1,2 , and 3, respectively (Fig. 3.6j - I). Anomalously high Ni measurements at $0.5 \mathrm{~m}$ depth in trench 1 (166.0 ppb) and $2.5 \mathrm{~m}$ depth in trench $3(244.8 \mathrm{ppb})$ accounted for their higher relative standard deviations. With the anomalies excluded from the dataset, $\mathrm{Ni}$ concentrations increased from 13.1 to 66.4 ( 0.0 to $5.0 \mathrm{~m}$ depth), from 3.3 to 36.9 (0.0 to $4.5 \mathrm{~m}$ depth), and from 1.4 to $22.2 \mathrm{ppm}$ ( 0.0 to $4.0 \mathrm{~m}$ depth) in trenches 1,2 , and 3 $\left(R_{\text {calc }}^{2}=0.68,0.69\right.$, and 0.63 , respectively $)$. 

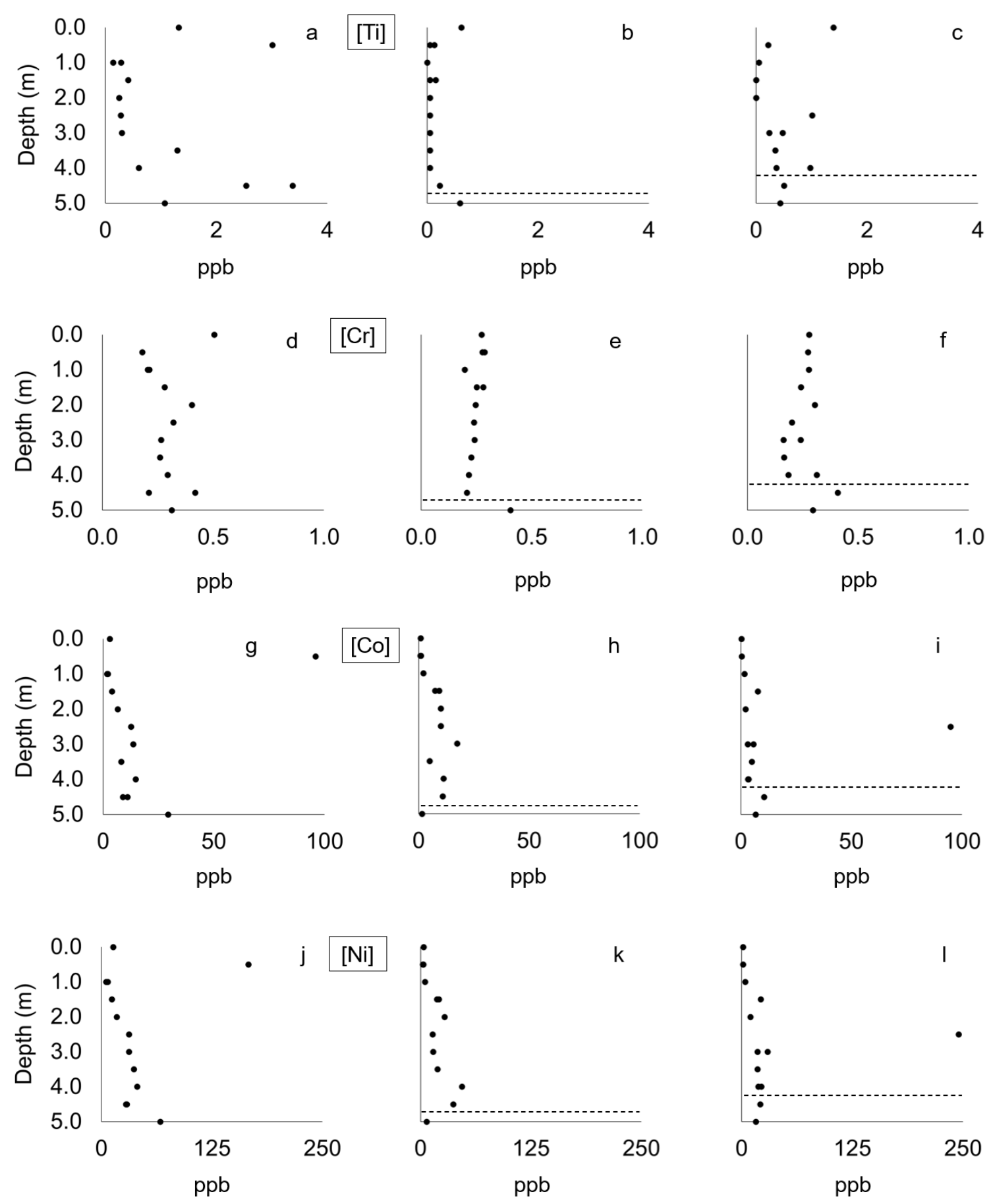

Figure 3.6: Aqueous-phase titanium (Ti), chromium (Cr), cobalt (Co), and nickel (Ni) depth plots for trench 1 (left), trench 2 (middle), and trench 3 (right). 
The average aluminum (Al) concentrations were $4.9(\sigma=5.2), 2.0(\sigma=1.4)$, and $4.9(\sigma=3.5) \mathrm{ppb}$ in trenches 1,2 , and 3 , respectively (Fig. 3.7a - c). Average Al concentrations were highest in trench 3 and statistically lower in trench 2 by a mean difference of $3.4 \mathrm{ppb}(\alpha=0.006)$. No statistical relationship between $\mathrm{Al}$ concentration and depth was observed in any trench. Porewater chloride $\left(\mathrm{Cl}^{-}\right)$ concentrations averaged $23.1(\sigma=16.2), 10.1(\sigma=2.6)$, and $9.9(\sigma=3.2)$ ppm in trenches 1,2 , and 3 , respectively (Fig. $3.7 \mathrm{~d}-\mathrm{f}$ ). Average $\mathrm{Cl}$ concentrations were highest in trench 1 and statistically lower in trenches 2 and 3 by mean differences of 14.9 and $15.1 \mathrm{ppm}(\alpha=0.03$ and 0.03 ). Chloride measurements did not reveal a statistically significant relationship with depth in any trench. The average phosphate $\left(\mathrm{PO}_{4}{ }^{3-}\right)$ concentrations were $0.15(\sigma=0.02), 0.14(\sigma=0.01)$, and 0.15 $(\sigma=0.04)$ ppm for trenches 1,2 , and 3 , respectively (Fig. 3.7g - i). Porewater $\mathrm{PO}_{4}{ }^{3-}$ concentrations were relatively consistent between trenches and did not show a statistically significant relationship with depth.

In summary, $\mathrm{SO}_{4}{ }^{2-}, \mathrm{Na}, \mathrm{Mg}, \mathrm{Fe}$, and $\mathrm{Ti}$ measured the lowest average concentrations in trench 2 and were consistently higher in trenches 1 and 3 . Alkalinity and Ca measurements also reported the lowest average concentrations in trench 2 with statistically higher average alkalinity readings in trench 1 and higher $\mathrm{Ca}$ readings in trench 3 . Concentrations of $\mathrm{Na}$ and $\mathrm{K}$ increased with depth in trench 3 and $\mathrm{Cu}, \mathrm{Zn}, \mathrm{Pb}$, and $\mathrm{Cd}$ concentrations increased with depth in trench 2. Furthermore, all three trenches showed increasing concentrations of $\mathrm{SO}_{4}{ }^{2-}$ and $\mathrm{Ca}$ with depth. Magnesium concentrations may also show some indication of increasing concentrations with depth in all three trenches; however, the relationship was not statistically significant $\left(R^{2}\right.$ calc $=0.50,0.35$, and 0.51 for trenches 1, 2, and 3, respectively). Likewise, Ni concentrations were observed to increase with depth in all three trenches but only when anomalous readings at 0.5 $\mathrm{m}$ depth in trench 1 and $2.5 \mathrm{~m}$ depth in trench 3 were excluded from the dataset $\left(R^{2}\right.$ calc $=0.68,0.69$, and 0.63 for trenches 1,2 , and 3 , respectively $)$. Alkalinity and $\mathrm{pH}$ recorded relatively low readings and $\mathrm{Eh}$ and $\mathrm{Pb}$ measurements were anomalously high at $0.5 \mathrm{~m}$ depth in trench 1 and $\mathrm{Cu}, \mathrm{Zn}, \mathrm{Mn}, \mathrm{Cd}, \mathrm{Co}$, and $\mathrm{Ni}$ all 
measured anomalously high concentrations at $0.5 \mathrm{~m}$ depth in trench 1 and $2.5 \mathrm{~m}$ depth in trench 3.
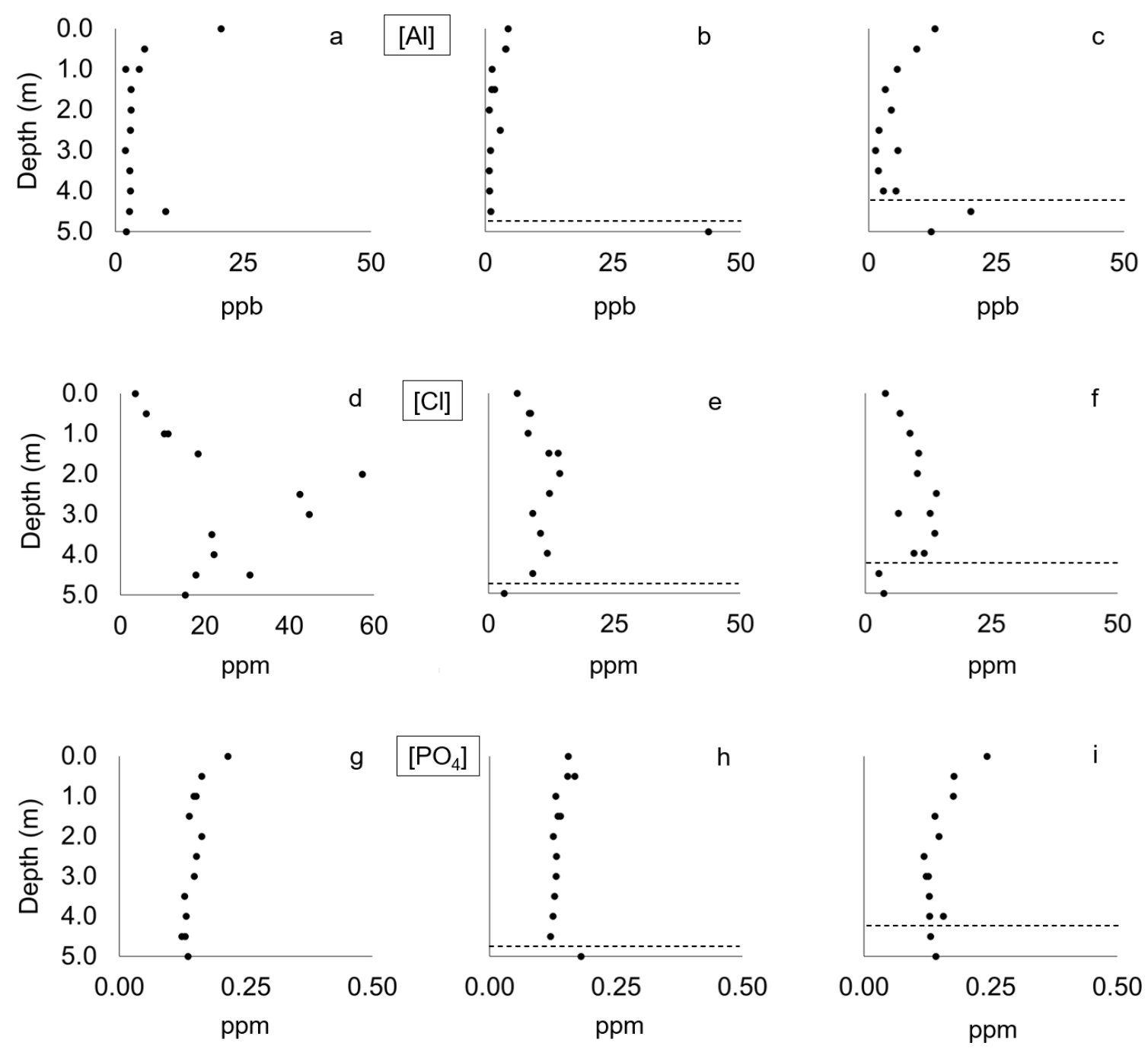

Figure 3.7: Aqueous-phase aluminum (Al), chloride $\left(\mathrm{Cl}^{-}\right)$, and phosphate $\left(\mathrm{PO}_{4}{ }^{3-}\right)$ depth plots for trench 1 (left), trench 2 (middle), and trench 3 (right). 


\subsubsection{Mineral Saturation Indices}

Calcite was typically undersaturated throughout the waste-rock pile with average SI values of $-0.8(\sigma=0.7),-0.8(\sigma=0.5)$, and $-0.4(\sigma=0.7)$ in trenches 1,2 , and 3 , respectively (Fig. $3.8 \mathrm{a}-\mathrm{C}$ ). The lowest calcite SI measurements of -2.1 and -1.6 were observed at 0.5 and $4.0 \mathrm{~m}$ depth in trench 1 . Porewaters were near saturation $(-0.5 \leq \mathrm{SI} \leq+0.5)$ with respect to calcite at 1.0 to 1.5 and $4.5 \mathrm{~m}$ in trench 1 , from surface to $1.5 \mathrm{~m}$ in trench 2 , and from surface to 0.5 and 3.0 to $4.0 \mathrm{~m}$ depth in trench 3. Dolomite was also frequently undersaturated with average SI values of $-2.3(\sigma=1.3),-2.4(\sigma=1.0)$, and $-1.4(\sigma=1.5)$ in trenches 1,2 , and 3 , respectively (Fig. 3.8d - f). Similar to calcite, the lowest dolomite SI measurements of -4.9 and -3.9 were observed at 0.5 and $4.0 \mathrm{~m}$ depth in trench 1. Porewaters were near saturation with dolomite at $1.5 \mathrm{~m}$ in trench 1 and from surface to 0.5 and 3.0 to 4.0 $m$ depth in trench 3 .

Porewaters were undersaturated with gypsum above $1.5 \mathrm{~m}$ depth in all three trenches with average SI values of $-0.8(\sigma=0.4),-1.3(\sigma=0.2)$, and $-1.7(\sigma=0.4)$ in trenches 1, 2, and 3, respectively (Fig. $3.8 \mathrm{~g}-\mathrm{i}$ ). Below (and including) $1.5 \mathrm{~m}$, all three trenches approached saturation with average SI values of $-0.3(\sigma=0.2),-0.5$ $(\sigma=0.2)$, and $-0.2(\sigma=0.2)$ in trenches 1,2 , and 3 , respectively. Porewaters were undersaturated with jarosite throughout all three trenches with average SI values of $-1.5(\sigma=1.1),-2.4(\sigma=0.6)$, and $-1.4(\sigma=1.5)$ in trenches 1,2 , and 3 , respectively (Fig. 3.8j - I). Jarosite only neared saturation at 0.5 and 4.0 to $4.5 \mathrm{~m}$ depth in trench 1. Saturation index values of jarosite shifted closer to equilibrium with depth in the waste-rock porewaters in all three trenches; however, remained undersaturated throughout the entire profile of trenches 2 and 3 . 

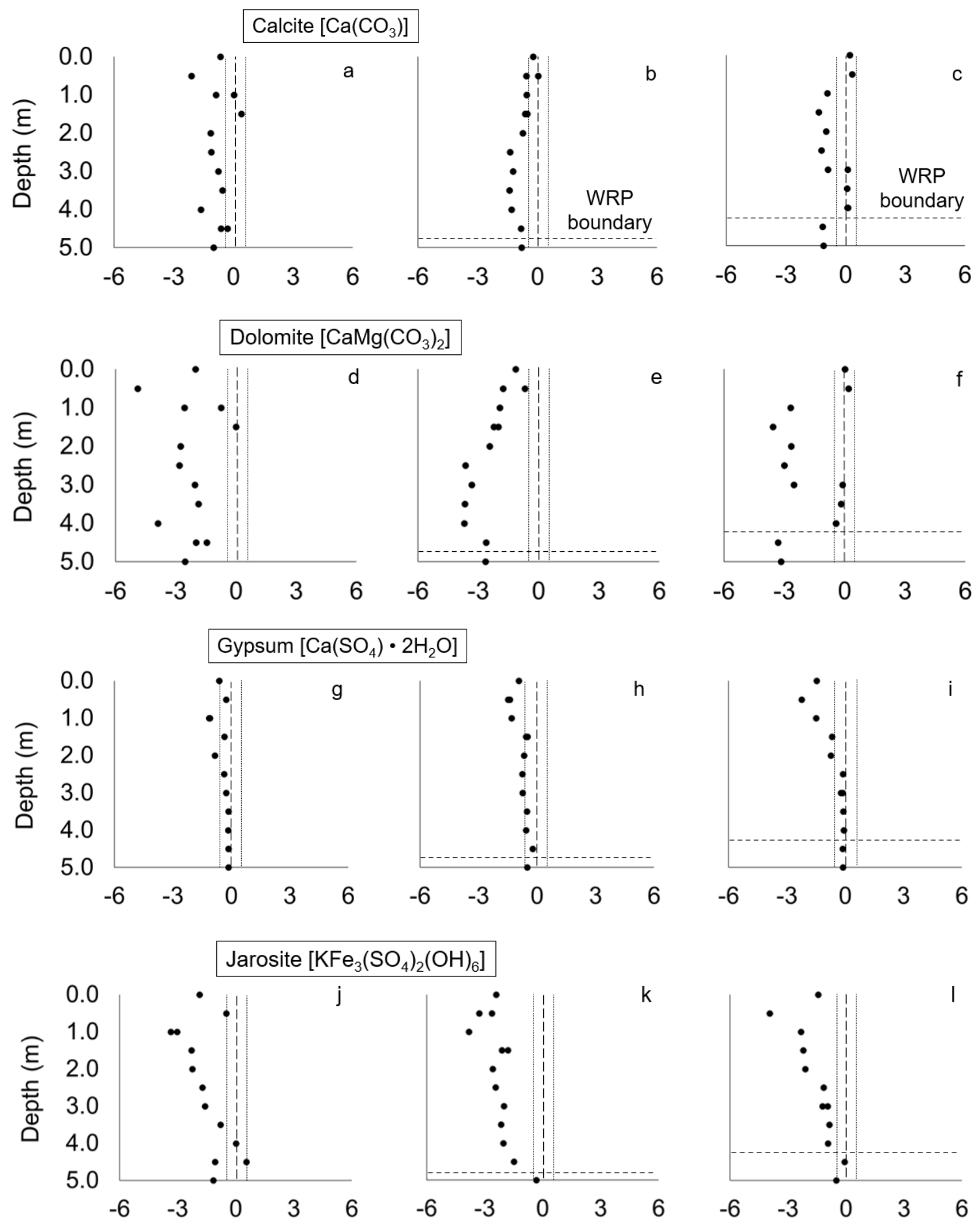

Figure 3.8: Calcite, dolomite, gypsum, and jarosite depth plot saturation indices for trench 1 (left), trench 2 (middle), and trench 3 (right). Dashed lines indicate $\mathrm{SI}$ boundary between -0.5 and +0.5 . 
Porewaters were consistently near saturation with respect to both gibbsite and boehmite in all three trenches ranging from -0.3 to $1.1(\mu=0.2, \sigma=0.3)$ and from -0.8 to $0.6(\mu=-0.3, \sigma=0.3)$, respectively (Fig. $3.9 a-f)$. Ferrihydrite was slightly oversaturated in all three trenches with average $S$ I values of $1.1(\sigma=0.4), 1.1$ $(\sigma=0.4)$, and $1.5(\sigma=0.7)$ in trenches 1,2 , and 3 , respectively (Fig. $3.9 \mathrm{~g}-\mathrm{i}$ ). Ferrihydrite was near saturation at 0.5 and $4.0 \mathrm{~m}$ in trench 1 and 2.5 and $3.5 \mathrm{~m}$ depth in trench 2 but remained slightly oversaturated throughout the entire depth profile of trench 3. Saturation index values of $\mathrm{Cr}(\mathrm{OH})_{3}(\mathrm{am})$ averaged $-1.2(\sigma=1.8)$, $-0.8(\sigma=1.4)$, and $-0.7(\sigma=0.5)$ in trenches 1,2 , and 3 , respectively and most samples were slightly undersaturated throughout each trench (Fig. 3.9j - I). However, waste-rock porewaters were near saturation with $\mathrm{Cr}(\mathrm{OH})_{3}(\mathrm{am})$ at the surface of the pile, $1.0,3.5$, and $4.5 \mathrm{~m}$ in trench 1 , from 0.5 to $2.0 \mathrm{~m}$ in trench 2 , and at 1.0 and $4.0 \mathrm{~m}$ depth in trench 3.

Manganite was frequently undersaturated throughout each trench with average SI values of $-2.0(\sigma=1.5),-2.3(\sigma=1.3)$, and $-2.1(\sigma=0.9)$ in trenches 1,2 , and 3 , respectively (Fig. $3.10 \mathrm{a}-\mathrm{c}$ ). Porewaters were undersaturated with manganite throughout the entire depth profile of trench 3 and neared saturation at $1.5 \mathrm{~m}$ depth in trench 1 and at the surface of trench 2. Porewaters were almost always near saturation with respect to $\mathrm{Mn}\left(\mathrm{HPO}_{4}\right)$ with average SI values of $0.4(\sigma=0.4), 0.1$ $(\sigma=0.3)$, and $-0.3(\sigma=0.7)$ in trenches 1,2 , and 3, respectively (Fig. 3.10d - f). Except for an oversaturated $\mathrm{SI}$ reading of 1.5 at $2.5 \mathrm{~m}$ depth in trench $3, \mathrm{Mn}\left(\mathrm{HPO}_{4}\right)$ showed only minor variation in SI values and was especially consistent in trenches 1 and 2.

Malachite was either near saturation or undersaturated throughout the waste-rock pile with average SI values of $-1.0(\sigma=0.8),-0.4(\sigma=0.5)$, and $-0.5(\sigma=0.7)$ in trenches 1, 2, and 3, respectively (Fig. $3.10 \mathrm{~g}-\mathrm{i}$ ). Porewaters were near saturation with malachite most consistently in trench 2 and only reported undersaturated SI values of -1.1 and -1.6 at 2.5 and $3.5 \mathrm{~m}$ depth. Malachite was also observed to be near saturation at 1.0 to 1.5 and $3.0 \mathrm{~m}$ in trench 1 and from the surface to 0.5 and from 2.5 to $4.0 \mathrm{~m}$ depth in trench 3. Porewaters were almost always near saturation 
with otavite with average SI values of $-0.6(\sigma=0.5),-0.3(\sigma=0.3)$, and -0.4 $(\sigma=0.3)$ in trenches 1,2 , and 3, respectively (Fig. 3.10j $-\mathrm{I})$. Trench 1 yielded the greatest SI variability with observed values of -1.4 and -1.4 at 0.5 and $4.0 \mathrm{~m}$ depth; however, the variation in otavite $\mathrm{SI}$ values was relatively minor, especially in trenches 2 and 3.

Cerussite was either near saturation or undersaturated in the porewaters with average SI values of $-0.7(\sigma=0.3),-0.5(\sigma=0.2)$, and $-0.6(\sigma=0.3)$ in trenches 1 , 2 , and 3, respectively (Fig. 3.11a - c). Cerussite was near saturation from 1.0 to 1.5 and $3.0 \mathrm{~m}$ in trench 1 , from the surface to $2.0 \mathrm{~m}$ in trench 2 , and from the surface to 1.0 and from 3.0 to $4.0 \mathrm{~m}$ depth in trench 3 . However, remaining locations were observed to only be slightly undersaturated with cerussite and SI values were relatively consistent throughout all three trenches. Porewaters were typically undersaturated with respect to $\mathrm{Pb}(\mathrm{OH})_{2}$ with average SI values of -1.6 $(\sigma=0.7),-1.2(\sigma=0.5)$, and $-1.2(\sigma=0.6)$ in trenches 1,2 , and 3, respectively (Fig. 3.11d - f). The higher relative standard deviation in trench 1 corresponds to the lowest overall SI value of -3.1 at $4.0 \mathrm{~m}$ depth. Porewaters were undersaturated with $\mathrm{Pb}(\mathrm{OH})_{2}$ throughout the entire depth profile of trench 2 and neared saturation from 1.0 to $1.5 \mathrm{~m}$ in trench 1 and at $0.5 \mathrm{~m}$ depth in trench 2 .

Smithsonite monohydrate was either near saturation or slightly undersaturated with average SI values of $-0.6(\sigma=0.4),-0.4(\sigma=0.3)$, and $-0.5(\sigma=0.5)$ in trenches 1,2 , and 3 , respectively (Fig. $3.11 \mathrm{~g}-\mathrm{i}$ ). Smithsonite monohydrate was typically undersaturated from the surface to $1.0 \mathrm{~m}$ depth in all three trenches with an average SI value of -0.9 and neared saturation beyond $1.0 \mathrm{~m}$ with an average SI value of -0.4 . Porewaters were typically undersaturated with respect to $\mathrm{Zn}(\mathrm{OH})_{2}$ throughout all three trenches with averages of $-1.4(\sigma=0.7),-1.1(\sigma=0.6)$, and $-1.1(\sigma=0.6)$ in trenches 1,2 , and 3, respectively (Fig. 3.11j - I). The lowest $\mathrm{Zn}(\mathrm{OH})_{2} \mathrm{SI}$ measurement of -3.0 was observed at $4.0 \mathrm{~m}$ depth in trench 1 accounting for the higher relative standard deviation. Furthermore, $\mathrm{Zn}(\mathrm{OH})_{2}$ was observed to approach saturation with depth in trench 3. Porewaters were also near 
saturation with $\mathrm{Zn}(\mathrm{OH})_{2}$ from 1.0 to $1.5 \mathrm{~m}$ in trench 1 and 0.5 and from 1.5 to 2.0 $\mathrm{m}$ depth in trench 2 .
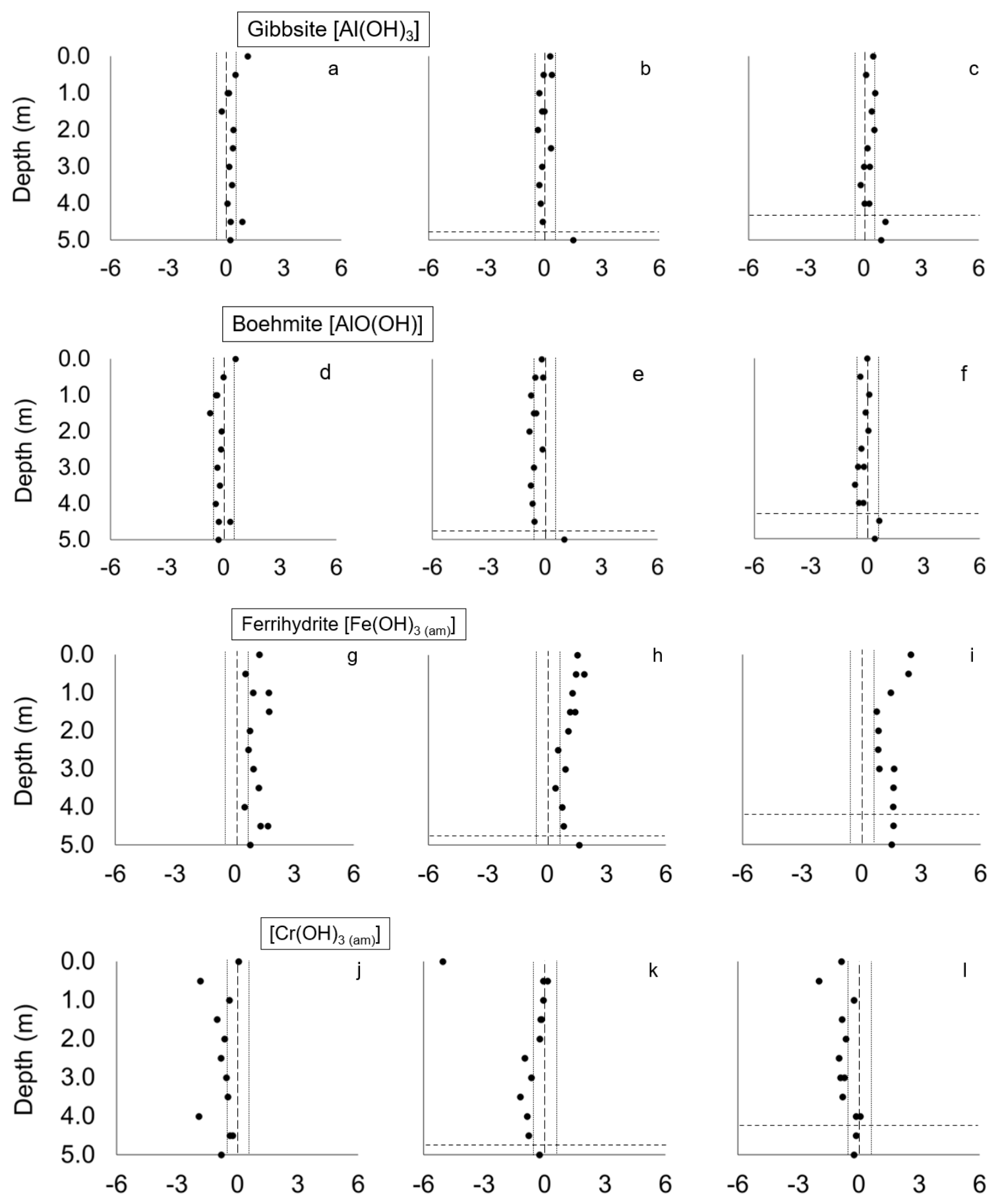

Figure 3.9: Gibbsite, boehmite, ferrihydrite, and $\mathrm{Cr}(\mathrm{OH})_{3 \text { (am) }}$ depth plot saturation indices for trench 1 (left), trench 2 (middle), and trench 3 (right). 

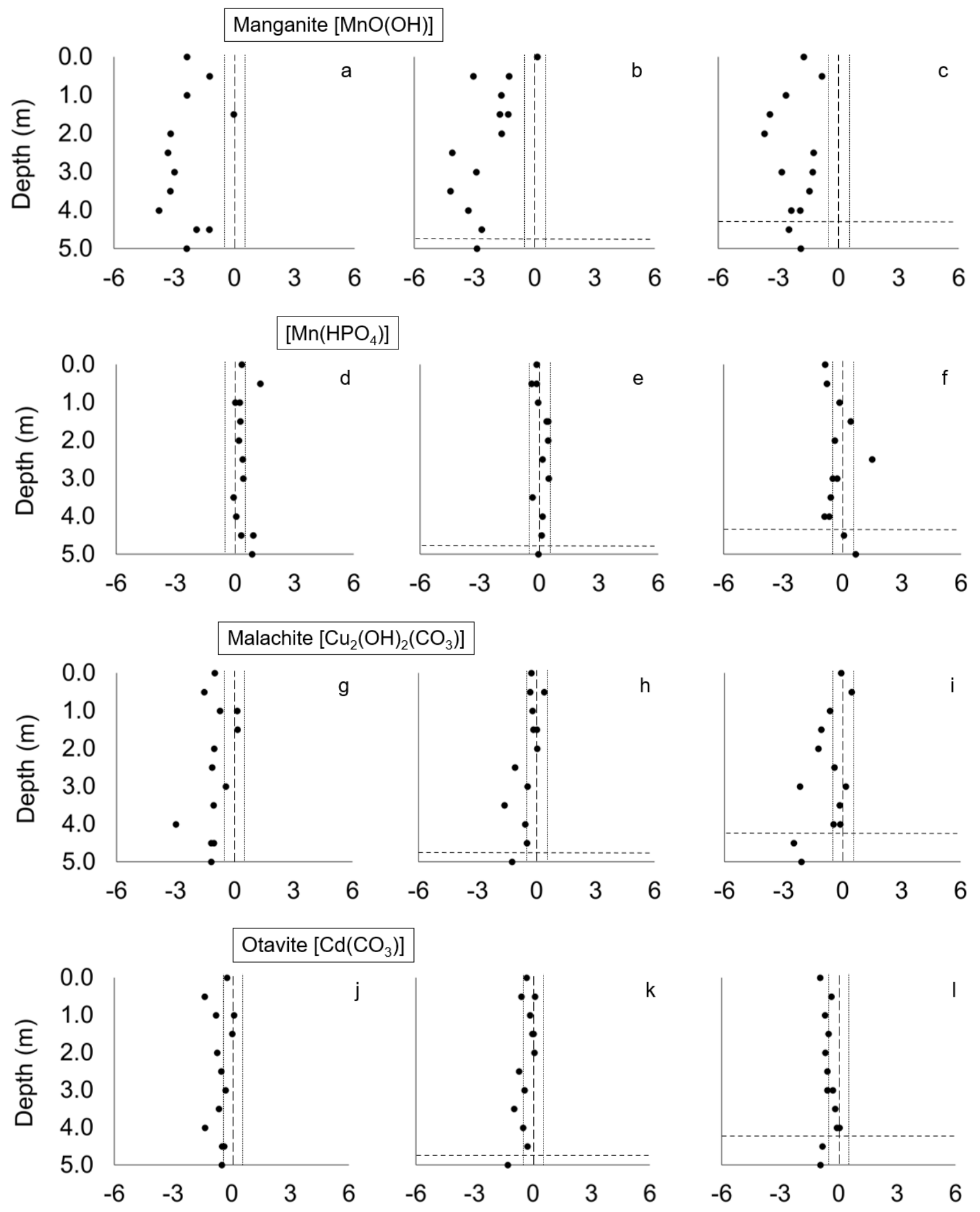

Figure 3.10: Manganite, $\mathrm{Mn}\left(\mathrm{HPO}_{4}\right)$, malachite, and otavite depth plot saturation indices for trench 1 (left), trench 2 (middle), and trench 3 (right). 

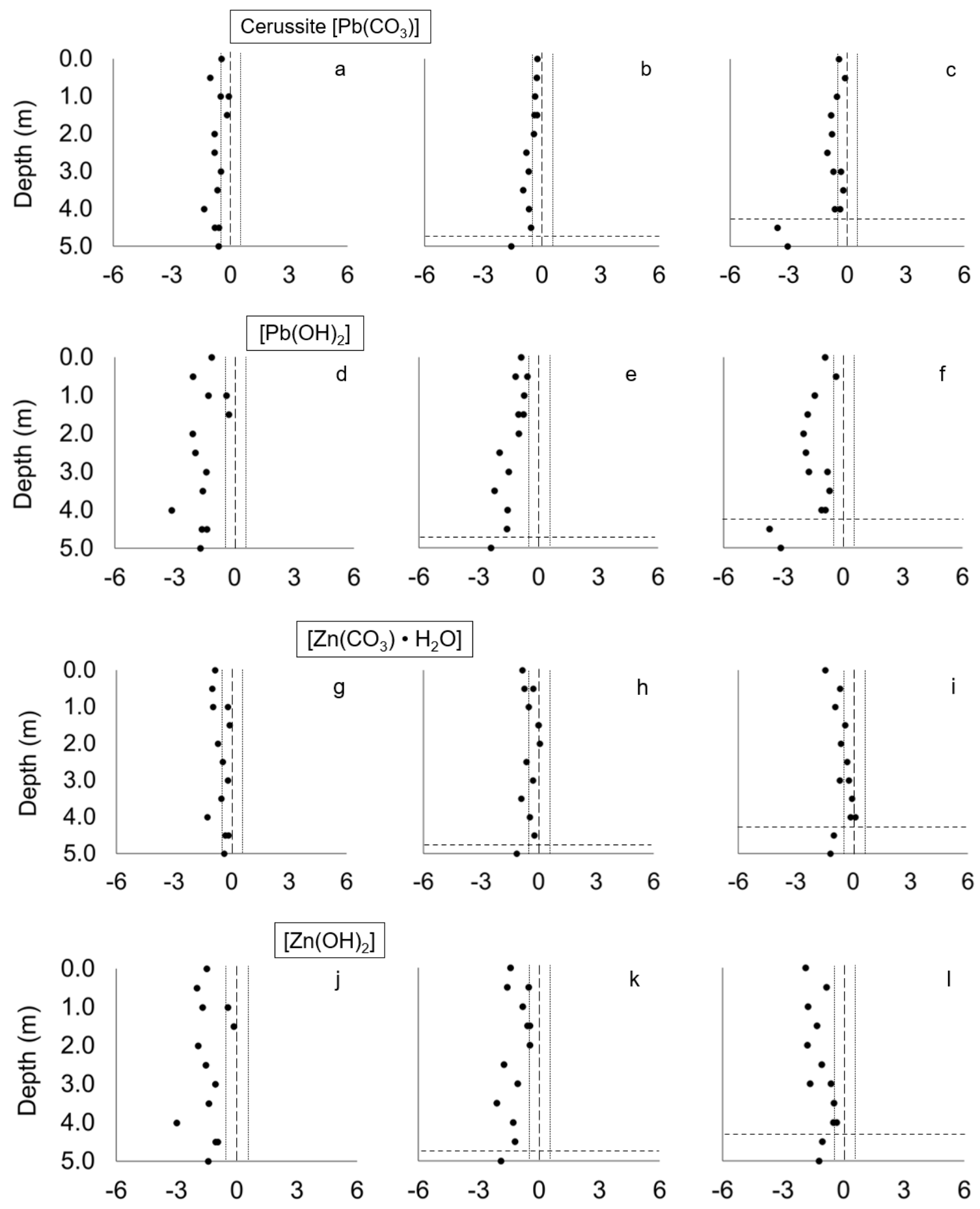

Figure 3.11: Cerussite, $\mathrm{Pb}(\mathrm{OH})_{2}$, smithsonite monohydrate, and $\mathrm{Zn}(\mathrm{OH})_{2}$ depth plot saturation indices for trench 1 (left), trench 2 (middle), and trench 3 (right). 
In summary, gypsum, jarosite and smithsonite monohydrate were the only minerals that were undersaturated towards the surface and approached saturation with depth in all three trenches. Otavite, cerussite, and $\mathrm{Zn}(\mathrm{OH})_{2}$ were also observed to approach saturation with depth, but only in trench 3. Calcite, dolomite, gypsum, and jarosite all showed lower relative average SI readings in trench 2. Furthermore, calcite, dolomite, otavite, and cerussite (carbonate-bearing) all recorded the lowest relative SI readings at 0.5 and $4.0 \mathrm{~m}$ depth in trench 1 . The mineral phases that were near or slightly above saturation for at least ten porewater samples between all three trenches included calcite, gypsum, gibbsite, boehmite, ferrihydrite, $\mathrm{Cr}(\mathrm{OH})_{3}(\mathrm{am}), \mathrm{Mn}\left(\mathrm{HPO}_{4}\right)$, malachite, otavite, cerussite, and smithsonite monohydrate.

\subsection{Discussion}

\subsubsection{Porewater Chemistry and Secondary Controls}

Porewater $\mathrm{pH}$ at the Ore Chimney waste-rock pile was near-neutral (6.4 to 8.4) and showed minor variability throughout all three trenches. Alkalinity concentrations always exceeded $25 \mathrm{mg} / \mathrm{L} \mathrm{CaCO}_{3}$ except for a $13 \mathrm{mg} / \mathrm{L}$ measurement at $0.5 \mathrm{~m}$ depth in trench 1, which correlated with lower $\mathrm{pH}$ (6.4), lower total inorganic carbon content measured by total $\mathrm{C} / \mathrm{S}$ analysis, and reduced calcite and dolomite concentrations predicted by PXRD (Ch. 2). Calcite and dolomite SI values were near saturation in many locations and are therefore the likely sources of alkalinity, $\mathrm{Ca}$, and $\mathrm{Mg}$ in the porewaters. Calcite and dolomite typically buffer acidity to a pH range of 6.2 to 8.3 (Parbhakar-Fox and Lottermoser, 2017) and are likely controlling the near-neutral pH levels observed throughout the entire waste-rock pile even after $\sim 100$ years of weathering above ground surface.

Measurements of bisulfide ( $\left.\mathrm{HS}^{-}\right)$and ferrous iron $\left(\mathrm{Fe}^{2+}\right)$ were consistently under range indicating that oxidizing conditions likely prevail throughout the entire depth profile of the waste-rock pile. Sulfate was observed as the dominant anion with concentrations ranging from 31 to $2,023 \mathrm{ppm}$ and average molar concentrations accounting for $84 \%$ of the total anion concentration including bicarbonate $\left[\mathrm{HCO}_{3}{ }^{-}\right]$. 
Elevated $\mathrm{SO}_{4}{ }^{2-}$ concentrations observed in the porewaters are indicative of sulfide oxidation processes (Blowes et al., 2013). Likewise, porewater Eh measurements ranged from (+341) to $(+547) \mathrm{mV}$ corroborating observations of a strongly oxidizing system, which is required for sulfide mineral oxidation (Langmuir, 1997). Measurements of Eh did not significantly change with depth, which coincides with petrographic observations of consistent sulfide mineral weathering throughout the entire depth profile of the waste-rock pile (Ch. 2). Consistencies with elevated porewater Eh measurements and apparent sulfide mineral oxidation throughout the entirety of each trench suggests that atmospheric oxygen has infiltrated the entire waste-rock pile and is the main oxidizing agent irrespective of depth (Amos et al., 2015).

Moncur et al (2005) measured porewater chemistry from the surface to $4.0 \mathrm{~m}$ depth of the Sheritt-Gordon tailings profile in Manitoba, Canada, to investigate mineral alteration and metal transport after 70 years of subaerial weathering. Observations indicated the formation of a $1.5 \mathrm{~m}$ thick hardpan layer primarily composed of consolidated secondary mineral phases including melanterite $\left(\mathrm{Fe}^{2+} \mathrm{SO}_{4} \cdot 7 \mathrm{H}_{2} \mathrm{O}\right)$, rozenite $\left(\mathrm{Fe}^{2+} \mathrm{SO}_{4} \cdot 4 \mathrm{H}_{2} \mathrm{O}\right)$, goethite $\left[\mathrm{Fe}^{3+} \mathrm{O}(\mathrm{OH})\right]$, gypsum $\left(\mathrm{CaSO}_{4} \cdot 2 \mathrm{H}_{2} \mathrm{O}\right)$, and jarosite $\left[\mathrm{KFe}^{3+}{ }_{3}\left(\mathrm{SO}_{4}\right)_{2}(\mathrm{OH})_{6}\right]$. The hardpan layer was observed to limit oxygen infiltration, which was indicated by a sharp decline in Eh readings from $+802 \mathrm{mV}$ at the surface $(0.0 \mathrm{~m})$ to $+300 \mathrm{mV}$ at approximately $1 \mathrm{~m}$ depth (Moncur et al., 2005). The particle size composition of tailings and subsequent moisture retention properties are usually similar to ordinary silts and clays (Qiu and Sego, 2001), which are finer-grained, less permeable, and have a greater resistance to the ingress of oxygen than coarser-grained material that typically represents waste rock (Gorakhki and Bareither, 2017; Azam et al., 2020).

Tailings material often contains higher concentrations of sulfur than waste rock (Goumih et al., 2013). The accelerated weathering of finer-grained tailings material has the potential to establish a $\mathrm{pH}$ and redox gradient showing elevated acidity and Eh readings near the surface that significantly reduce beyond $1 \mathrm{~m}$ depth even after 70 years of weathering (Moncur et al., 2005; Moncur et al., 2009). Porewater 
$\mathrm{pH}$ and Eh depth profiles from coarser grained waste-rock material at Ore Chimney did not reveal the development of a gradient nor the formation of a hardpan layer and maintained relatively consistent $\mathrm{pH}$ and $\mathrm{Eh}$ readings from the surface to $5.0 \mathrm{~m}$ depth. However, the formation of a hardpan layer observed by Moncur et al (2005) did not completely restrict the vertical movement of water as indicated by the accumulation of $\mathrm{SO}_{4}{ }^{2-}$ in the porewaters at greater depth. Ore Chimney also revealed sulfate accumulation with depth but is likely due to transport processes plus additional oxidation at depth.

Calcium was observed as the dominant cation in the porewaters accounting for an average of $59 \%$ of the total (molar) cation concentration measured by ICP$\mathrm{AES} / \mathrm{MS}$. Furthermore, $\mathrm{Ca}$ concentrations, in addition to $\mathrm{SO}_{4}{ }^{2-}$, significantly increased with depth suggesting that $\mathrm{Ca}$ and $\mathrm{SO}_{4}{ }^{2-}$ were being leached from upper portions of the waste-rock pile and accumulating towards the base (Shum and Lavkulich, 1999). The average solid-phase sulfur concentration above $2.0 \mathrm{~m}$ depth in the Ore Chimney waste-rock pile is $1.6 \mathrm{wt} . \%(\sigma=0.9)$ and sulfide alteration extent did not significantly change with depth (Ch. 2) suggesting that mineral weathering is ongoing and gravity-assisted vertical transport through the pile is elevating $\mathrm{Ca}$ and $\mathrm{SO}_{4}{ }^{2-}$ in the porewaters at greater depth. Although grain size distributions and the vertical flow velocity of water through the waste-rock pile at Ore Chimney was not determined, other unsaturated waste-rock piles have observed thawing periods that permeate water at an average rate on the order of 2 to $3 \mathrm{~cm} /$ day (Zak, 2013).

Smith et al (2013b) observed $\mathrm{SO}_{4}{ }^{2-}$ and $\mathrm{Ca}$ accumulation from waste-rock effluent at a test pile at the Diavik mine that plateaued at 2,000 and $350 \mathrm{ppm}$, respectively, after only four months of subaerial weathering. Similar to Diavik, elevated $\mathrm{SO}_{4}{ }^{2-}$ $(2,000 \mathrm{ppm})$ and $\mathrm{Ca}(400 \mathrm{ppm})$ concentrations near the base of the Ore Chimney waste-rock pile suggest that $\mathrm{Ca}$ and $\mathrm{SO}_{4}{ }^{2-}$ concentrations are controlled primarily by the formation of gypsum, which was maintained near saturation at Ore Chimney below (and including) $1.5 \mathrm{~m}$ depth and is consistent with carbonate-bearing wasterock weathering studies at both four-month (Smith et al., 2013b) and 30-year 
(Smith et al., 2021) time scales. The $\mathrm{Ca}$ and $\mathrm{SO}_{4}{ }^{2-}$ signatures at Ore Chimney are likely not a function of long-term weathering processes but rather an indication that $\mathrm{Ca}$ and $\mathrm{SO}_{4}{ }^{2-}$ are mobile, and concentrations are being controlled to a similar extent even after $\sim 100$ years of sulfide oxidation (Smith et al., 2013b; Moncur et al., 2015).

Calcium is typically released into porewaters from Ca-bearing carbonate minerals that dissolve into solution from neutralization reactions buffering acidity that is generated from the oxidation of sulfide minerals (Blowes et al., 2013; Amos et al., 2015). Sulfide mineral oxidation and PXRD measurements of calcite and dolomite phases (Ch. 2) coupled with observations of near-neutral $\mathrm{pH}$ and instances of calcite and dolomite phases near saturation provides a strong indication that carbonate mineral dissolution has been an active process within the waste rock at Ore Chimney over the past $\sim 100$ years. The dissolution of dolomite from $\mathrm{pH}$ buffering can strongly influence dissolved $\mathrm{Mg}$ concentrations in mine wastes (Jurjovec et al., 2002). Magnesium concentrations exhibited a strong positive relationship with Ca measuring $R^{2}$ calc values of $0.63,0.73$, and 0.66 in trenches 1 , 2 , and 3 , respectively (Fig. $3.12 a-c$ ), which suggests that dolomite and calcite are both being weathered in the system. However, calcite dissolution neutralizes acidity at a higher rate than dolomite by one order of magnitude (Lapakko, 2002) and porewater Mg concentrations were observed to be at least twofold lower than Ca suggesting that calcite has been the primary carbonate buffering phase at Ore Chimney.
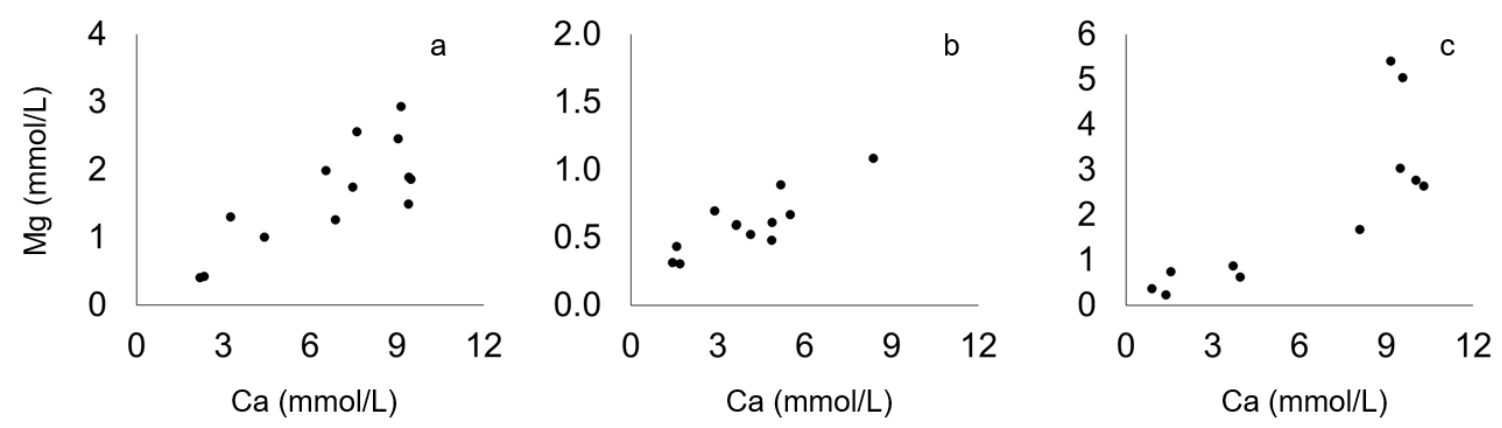

Figure 3.12: Ca correlation plot with $\mathrm{Mg}$ for trench 1 (left), trench 2 (middle), and trench 3 (right). 
Magnesium-bearing mineral phases identified by PXRD included hornblende, biotite, chlorite, and dolomite ( $\mathrm{Ch}$. 2). Porewater $\mathrm{Mg}$ concentrations were statistically higher in trench 1 than trench 2 by a mean difference of $25.8 \mathrm{ppm}$; however, Mg-bearing mineral content was relatively consistent. Alternatively, average calcite concentrations from both grain fractions in trench 1 were $50 \%$ higher than trench 2 (Ch. 2). Calcite often hosts trace concentrations of $\mathrm{Mg}$ in its mineral structure (Lane and Dalton, 1994; Zaitsev and Polezhaeva, 1994) and SEM analysis of calcite at Ore Chimney revealed up to 2 wt.\% Mg (Ch. 2). Furthermore, calcite dissolution is typically favoured over dolomite in weathering systems (Lapakko, 2002; White et al., 2005) thereby suggesting that calcite may also be contributing to dissolved $\mathrm{Mg}$ in the porewaters.

Relative to trenches 1 and 2, PXRD measured under range calcite content ( $\mu=1.4$ wt. $\%$ ) and the highest dolomite concentrations ( $\mu=5.8$ wt. $\%$ ) in trench 3 (Ch. 2). Likewise, elevated porewater Mg concentrations towards the base of trench 3 correspond to low calcite content (below detection) and a significantly higher proportion of dolomite from 3.0 to $4.0 \mathrm{~m}$ depth suggesting that dolomite may have begun to replace calcite as the principal carbonate buffering phase in this locality. Moreover, dolomite was observed to be near saturation from 3.0 to $4.0 \mathrm{~m}$ depth in trench 3 and may act as the primary control for elevated $\mathrm{Mg}$ in the porewaters. The lower average calcite content and subsequently higher concentrations of dissolved $\mathrm{Ca}$ in the porewaters may indicate that calcite has depleted to a greater extent than dolomite but remains in the waste-rock pile after $\sim 100$ years of weathering. Should the remaining portion of calcite continue to react with acidity from oxidizing sulfide minerals, it is proposed that dolomite will eventually transition into the primary carbonate buffering mineral and the relatively high dolomite concentrations measured from both grain size fractions throughout each trench $\left(\mu_{\text {pile }}=4.1 \mathrm{wt} . \%\right.$ ) should maintain near-neutral $\mathrm{pH}$ as the pile continues to weather (Parbhakar-Fox and Lottermoser, 2017).

Dissolved concentrations of $\mathrm{Fe}, \mathrm{Mg}$, and $\mathrm{K}$ are often derived from the subaerial weathering of biotite (Strömberg and Banwart, 1999; Moncur et al., 2009). 
Furthermore, biotite typically weathers at a faster rate than most silicate minerals due to its layered structure and the incorporation of ferrous iron that is reactive with oxygen (Fordham, 1990; Bhatti et al., 2011). Monovalent cations, typically as potassium, are present between the biotite sheet structures and are released into porewaters approximately two orders of magnitude higher than $\mathrm{Mg}$ and $\mathrm{Fe}^{2+}$, which are more tightly bound within the internal layers of the mineral lattice (Malmstrom and Banwart, 1997). Therefore, biotite is likely subsidiary to carbonate minerals as a source for dissolved $\mathrm{Mg}$ but the principal source for the observed $\mathrm{K}$ concentrations in the porewaters (Langman et al., 2014).

The biotite mineral phase identified by PXRD was predicted to host trace concentrations of $\mathrm{Na}$, which would substitute for weakly bonded $\mathrm{K}$ ions and be released into solution at a similar rate (Ch. 2) (Malmstrom and Banwart, 1997). Sodium-bearing plagioclase feldspar (oligoclase) and hornblende are more resistant to weathering than biotite but are still predicted to dissolve into solution at near-neutral $\mathrm{pH}$ at very slow rates (Stillings et al., 1996; Frogner and Schweda, 1998). Therefore, dissolved $\mathrm{Na}$ concentrations observed at Ore Chimney may originate from biotite, oligoclase, and hornblende and indicates that aluminosilicate weathering is occurring to some extent. There were no controls observed for porewater $\mathrm{Na}$; however, dissolved concentrations of $\mathrm{K}$, and to a lesser extent $\mathrm{SO}_{4}{ }^{2-}$ and $\mathrm{Fe}$, may be controlled by the formation of jarosite at 0.5 and $4.0 \mathrm{~m}$ depth in trench 1, which favours acidic conditions and corresponds to the lowest relative pH readings of 6.5 and 6.4 (Elwood Madden et al., 2012; Blowes et al., 2013).

Under-range measurements of $\mathrm{Fe}^{2+}$ by spectrophotometry coupled with under range $\mathrm{HS}^{-}$and elevated $\mathrm{Eh}$ and $\mathrm{SO}_{4}{ }^{2-}$ readings provides a strong indication that porewater ICP-MS Fe measurements predominantly consisted of ferric iron $\left(\mathrm{Fe}^{3+}\right)$. Ferric iron content in the porewaters was relatively consistent with depth and is likely being controlled by the precipitation of ferrihydrite, which may play a significant role in masking Fe correlations with other dissolved metals (Nordstrom, 1982). Ferrous iron-bearing mineral phases such as siderite $\left(\mathrm{Fe}^{2+} \mathrm{CO}_{3}\right)$, melanterite, and rozenite, have been observed to control porewater $\mathrm{Fe}$ 
concentrations in some mine-waste systems (Moncur et al., 2005; Moncur et al., 2009) but correspond to lower $\mathrm{Eh} / \mathrm{pH}$ conditions than what was observed herein and are not considered to limit Fe porewater concentrations at Ore Chimney. Ferrihydrite precipitation is favoured under circumneutral pH (Blowes et al., 2013) and was slightly oversaturated; thus, potentially controlling $\mathrm{Fe}$ in the porewaters. Investigations along the alteration rims of Fe-bearing sulfides by SEM-EDX revealed an Fe-oxyhydroxide phase that most likely resembled goethite (Ch. 2), which was predicted to be more saturated than ferrihydrite in the porewaters. Goethite has been observed as a more stable Fe-oxyhydroxide phase that is transformed from ferrihydrite over time (Combes et al., 1989) and is likely the longterm mechanism that is controlling the rates of pyrite and chalcopyrite oxidation and the low ppb-level porewater Fe concentrations at Ore Chimney (Moncur et al., 2009).

Measurable concentrations of $\mathrm{Zn}, \mathrm{Cu}$, and $\mathrm{Pb}$ in the porewaters indicate that sphalerite, chalcopyrite, and galena are being weathered throughout the wasterock pile. Analysis of Fe-oxyhydroxide weathering phases of Fe-bearing sulfide alteration rims by SEM-EDX also detected $\mathrm{Zn}$ and $\mathrm{Cu}$ concentrations up to $5 \mathrm{wt} . \%$ and $\mathrm{Pb}$ concentrations as high as $10 \mathrm{wt} . \%$ (Ch. 2). The adsorption capacity of $\mathrm{Zn}$, $\mathrm{Cu}$, and $\mathrm{Pb}$ onto goethite significantly increases at $\mathrm{pH}$ values greater than 5 , and the near-neutral $\mathrm{pH}$ levels measured at Ore Chimney suggest that $\mathrm{Fe}$ oxyhydroxide alteration phases may be retaining portions of $\mathrm{Zn}, \mathrm{Cu}$, and $\mathrm{Pb}$ from the porewaters through adsorption processes (Kooner, 1993; Rodda et al., 1993). However, dissolved $\mathrm{Zn}, \mathrm{Cu}$, and $\mathrm{Pb}$ were all observed to increase with depth suggesting that despite co-precipitation/adsorption processes, these metals are still being transported through the waste-rock pile.

On average, porewater $\mathrm{Zn}$ content measured via ICP-AES accounted for $92 \%$ of total metalloid, transition, and post-transition metal (molar) concentrations. Elevated concentrations of $\mathrm{Zn}$ may be attributed to high relative abundance and prolonged subaerial weathering of sphalerite (Moncur et al., 2009). Carbonate mineral dissolution often occurs in tandem with sulfide mineral oxidation (Blowes 
et al., 2013) and the weathering of sphalerite under the presence of calcite is expected to simultaneously elevate dissolved $\mathrm{Zn}, \mathrm{SO}_{4}{ }^{2-}$, and possibly $\mathrm{Ca}$ in the porewaters (Fig. 3.13a - f). However, once Zn concentrations exceeded approximately $0.5 \mathrm{mmol} / \mathrm{L}$, both $\mathrm{SO}_{4}{ }^{2-}$ and $\mathrm{Ca}$ concentrations were observed to plateau at around 16 and $10 \mathrm{mmol} / \mathrm{L}$, respectively, indicating that they were likely being controlled by the formation of gypsum (Jurjovec et al., 2002).

The porewater alkalinity was high enough at Ore Chimney for $\mathrm{pH}$ levels to always remain above 6.4; however, elevated $\mathrm{Zn}$ concentrations were observed to correspond with lower $\mathrm{pH}$ readings (Fig. $3.13 \mathrm{~g}$ - i). Among all metals, $\mathrm{Zn}$ concentrations exhibited the strongest positive correlation with $\mathrm{Cd}$ with $\mathrm{R}^{2}$ calc values of $0.86,0.94$, and 0.96 for trenches 1,2 , and 3, respectively (Fig. 3.13j-I). The presence of solid-phase $\mathrm{Cd}$ was measured exclusively in sphalerite grains as high as 2 wt.\% (Ch. 2) and the average molar Cd concentration in the porewaters was approximately tenfold and thirtyfold higher than $\mathrm{Pb}$ and $\mathrm{Cu}$, respectively, which may be due to the fact that the secondary controls for $\mathrm{Zn}$ and $\mathrm{Cd}$ [i.e. smithsonite monohydrate (Ksp: 10-10.3) and otavite (Ksp: 10-12.1)] have higher solubilities than cerussite (Ksp: 10-13.1) and malachite (Ksp: 10-33.2), and sphalerite may be more susceptible to mineral weathering than galena and chalcopyrite (Parkhurst and Appelo, 1999). Cadmium was not detected as a component of secondary Fe-oxyhydroxides, which may be because the available sorption sites are entirely occupied by $\mathrm{Pb}, \mathrm{Zn}$, and $\mathrm{Cu}$. Likewise, $\mathrm{Cd}$ has a lower relative adsorption affinity onto goethite, which may enhance $\mathrm{Cd}$ mobility under these conditions (Swedlund et al., 2009; Mohapatra et al., 2011; Komárek et al., 2018).

SEM-EDX analysis along sphalerite alteration rims occasionally detected the presence of a zinc carbonate phase (Ch. 2), which coincides with the relatively high carbonate content and subsequent porewater alkalinity. These findings are consistent with $\mathrm{Zn}$ porewater concentrations nearing saturation with smithsonite monohydrate beyond $1.0 \mathrm{~m}$ depth in all three trenches. Anhydrous zinc carbonate (i.e. pure smithsonite) was slightly less saturated than its hydrated counterpart by a mean difference of $0.4(\sigma=0)$. Therefore, it is likely that $\mathrm{Zn}$ first precipitates as 
a hydrous zinc carbonate phase and recrystallizes into a more stable anhydrous product over time and "smithsonite" can be generalized as the main $\mathrm{Zn}$ control in the porewaters (Bain et al., 2001). Cadmium was not detected as a component of any secondary mineral phase along sphalerite alteration rims; however, otavite $\left(\mathrm{CdCO}_{3}\right)$ was predicted to be consistently near saturation potentially controlling porewater $\mathrm{Cd}$ throughout the waste-rock pile, which is typical for carbonate and sphalerite-rich systems (Eary, 1999; Bain et al., 2001; Laurenzi et al., 2015).

Among the sulfide minerals, solid-phase Co concentrations were only detected in pyrite grains and $\mathrm{Ni}$ concentrations were measured exclusively in both pyrite and sphalerite grains via SEM-EDX. Although they often measured below the SEMEDX detection limit, ICP-AES/MS analyses accurately measured concentrations of these elements in the solid phase. Moreover, molar concentrations of $\mathrm{Co}$ and $\mathrm{Ni}$ were found to be at least twofold higher than $\mathrm{Fe}$ in the porewaters despite measuring thousandfold lower concentrations from solid-phase ICP-MS and measuring below detection ( $<1 \mathrm{wt} . \%)$ in pyrite grains (Ch. 2). Therefore, $\mathrm{Fe}$ concentrations in the porewaters were likely being restricted by the formation of ferrihydrite whereas no secondary controls were observed for Co or Ni. SEM-EDX analysis on pyrite alteration zones did not detect $\mathrm{Co}$ nor $\mathrm{Ni}$ (Ch. 2) suggesting that they are not well retained within the structure of secondary ferric oxyhydroxides and may have a higher relative affinity than $\mathrm{Fe}$ to be released into the porewaters from long-term subaerial exposure under neutral pH (Lehner et al., 2007). Furthermore, the absence of $\mathrm{Co}$ and $\mathrm{Ni}$ on $\mathrm{Fe}$-oxyhydroxide alteration phases indicates no attenuation via surface complexation reactions, which is consistent with Rose and Bianchi-Mosquera (1993) who observed lower adsorption affinities of $\mathrm{Co}$ and $\mathrm{Ni}$ onto goethite than $\mathrm{Pb}, \mathrm{Zn}$, and $\mathrm{Cu}$ at near-neutral $\mathrm{pH}$. Therefore, it is suggested that accelerated incipient weathering of sphalerite and galena compared to pyrite enriches porewaters with $\mathrm{Zn}$ and $\mathrm{Pb}$ that preferentially occupy available sorption sites on Fe-oxyhydroxides. Consequently, $\mathrm{Co}$ and $\mathrm{Ni}$ attenuation is restricted and their mobilities are increased, which coincided with increasing porewater concentrations with depth in trenches 1 and 2 and the suspected relative 
adsorption affinities of $\mathrm{Co}$ and $\mathrm{Ni}$ are similar to observations made by Blowes and Jambor (1990) and Jurjovec et al. (2002).
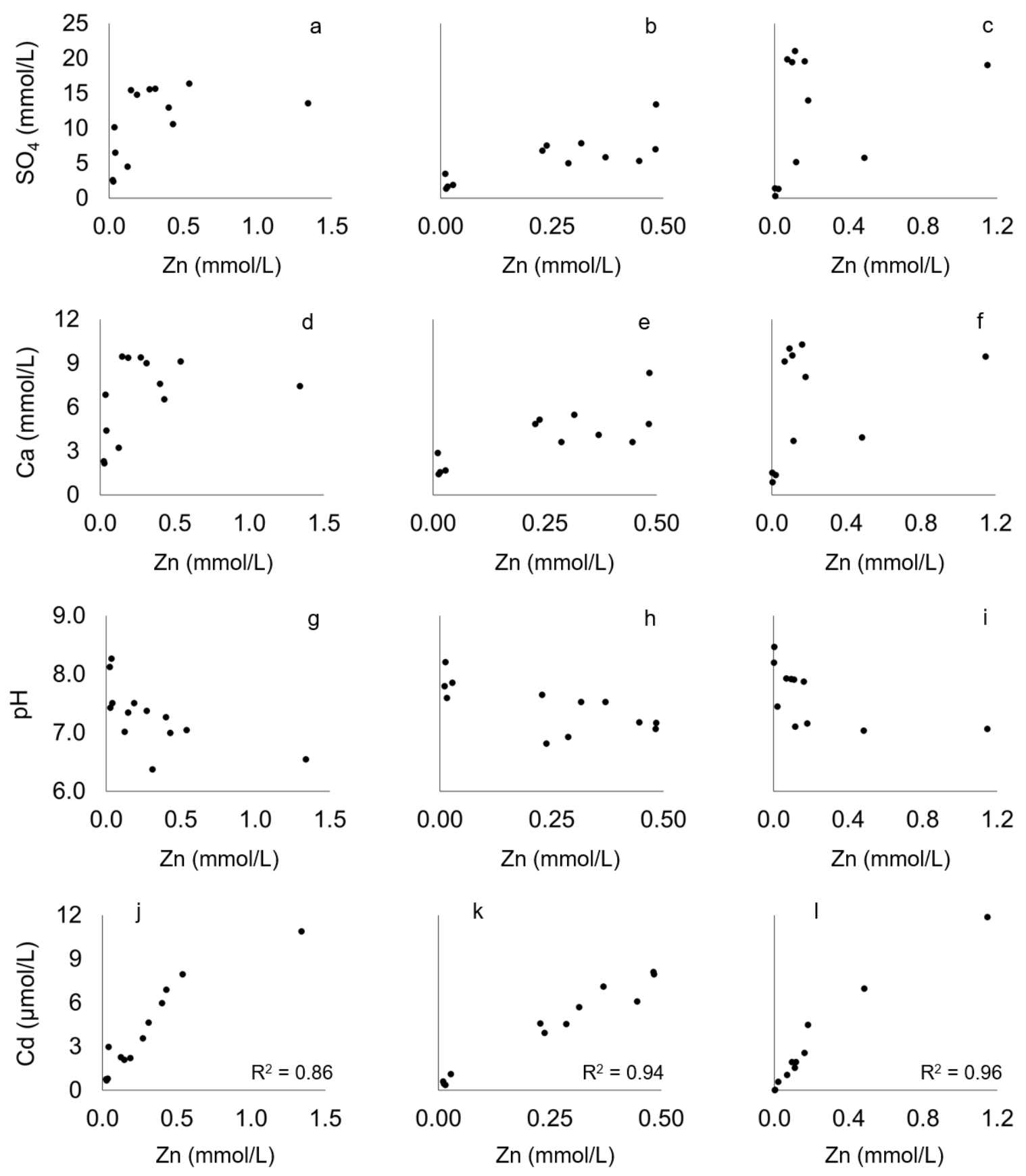

Figure 3.13: $\mathrm{Zn}$ correlation plots with $\mathrm{SO}_{4}{ }^{2-}, \mathrm{Ca}(\mathrm{mmol} / \mathrm{L}), \mathrm{pH}$, and $\mathrm{Cd}(\mu \mathrm{mol} / \mathrm{L})$ for trench 1 (left), trench 2 (middle), and trench 3 (right). 
The strong positive correlations between $\mathrm{Zn}$ with $\mathrm{Pb}, \mathrm{Cu}, \mathrm{Co}$, and $\mathrm{Ni}$ indicates ongoing simultaneous sphalerite, galena, chalcopyrite, and pyrite weathering (Fig. $3.14 a-1)$. Relatively abundant carbonate content and subsequently high alkalinity suggests porewater concentrations of $\mathrm{Pb}$ and $\mathrm{Cu}$ are controlled by the formation of cerussite and malachite, respectively, throughout most of the waste-rock pile and is consistent with SEM-EDX measurements of cerussite along the alteration rims of galena grains (Ch. 2). Undersaturated cerussite SI values of -1.0 (0.5 m) and -1.4 (4.0 $\mathrm{m}$ depth) in trench 1 corresponded to lower $\mathrm{pH}$ readings of 6.4 and 6.5 , respectively, which also applied to calcite, dolomite, malachite, otavite, and smithsonite. Likewise, the highest porewater $\mathrm{pH}$ readings of 8.3 at $1.5 \mathrm{~m}$ in trench 1 and 8.4 at $0.5 \mathrm{~m}$ depth in trench 3 indicated near saturation with $\mathrm{Pb}(\mathrm{OH})_{2(\mathrm{~s})}$ and $\mathrm{Zn}(\mathrm{OH})_{2(\mathrm{~s})}$ and may also control dissolved $\mathrm{Pb}$ and $\mathrm{Zn}$ concentrations but to a lesser extent than cerussite and smithsonite.

Anomalously high porewater concentrations of $\mathrm{Zn}, \mathrm{Cd}, \mathrm{Pb}, \mathrm{Cu}, \mathrm{Co}$, and $\mathrm{Ni}$ measured at $0.5 \mathrm{~m}$ in trench 1 and $2.5 \mathrm{~m}$ depth in trench 3 were not observed to coincide with elevated metal concentrations from solid-phase ICP-MS/AES nor elevated sulfur content from total $\mathrm{C} / \mathrm{S}$ analysis suggesting that the porewater chemistry was not directly proportional to the in situ solid-phase sulfide content presented in Chapter 2. Elevated signatures may be influenced by the presence of colloidal material (Aiken et al., 2011); However, porewater signatures of Zn, Cd, $\mathrm{Pb}, \mathrm{Cu}, \mathrm{Co}$, and $\mathrm{Ni}$ at $0.5 \mathrm{~m}$ in trench 1 and $2.5 \mathrm{~m}$ depth in trench 3 corresponded with low alkalinity. Metal-carbonate complexes were the strongest/only secondary controls predicted for $\mathrm{Zn}, \mathrm{Cd}, \mathrm{Pb}$, and $\mathrm{Cu}$ and undersaturated $\mathrm{SI}$ values corresponded with insufficient alkalinity concentrations. Therefore, elevated $\mathrm{Zn}$, $\mathrm{Cd}, \mathrm{Pb}$, and $\mathrm{Cu}$ at $0.5 \mathrm{~m}$ in trench 1 and $2.5 \mathrm{~m}$ depth in trench 3 are likely due to the absence of a secondary (carbonate) control due to decreased alkalinity, which was attributed to relatively low solid-phase inorganic carbon content (Ch. 2). In addition, the subsamples for porewater analyses in the abovementioned localities may have represented finer-grained waste-rock material where accelerated sulfide oxidation further depleted the alkalinity supply. The magnitude of porewater metal concentrations may depend on both mineralogy and grain size thus outlining the 
importance of collecting a high sample density across multiple vertical transects (Atherton, 2017; Barsi, 2017; Vriens et al., 2019).
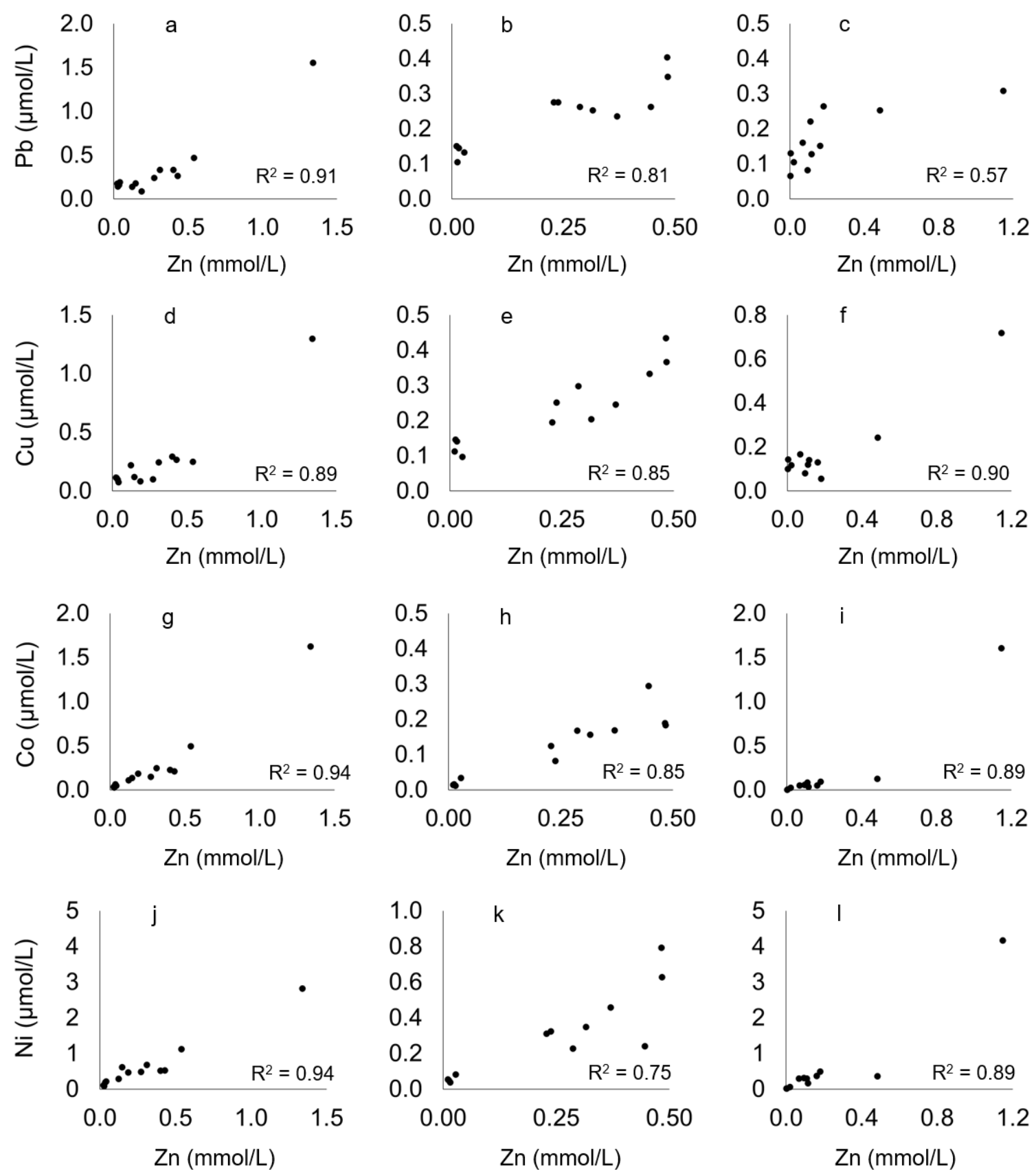

Figure 3.14: $\mathrm{Zn}(\mathrm{mmol} / \mathrm{L})$ correlation plots with $\mathrm{Pb}, \mathrm{Cu}, \mathrm{Co}$, and $\mathrm{Ni}(\mu \mathrm{mol} / \mathrm{L})$ for trench 1 (left), trench 2 (middle), trench 3 (right). 
Manganese was the only other metal that measured anomalously high concentrations at $0.5 \mathrm{~m}$ in trench 1 and $2.5 \mathrm{~m}$ depth in trench 3 , which also did not correspond with solid-phase chemical data. Manganese was not detected as a trace component of any sulfide mineral, so it was less likely that Mn was being released from oxidizing sulfides. Alternatively, under range ( $\leq 1 \mathrm{wt} . \%)$ Mn was detected in calcite and dolomite grains (Ch. 2) and the anomalously high concentrations of $\mathrm{Mn}$ in these localities may be a function of continual carbonate buffering from accelerated long-term sulfide oxidation in finer-grained fractions of waste-rock material (McCreadie et al., 2000). In most cases, concentrations of Mn in the porewaters were three orders of magnitude lower than dissolved $\mathrm{Ca}$ and did not show a positive correlation beyond $\mathrm{Ca}$ concentrations of approximately 9 $\mathrm{mmol} / \mathrm{L}$ indicating that $\mathrm{Ca}$ porewater concentrations are being controlled by secondary minerals, likely gypsum and calcite (Fig. 3.15a - c), whereas rhodochrosite was too undersaturated for the removal of $\mathrm{Mn}^{2+}$ (Langmuir, 1997; Blowes et al., 2013).

Jeong and Lee (2003) measured seepage water Mn, Ca, and Zn concentrations of $9.10 \mu \mathrm{mol} / \mathrm{L}, 3.27 \mathrm{mmol} / \mathrm{L}$, and $0.16 \mathrm{mmol} / \mathrm{L}$, respectively, from a waste-rock pile at the Dadeok mine subjected to 50 years of sphalerite $(\mathrm{Zn} 0.84 \mathrm{Fe} 0.15 \mathrm{Mn} 0.01 \mathrm{~S})$ weathering and subsequent circumneutral $\mathrm{pH}$ buffering primarily by manganoan calcite $\left(\mathrm{Ca} 0.84 \mathrm{Mn}_{0.16} \mathrm{CO}_{3}\right)$. Manganese was not contained in sphalerite at Ore Chimney and under range Mn signals from SEM-EDX analysis of calcite in the Ore Chimney waste rock revealed a conservative mineral formula with a Mn content no greater than $\sim \mathrm{Ca}_{0.98} \mathrm{Mn}_{0.02} \mathrm{CO}_{3}$, which has an eightfold lower $\mathrm{Mn}$ content than observations by Jeong and Lee (2003). Therefore, despite Mn being significantly less concentrated in Ore Chimney carbonates in contrast to Dadeok, the similar concentrations of dissolved $\mathrm{Mn}(12.36 \mu \mathrm{mol} / \mathrm{L}$ at $5.0 \mathrm{~m}$ in trench 1$)$ and comparable $\mathrm{Ca} / \mathrm{Mn}$ ratios (Ca:Mn $=\sim 360$ at Dadeok; $\mathrm{Ca}: \mathrm{Mn}=\sim 740$ at $5.0 \mathrm{~m}$ depth in trench 1 at Ore Chimney) coupled with higher porewater $\mathrm{Zn}(0.54 \mathrm{mmol} / \mathrm{L})$ at Ore Chimney may have resulted from the nearly doubled exposure time and additional 50 years of weathering. 
SEM-EDX observations indicate apatite (Ch. 2; Fig. 2.18a) as a potential source for $\mathrm{PO}_{4}{ }^{3-}$ in the porewaters, which measured an average of $0.15(\sigma=0.03) \mathrm{ppm}$ $\left(\mathrm{PO}_{4}{ }^{3-}\right)$ and was very consistent with depth. It is likely that dissolved concentrations of $\mathrm{PO}_{4}{ }^{3-}$ and $\mathrm{Mn}\left(\right.$ as $\mathrm{Mn}^{2+}$ ) are being constrained by the formation of $\mathrm{Mn}^{2+} \mathrm{HPO}_{4}$, which has been proposed as an important $\mathrm{Mn}$ control under near-neutral $\mathrm{pH}$ with available $\mathrm{PO}_{4}{ }^{3-}$, whereas rhodochrosite is favoured in more alkaline environments (Boyle and Lindsay, 1985; Eary, 1999; Enviromin, 2017). Porewater Eh and pH readings at Ore Chimney predict $\mathrm{Mn}$ to be metastable in the $\mathrm{Mn}^{3+}$ oxidation state (Pourbaix, 1974), which explains why SI simulations also predicted manganite $\left[\mathrm{Mn}^{3+} \mathrm{O}(\mathrm{OH})\right]$ as a potential control at $0.5 \mathrm{~m}$ depth in trench 1 and at the surface of trench 2, which corresponded to the highest Eh readings of +547 and $+518 \mathrm{mV}$, respectively.
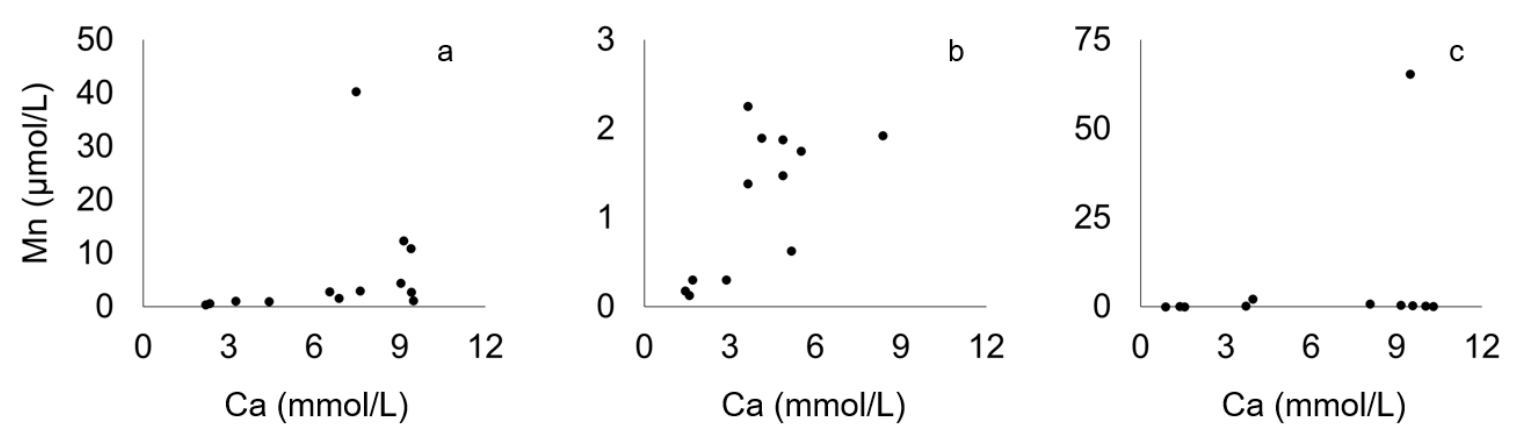

Figure 3.15: $\mathrm{Ca}(\mathrm{mmol} / \mathrm{L})$ correlation plot with $\mathrm{Mn}(\mu \mathrm{mol} / \mathrm{L})$ for trench 1 (left), trench 2 (middle), and trench 3 (right).

Eh and $\mathrm{pH}$ conditions throughout the waste-rock pile at Ore Chimney also predicted polyvalent $\mathrm{Fe}$ and $\mathrm{Cr}$ to be most stable in the (3+) oxidation state and subsequently controlled by the formation of amorphous $\mathrm{Fe}(\mathrm{OH})_{3(\mathrm{~s})}$ and $\mathrm{Cr}(\mathrm{OH})_{3(\mathrm{~s})}$ phases, which have the lowest solubilities at near-neutral $\mathrm{pH}$ thus maintaining considerably lower porewater concentrations compared to most other metals (Pourbaix, 1974; Langmuir, 1997). Similar to $\mathrm{Fe}$ and $\mathrm{Cr}$, porewater $\mathrm{Al}$ concentrations were consistent with depth and showed minimal variation between trenches. Dissolved Al was predicted to be consistently near saturation with 
boehmite and gibbsite, which also have relatively low solubilities, especially at near-neutral $\mathrm{pH}$, explaining why the porewaters at Ore Chimney measured low average Al concentrations of $5.6(\sigma=3.9)$ ppb throughout the entire pile (Langmuir, 1997). Higher dissolved concentrations of $\mathrm{Fe}^{3+}$ and $\mathrm{Al}$ are ordinarily observed in acidic mine-waters due to the accelerated dissolution of $\mathrm{Al} / \mathrm{Fe}$-hydroxides and aluminosilicates, which have increased solubilities at lower $\mathrm{pH}$ (Bigham and Nordstrom, 2019; Vriens et al., 2019), whereas the dissolution of $\mathrm{Al}(\mathrm{OH})_{3}$ and $\mathrm{Fe}(\mathrm{OH})_{3}$ was not favoured at Ore Chimney due to the neutral $\mathrm{pH}$ levels maintained by the abundance of calcite and dolomite. Furthermore, the geochemical signatures at Ore Chimney provide empirical evidence that dissolved concentrations of in situ $\mathrm{Fe}$ and $\mathrm{Al}$ that may leach through weathered waste-rock can be regulated significantly for at least $\sim 100$ years by maintaining a sufficient Ca-carbonate neutralization capacity.

The blasting of waste rock is often facilitated by perchlorate $\left(\mathrm{ClO}_{4}^{-}\right)$, which can be enriched in the stockpiled material and contribute to measurable porewater $\mathrm{Cl}$ concentrations (Cox, 2005; Bailey et al., 2013). Chloride also acts as a conservative tracer that can be measured to help elucidate waste-rock permeability and the downward migration of water through the vadose zone (Neuner et al., 2013). However, if mining activities at Ore Chimney incorporated perchlorate as a blasting agent, the contaminated signature would have likely flushed through the pile within the first few years (Bailey et al., 2013). Porewater $\mathrm{Cl}$ was not observed to be controlled by secondary phases and measurements likely resembled natural signatures derived a from a variety of minerals hosting $\mathrm{Cl}$ in trace amounts. Likewise, no controls were observed for porewater concentrations of Ti. Although concentrated in the solid phase by an average of $3600 \mathrm{ppm}$, Ti concentrations in the porewaters measured average concentrations of $0.6 \mathrm{ppb}$ indicating that ilmenite and rutile have a very high resistance to weathering (Sudom and St. Arnaud, 1971) and partition into porewaters at extremely low ppb levels (Skrabal and Terry, 2002) even after $\sim 100$ years of exposure above ground surface. 
SEM-EDX analysis did not detect As nor Sb as a solid-phase component for pyrite, chalcopyrite, sphalerite, or galena. Instead, $\mathrm{As}$ and $\mathrm{Sb}$ concentrations were exclusively contained by arsenopyrite (FeAsS), and a ( $\mathrm{Cu}, \mathrm{Sb}, \mathrm{Ag}$ )-bearing sulfide mineral (freibergite), respectively, found only in a few sample locations (Ch. 2). Dissolved $\mathrm{As}$ and $\mathrm{Sb}$ concentrations are likely derived from the oxidative dissolution of arsenopyrite and freibergite (Koski et al., 2008) and these minerals have been previously documented to exist within the mineralized Ore Chimney Formation (Harnois and Moore, 1989). Redox and pH conditions predict Sb to be more stable in the $\mathrm{Sb}(\mathrm{V})$ oxidation state, which adsorbs strongly to goethite across a pH range from 3 to 8 (Pourbaix, 1974; Martínez-Lladó et al., 2008). No secondary controls were predicted for As nor Sb from SI simulations; however, Sb was occasionally measured up to $3 \mathrm{wt} . \%$ as a potential adsorption phase on $\mathrm{Fe}$ oxyhydroxide alteration surfaces, which is less significant than $\mathrm{Pb}, \mathrm{Zn}$, and $\mathrm{Cu}$, but may control dissolved $\mathrm{Sb}$ to some extent.

\subsubsection{Implications}

Porewater concentrations of $\mathrm{Ca}$ and $\mathrm{SO}_{4}{ }^{2-}$ at Ore Chimney peaked at approximately 400 and 2,000 ppm, which were observed closer to the base of the waste-rock pile. Smith et al (2013b) measured $\mathrm{Ca}$ and $\mathrm{SO}_{4}{ }^{2-}$ concentrations in drainage waters from a constructed waste-rock test pile at Diavik mine with low relative carbon ( $\sim 0.02 \mathrm{wt} . \%)$ and sulfur $(0.16 \mathrm{wt} . \%)$ content, which plateaued at approximately 350 and $2,000 \mathrm{ppm}$, respectively, after only four months of weathering. Gypsum saturation was interpreted to limit dissolved $\mathrm{Ca}$ and $\mathrm{SO}_{4}{ }^{2-}$ at Diavik and Ore Chimney, which demonstrates that elevated sulfide and carbonate content and prolonged subaerial exposure (i.e. Ore Chimney) are not required to saturate $\mathrm{Ca}$ and $\mathrm{SO}_{4}{ }^{2-}$ concentrations with respect to Gypsum. It also indicates that gypsum can serve as a major control for dissolved $\mathrm{Ca}$ and $\mathrm{SO}_{4}{ }^{2-}$ concentrations over long timescales when there is ongoing sulfide oxidation and an abundancy of Ca-bearing carbonate minerals in the waste rock. Elevated alkalinity measurements $\left(\mu=60.2 \mathrm{mg} / \mathrm{L} \mathrm{CaCO}_{3}\right)$ throughout the Ore Chimney waste-rock pile are derived from calcite and dolomite dissolution resulting in stable 
near-neutral $\mathrm{pH}$ levels. Consistently low-ppb measurements of $\mathrm{Fe}, \mathrm{Al}$, and $\mathrm{Cr}$ are suggested to be controlled by the formation of secondary hydroxide phases with low relative solubilities, which signifies that the concentrations of dissolved in situ $\mathrm{Fe}, \mathrm{Al}$, and $\mathrm{Cr}$ are minimized over long time periods by near-neutral $\mathrm{pH}$ conditions maintained by an abundance of calcite and dolomite.

Atherton (2017) deconstructed a low-carbon ( 0.02 wt.\% C) and low-sulfur ( 0.02 wt.\% S) 10-metre-high waste-rock test pile at the Diavik mine that had weathered for approximately eight years and collected in situ porewater samples throughout the entire depth profile at $\sim 3 \mathrm{~m}$ sampling intervals. The carbonate neutralization capacity was depleted in at least one location ( $\sim 3 \mathrm{~m}$ depth) yielding a $\mathrm{pH}$ of 4 that corresponded with elevated dissolved porewater concentrations of $\mathrm{SO}_{4}{ }^{2-}, \mathrm{Ca}, \mathrm{Fe}$, $\mathrm{Al}, \mathrm{Ni}, \mathrm{Co}, \mathrm{Cu}$, and $\mathrm{Zn}$. Likewise, $\mathrm{Ca}$ and $\mathrm{SO}_{4}{ }^{2-}$ measurements of $\sim 400$ and $\sim 2,500$ ppm, respectively, were likely being controlled by the formation of gypsum, which was observed to be nearest saturation at that locality. The geochemical signatures in the waste-rock test pile at Diavik investigated by Atherton (2017) were observed to be heavily dependent on $\mathrm{pH}$, which depended on the carbonate content, or lack thereof. Atherton (2017) also observed elevated $\mathrm{SO}_{4}{ }^{2-}, \mathrm{Ca}$, and $\mathrm{Mg}$ at $\sim 6 \mathrm{~m}$ depth, which did not correspond to low $\mathrm{pH}$ nor other abovementioned metals suggesting the accumulation of $\mathrm{SO}_{4}{ }^{2-}, \mathrm{Ca}$, and $\mathrm{Mg}$ to a depth range of $3 \mathrm{~m}$ from eight years of weathering.

Porewater concentrations of $\mathrm{SO}_{4}{ }^{2-}, \mathrm{Ca}$, and $\mathrm{Mg}$ at Ore Chimney accumulated from 0.0 to $5.0 \mathrm{~m}$ depth, which is greater than the $\sim 3 \mathrm{~m}$ depth range observed by Atherton (2017), possibly due to a longer weathering period, but likely not a signature unique to $\sim 100$ years. Instead, it provides an indication that weathering processes drive $\mathrm{Ca}$ and $\mathrm{SO}_{4}{ }^{2-}$ to near saturation within approximately a decade if weathering is accelerated due to a limited carbonate content and can reveal $\mathrm{SO}_{4}{ }^{2-}, \mathrm{Ca}$, and $\mathrm{Mg}$ depth profiles similar to what was observed at Ore Chimney despite the significant difference in exposure times. An abundance of carbonate minerals that maintain near-neutral $\mathrm{pH}$ for nearly a century (i.e. Ore Chimney) subject sulfide minerals to slower weathering rates than younger waste-rock piles 
that are weathering faster under acidic conditions and can create difficulties in making comparisons based on differences in age. Therefore, the mineralogy and mineral abundance plays a significant role in characterizing waste-rock weathering, and it is imperative to have a comprehensive understanding on the physical properties of mine-waste material and in situ solid-phase and aqueousphase geochemical signatures to isolate and properly address the influence of time.

Jeong and Lee (2003) investigated the weathering of waste rock derived from quartz veins bearing galena, sphalerite and manganoan carbonates that weathered at the Dadeok mine for at least 50 years. Drainage waters underneath the Dadeok waste-rock pile measured $\mathrm{Zn}$ concentrations as high as $10.2 \mathrm{ppm}$ derived from sphalerite weathering under near-neutral $\mathrm{pH}$ with a similar Fe content as Ore Chimney sphalerite (Ch.2). Porewater $\mathrm{Zn}$ concentrations at the base of trenches 1 and 2 at Ore Chimney measured 35.2 and $31.6 \mathrm{ppm}$, which are threefold higher than measurements by Jeong and Lee (2003). While the higher $\mathrm{Zn}$ concentrations at Ore Chimney may be a function of an additional 50 years of weathering, seepage waters may represent more dilute concentrations than in situ centrifuged porewaters. Moreover, Jeong and Lee (2003) did not quantify solidphase $\mathrm{Zn}$ concentrations so the elevated $\mathrm{Zn}$ (and $\mathrm{Cd}$ ) at Ore Chimney may also be from a higher proportion of sphalerite.

Jeong and Lee (2003) and Ore Chimney measured significantly higher dissolved $\mathrm{Zn}$ concentrations than $\mathrm{Pb}$. The $\mathrm{Zn}: \mathrm{Pb}$ ratio measured at Dadeok was approximately 50 whereas $\mathrm{Zn}: \mathrm{Pb}$ ratios at the base of trenches 1 and 2 at Ore Chimney were 360 and 440, respectively. Jeong and Lee (2003) observed alteration rims of Galena to be replaced by anglesite whereas $\mathrm{Pb}$ concentrations at Ore Chimney were undersaturated with respect to anglesite and alteration rims were determined to be replaced by cerussite, which may be due to a higher carbonate content in the waste rock. The solubility product (i.e. Ksp) of cerussite $\left(1.6 \times 10^{-13}\right)$ is five orders of magnitude lower than anglesite $\left(1.6 \times 10^{-8}\right)$, which may help explain why the $\mathrm{Zn}: \mathrm{Pb}$ ratios are significantly higher at Ore Chimney than 
Dadeok mine (Marani et al., 1995). Therefore, carbonate-rich waste rock may exert a stronger control on $\mathrm{Pb}$ through the formation of cerussite even after $\sim 100$ years of weathering, as observed at Ore Chimney.

Waste-rock piles are inherently complex, and the geochemical signatures are evidently a function of variable weathering characteristics such as mineralogy, grain size, hydrologic flow regimes, and time (Blowes et al., 2013). Despite these inherent differences among various waste-rock studies, including Ore Chimney and others in the literature, the fundamental processes for sulfide weathering, $\mathrm{pH}$ buffering, and secondary chemical controls that are described for young waste rock, are also observed for much older systems (i.e. Ore Chimney). After $\sim 100$ years, the liberation of metals from sulfide oxidation and carbonate mineral dissolution remains an ongoing process. Likewise, dissolved metal concentrations as a function of long-term weathering are similarly controlled by secondary attenuation processes such as mineral precipitation and adsorption onto the surfaces of secondary mineral phases. The differences in geochemical signatures between waste rock exposed for a year compared to $\sim 100$ years has a greater dependency on internal factors such as alkalinity, mineralogy, and grain size than external factors such as exposure time. For Ore Chimney, the remaining presence of sphalerite in addition to galena, pyrite, and chalcopyrite strongly suggests that weathering processes will continue to occur. Likewise, the in situ signatures will continue to be regulated by secondary controls, and abundant alkalinity and carbonate minerals suggest that drainage $\mathrm{pH}$ will remain neutral as the waste-rock pile continues to age. 


\section{Chapter 4: Conclusions}

\subsection{General Summary of Implications}

The Ore Chimney waste-rock pile revealed total S (2.02 wt.\%) and C (1.38 wt.\%) concentrations that are significantly higher than what is commonly reported in the literature for waste-rock piles at other mines (Smith et al., 2013a; Fan et al., 2014; Essilfie-Dughan et al., 2017). The sulfide mineral assemblage at Ore Chimney was mainly derived from calcite- and dolomite-bearing quartz veins and primarily composed of sphalerite and galena with a lower occurrence of pyrite and chalcopyrite. High concentrations of in situ porewater alkalinity $(\mu=60.2 \mathrm{mg} / \mathrm{L}$ $\left.\mathrm{CaCO}_{3}\right)$ and consistent near-neutral $\mathrm{pH}(6.4-8.3)$ at Ore Chimney are a function of high concentrations of calcite and dolomite, but also due to a reduced tendency for sphalerite and galena to generate acidity from weathering processes under the availability of oxygen (Equation 1) (Plumlee, 1999). High Eh readings coupled with observations of sulfide alteration were consistent across depth and location indicating a fully aerobic system, which may be attributed to the accumulation of coarse material towards the base of the waste-rock pile from edge dumping and prolonged weathering (Lahmira et al., 2016).

Total S and C content of the waste rock were observed to be independent of grain size between ranges of $<0.5 \mathrm{~mm}$ and 0.5 to $2.0 \mathrm{~mm}$. It is therefore suggested that sulfide and carbonate grains encapsulated by quartz have a decreased propensity for partitioning into finer grain sizes from blasting and long-term subaerial exposure and the source of sulfide minerals may play an important role in weathering. Studies of younger mine-waste systems [i.e. Gunsinger et al., 2006a (28 years), Jeong and Lee, 2003 (50 years), and Moncur et al., 2009 (70 years)] described a relative sulfide mineral resistance to alteration in the order chalcopyrite $>$ pyrite $>$ galena > sphalerite, which was consistently observed after $\sim 100$ years at Ore Chimney. Sphalerite showed the highest susceptibility to weathering but was still abundant throughout the entire waste-rock pile suggesting that sulfide weathering will actively continue. Observations of secondary Fe-oxyhydroxide phases on the 
alteration rims of pyrite and chalcopyrite suggest higher adsorption affinities of $\mathrm{Cu}$, $\mathrm{Pb}$, and $\mathrm{Zn}$, and slower weathering rates; however, it is likely that they will continue to serve as the primary acid-generating sources in the waste-rock pile. Nonetheless, the uncertain acid-generating capacity at Ore Chimney governed by inherent physical and chemical heterogeneities and the presence of pyrite and chalcopyrite is not expected to generate AMD in the near future due to the abundance of Ca-carbonates.

The high alkalinity in the waste-rock porewaters derived from the abundance of Ca-carbonates controlled dissolved $\mathrm{Zn}, \mathrm{Cd}, \mathrm{Pb}$, and $\mathrm{Cu}$ by the formation of secondary metal-carbonates. The magnitude of concentration of dissolved $\mathrm{Zn}, \mathrm{Cd}$, $\mathrm{Pb}$, and $\mathrm{Cu}$ is likely due to differences in solubility products of the respective secondary carbonate mineral controls, and insufficient alkalinity (i.e. $0.5 \mathrm{~m}$ in trench 1 and $2.5 \mathrm{~m}$ depth in trench 3 ) corresponded with elevated metals in the porewater. Results from this study indicate that principal waste-rock weathering mechanisms, such as the accumulation of heavy metals and sulfate from sulfide oxidation, $\mathrm{pH}$ buffering from $\mathrm{Ca}$-carbonates, and secondary controls on porewater chemistry can appropriately describe mine-waste systems that have weathered across a wide range of timescales. As such, the differences in drainage chemistry and in situ geochemical signatures between mine-waste studies of different exposure times tends to be a result of lithological and mineralogical variations as opposed to prolonged weathering.

\subsection{Recommendations for Areas of Future Research}

It can be assumed that gypsum has been near saturation in the waste-rock porewaters at Ore Chimney for an extended period. As such, a more detailed investigation looking at gangue minerals under transmitted light and SEM-EDX may have led to direct observations of gypsum, which would corroborate interpretations of its presence and help understand the effect that the abundance of gypsum may have on AP and subsequent NPR calculations. Solid-phase sulfide and sulfate content can be distinguished by employing certain laboratory analytical methods described by Pillai et al, (2007) and Mussa et al, (2009) that may have 
greater utility in the case for Ore Chimney. Likewise, samples of waste-rock material can be sieved to an even finer grain size fraction and analyzed by PXRD to potentially resolve and quantify the presence of gypsum among other secondary mineral phases (Piantone et al., 2004). Estimations of NPR values at Ore Chimney may also be adjusted to account for differences in chemical weathering between acid-generating and non-acid generating sulfide minerals.

The oxidation ranking scheme and subsequent SAI developed herein was performed only on the coarse-grained fraction of waste-rock material (0.5 to 2.0 $\mathrm{mm}$ ) since SEM-EDX analysis on polished grain mounts representing the finegrained fraction $(<0.5 \mathrm{~mm})$ required a carbon coating, which rendered them ineffective for further investigation with optical microscopy. SAI assessments could have been conducted on the entire suite of both grain fractions prior to SEM-EDX analysis and weathering extents could have been compared in greater detail to gain a better understanding on long-term weathering with grain size. However, mineral obscurities from high degrees of weathering and difficulties with preparing the $<0.5 \mathrm{~mm}$ polished grain mounts necessitated the use of SEM-EDX to ensure that ore minerals were properly identified. In addition, electron microprobe analysis (EMPA) can be employed to perform higher chemical and spatial resolution analyses of alteration phases.

The high-resolution sampling technique facilitated by carefully deconstructing the waste-rock pile resulted in field work that could only be attempted once. Likewise, additional 5 to $6 \mathrm{~kg}$ samples of waste-rock material were collected in tandem with samples collected for solid-phase and aqueous-phase investigations in consideration for particle size distributions throughout the waste-rock pile and their effect on geochemical signatures in the waste rock. Samples under a wider range of grain sizes can be analyzed for total $\mathrm{C} / \mathrm{S}$ to help investigate how sulfur derived from quartz veins partitions into different grain sizes and how this compares with sulfur derived from other lithologies, such as biotite schist at Diavik (Smith et al., 2013a). 


\subsection{References}

Abdus-Salam, N., \& Adekola, F. A. (2005). The Influence of pH and Adsorbent Concentration on Adsorption of Lead and Zinc on a Natural Goethite. African Journal of Science and Technology, 6, 55-66.

Aguilar, V., Ruvalcalba-Sil, J. L., Brucio, L., \& Rivera-Muñoz, E. M. (2019). Characterization and setting protocol for a simultaneous X-ray Diffraction $\mathrm{X}$-ray Fluorescence system (XRD/XRF) for in situ analysis. The European Physical Journal Plus, 134: 286

Aiken, G. R., Hsu-Kim, H., \& Ryan, J. N. (2011). Influence of dissolved organic matter on the environmental fate of metals, nanoparticles, and colloids. Environmental science and technology, 45:3196-3201.

Akcil, A., \& Koldas, S. (2006). Acid Mine Drainage (AMD): causes, treatment and case studies. Journal of Cleaner Production, 14, 1139-1145. https://doi.org/10.1016/j.jclepro.2004.09.006

Amos, R. T., Blowes, D. W., Bailey, B. L., Sego, D. C., Smith, L., lan, A., \& Ritchie, M. (2015). Waste-rock hydrogeology and geochemistry. Applied Geochemistry, 57, 140-156. https://doi.org/10.1016/j.apgeochem.2014.06.020

Amrani, M., Taha, Y., Elghali, A., Benzaazoua, M., Kchikach, A., \& Hakkou, R. (2021). An experimental investigation on collapsible behavior of dry compacted phosphate mine waste rock in road embankment. Transportation Geotechnics, 26, 100439. https://doi.org/10.1016/j.trgeo.2020.100439

Archibald, J. C. (2012). Technical Report on the Diamond Drilling Program 20112012 Ore Chimney Mine Property NTS 31C/43 SW UTM Zone 18 329700E 4960300 N Barrie Township, S.W. Ontario.

ASTM C702/C702M-11 Standard Practice, (2011). Standard Practice for Reducing Samples of Aggregate to Testing Size. In: Anonymous Annual Book of ASTM Standards, American Society for Testing and Materials.

Atherton, C. (2017). An Investigation of Heterogeneity and the Impact of Acidic Regions on Bulk Effluent from a Deconstructed Low Sulfide Waste-Rock Pile. Masters Thesis, University of Waterloo.

Azam, S., Wilson, G. W., Herasymuik, G., Nichol, C., \& Barbour, L. S. (2007). Hydrogeological behaviour of an unsaturated waste rock pile: a case study at the Golden Sunlight Mine, Montana, USA. Bulletin of Engineering Geology and the Environment, 66, 259-268. 
Azam, S., Wilson, G. W., Fredlund, D. G., \& Van Zyl, D. (2011). Geotechnical characterization of mine waste rock. In Proceedings of the 17th International Conference on Soil Mechanics and Geotechnical Engineering: 5-9 October 2009, Alexandria, Egypt, 5, 3421-3425.

Bailey, B. L., Smith, L. J. D., Blowes, D. W., Ptacek, C. J., Smith, L., \& Sego, D. C. (2013). The Diavik Waste Rock Project: Persistence of contaminants from blasting agents in waste rock effluent. Applied Geochemistry, 36, 256-270. https://doi.org/10.1016/j.apgeochem.2012.04.008

Bain, J. G., Mayer, K. U., Blowes, D. W., Frind, E. O., Molson, J. W. H., Kahnt, R., \& Jenk, U. (2001). Modelling the closure-related geochemical evolution of groundwater at a former uranium mine. Journal of Contaminant Hydrology, 52, 109-135. https://doi.org/10.1016/S0169-7722(01)00155-3

Balistrieri, L. S., Borrok, D. M., Wanty, R. B., \& Ridley, W. I. (2008). Fractionation of $\mathrm{Cu}$ and $\mathrm{Zn}$ isotopes during adsorption onto amorphous $\mathrm{Fe}(\mathrm{III})$ oxyhydroxide: Experimental mixing of acid rock drainage and ambient river water. Geochimica et Cosmochimica Acta, 72, 311-328. https://doi.org/10.1016/i.gca.2007.11.013

Bao, Z., Bain, J., Holland, S. P., Wilson, D., MacKenzie, P., Ptacek, C. J., \& Blowes, D. W. (2020). Faro Waste Rock Project: Characterizing geochemical heterogeneity in sulfide- and carbonate-rich waste rock. Applied Geochemistry, 121, 104691. https://doi.org/10.1016/j.apgeochem.2020.104691

Bao, Z., Al, T., Couillard, M., Poirier, G., Bain, J., Shrimpton, H. K., Finfrock, Y. Z., Lanzirotti, A., Paktunc, D., Saurette, E., Hu, Y., Ptacek, C. J., \& Blowes, D. W. (2021). A cross scale investigation of galena oxidation and controls on mobilization of lead in mine waste rock. Journal of Hazardous Materials, 412, 125130. https://doi.org/10.1016/j.jhazmat.2021.125130

Barsi, D. (2017). Spatial variability of particles in waste rock piles. Masters Thesis, University of Waterloo.

Berghorn, G. H., \& Hunzeker, G. R. (2001). Passive Treatment Alternatives for Remediating Abandoned-Mine Drainage. Remediation, 11, 111-127. https://doi.org/10.1002/rem.1007

Bhatti, T. M., Bigham, J. M., Vuorinen, A., \& Tuovinen, O. H. (2011). Weathering of biotite in Acidithiobacillus ferrooxidans cultures. Geomicrobiology Journal, 28, 130-134. https://doi.org/10.1080/01490451003720901 
Bigham, J. M., \& Nordstrom, D. K. (2019). Iron and aluminum hydroxysulfates from acid sulfate waters. Sulfate Minerals: Crystallography, Geochemistry, and Environmental Significance, 40, 351-403. https://doi.org/10.2138/rmg.2000.40.7

Blowes, David W., \& Jambor, J. L. (1990). The pore-water geochemistry and the mineralogy of the vadose zone of sulfide tailings, Waite Amulet, Quebec, Canada. Applied Geochemistry, 5, 327-346. https://doi.org/10.1016/08832927(90)90008-S

Blowes, D. W., Ptacek, C. J., Jambor, J. L., Weisener, C. G., Paktunc, D., Gould, W. D., \& Johnson, D. B. (2013). The Geochemistry of Acid Mine Drainage. In Treatise on Geochemistry: Second Edition (11th ed., Vol. 11). Elsevier Ltd. https://doi.org/10.1016/B978-0-08-095975-7.00905-0

Borgne, V. Le, Cosentino, A., Brehe, J-M., \& Thivierge, S-E. (2018). Deployment Of Large-area Radio-enabled Monitoring Systems In Northern Mines. In International Symposium on Field Measurements in Geomechanics: 16-20 July 2018, Rio De Janeiro, Brazil.

Boulanger-Martel, V., Bussière, B., \& Côté, J. (2021). Resistance of a soapstone waste rock to freeze-thaw and wet-dry cycles: implications for use in a reclamation cover in the Canadian Arctic. Bulletin of Engineering Geology and the Environment, 80, 41-54. https://doi.org/10.1007/s10064-020-01930$\underline{8}$

Boulet, M. P., \& Larocque, A. C. L. (1998). A comparative mineralogical and geochemical study of sulfide mine tailings at two sites in New Mexico, USA. Environmental Geology, 33, 130-142. https://doi.org/10.1007/s002540050233

Boyle, F. W., \& Lindsay, W. L. (1985). Diffraction Patterns and Solubility Products of Several Divalent Manganese Phosphate Compounds. Soil Science Society of America Journal, 49, 761-766. https://doi.org/10.2136/sssaj1985.03615995004900030046x

Carranza, E. J. M., \& Sadeghi, M. (2012). Primary geochemical characteristics of mineral deposits - Implications for exploration. Ore Geology Reviews, 45, 1 4. https://doi.org/10.1016/j.oregeorev.2012.02.002

Carter, T., R. (1984). Metallogeny of the Grenville Province, Southeastern Ontario. Ontario Geological Survey. Available at: http://www.geologyontario.mndmf.gov.on.ca/mndmfiles/pub/data/imaging/OF R5515//OFR5515.pDf

Cash, A. (2014). Structural and Hydrologic Characterization of Two HistoricalWaste Rock Piles. Masters Thesis, University of Alberta. 
Chidambaram, S., Anandhan, P., Prasanna, M. V., Ramanathan, A. L., Srinivasamoorthy, K., \& Kumar, G. S. (2012). Hydrogeochemical Modelling for Groundwater in Neyveli Aquifer, Tamil Nadu, India, Using PHREEQC: A Case Study. Natural Resources Research, 21, 311-324. https://doi.org/10.1007/s11053-012-9180-6

Combes, J. M., Manceau, A., Calas, G., \& Bottero, J. Y. (1989). Formation of ferric oxides from aqueous solutions: A polyhedral approach by $\mathrm{X}$-ray absorption spectroscdpy: I. Hydrolysis and formation of ferric gels. Geochimica et Cosmochimica Acta, 53, 583-594. https://doi.org/10.1016/0016-7037(89)90001-X

Cook, N. J., Ciobanu, C. L., Pring, A., Skinner, W., Shimizu, M., Danyushevsky, L., Saini-Eidukat, B., \& Melcher, F. (2009). Trace and minor elements in sphalerite: A LA-ICPMS study. Geochimica et Cosmochimica Acta, 73, 4761-4791. https://doi.org/10.1016/i.gca.2009.05.045

Cox, E. (2005). Alternative Causes of Wide-Spread, Low Concentration Perchlorate Impacts to Groundwater. Strategic Environmental Research and Development Program (SERDP) Arlington, Virginia; Geosyntec Consultants Guelph (Ontario). pp. 1-45.

Cranstone, D. (2002). A history of mining and mineral exploration in Canada and outlook for the future. Natural Resources Canada. pp. 1-47.

Dawson, J. B., \& Smith, J. V. (1977). The MARID (mica-amphibole-rutileilmenite-diopside) suite of xenoliths in kimberlite. Geochimica et Cosmochimica Acta, 41, 309-323. https://doi.org/10.1016/0016$\underline{7037(77) 90239-3}$

Demers, I., Molson, J., Bussière, B., \& Laflamme, D. (2013). Numerical modeling of contaminated neutral drainage from a waste-rock field test cell. Applied Geochemistry, 33, 346-356. https://doi.org/10.1016/j.apgeochem.2013.02.025

Dillon, E. P. (1985). Gold-quartz-arsenopyrite vein deposits localized near the base of the Flinton Group, Kaladar and Barrie Townships, Southeastern Ontario. Ontario Geological Survey, Open-file, pp. 1-53.

Eary, L. E. (1999). Geochemical and equilibrium trends in mine pit lakes. Applied Geochemistry, 14, 963-987. https://doi.org/10.1016/S0883-2927(99)00049-9

Easton, R., M. (2006). Precambrian Geology of the Cloyne-Plevna-Ompah Area, Northern Mazinaw Domain, Grenville Province. Ontario Geological Survey. Available at: http://www.geologyontario.mndmf.gov.on.ca/mndmfiles/pub/data/imaging/OF R5454/OFR5454.pdf. 
Elghali, A., Benzaazoua, M., Bouzahzah, H., Bussière, B., \& Villarraga-Gómez, $H$. (2018). Determination of the available acid-generating potential of waste rock, part I: Mineralogical approach. Applied Geochemistry, 99, 31-41. https://doi.org/10.1016/j.apgeochem.2018.10.021

Elghali, A., Benzaazoua, M., Bouzahzah, H., Abdelmoula, M., Dynes, J. J., \& Jamieson, H. E. (2021). Role of secondary minerals in the acid generating potential of weathered mine tailings: Crystal-chemistry characterization and closed mine site management involvement. Science of the Total Environment, 784, 147105. https://doi.org/10.1016/j.scitotenv.2021.147105

Elwood Madden, M. E., Madden, A. S., Rimstidt, J. D., Zahrai, S., Kendall, M. R., \& Miller, M. A. (2012). Jarosite dissolution rates and nanoscale mineralogy. Geochimica et Cosmochimica Acta, 91, 306-321. https://doi.org/10.1016/j.gca.2012.05.001

Enviromin. (2017). Black Butte Copper Project Water Quality Monitoring Report. Tintina Montana Inc. pp 1-55.

Environment Canada. (2010). Canadian Climate Normals 1981-2010 Station Data. Arnprior Grandon, Ontario. Available at:

https://climate.weather.gc.ca/climate normals/results 19812010 e.html?se archType $=$ stnProvandlstProvince $=$ ONandtxtCentralLatMin $=0$ andtxtCentralLa $\underline{t S e c}=0$ andtxtCentralLongMin=0andtxtCentralLongSec $=0$ andstn $\mid \mathrm{D}=4225 \mathrm{and}$ dispBack $=0$.

Essilfie-Dughan, J., Hendry, M. J., Dynes, J. J., Hu, Y., Biswas, A., Lee Barbour, S., \& Day, S. (2017). Geochemical and mineralogical characterization of sulfur and iron in coal waste rock, Elk Valley, British Columbia, Canada. Science of the Total Environment, 586, 753-769. https://doi.org/10.1016/j.scitotenv.2017.02.053

Ettler, V., Vrtišková, R., Mihaljevič, M., Šebek, O., Grygar, T., \& Drahota, P. (2009). Cadmium, lead and zinc leaching from smelter fly ash in simple organic acids-Simulators of rhizospheric soil solutions. Journal of Hazardous Materials, 170, 1264-1268. https://doi.org/10.1016/j.jhazmat.2009.05.068

Fan, G., Zhang, D., \& Wang, X. (2014). Reduction and utilization of coal mine waste rock in China: A case study in Tiefa coalfield. Resources, Conservation and Recycling, 83, 24-33. https://doi.org/10.1016/j.resconrec.2013.12.001

Fanfani, L., Zuddas, P., \& Chessa, A. (1996). Heavy metals speciation analysis as a tool for studying mine tailings weathering. Journal of Geochemical Explorations, 58, 241-248. 
Ford, K. L. (2003). Passive treatment systems for acid mine drainage. U.S. Bureau of Land Management Papers. pp. 1-13.

Fordham, A. W. (1990). Weathering of biotite into dioctahedral clay minerals. Clay Minerals, 25, 51-63. https://doi.org/10.1180/claymin.1990.025.1.06

Frogner, P., \& Schweda, P. (1998). Hornblende dissolution kinetics at $25^{\circ} \mathrm{C}$. Chemical Geology, 151, 169-179. https://doi.org/10.1016/S00092541(98)00078-3

Fu, X., Wang, Y., \& Wei, F. (2010). Phase transitions and reaction mechanism of ilmenite oxidation. Metallurgical and Materials Transactions A: Physical Metallurgy and Materials Science, 41, 1338-1348. https://doi.org/10.1007/s11661-010-0173-y

Gawdzik, A., Garbat, K., Gawdzik, A., \& Gawdzik, J. (2015). Chemical Composition of The Commerce Mineral Waters Versus Tap Water In The City Of Kielce. Proceedings of ECOpole, 9, 15-17. https://doi.org/10.2429/proc.2015.9(1)005

George, L., Cook, N. J., Cristiana, C., \& Wade, B. P. (2015). Trace and minor elements in galena: A reconnaissance LA-ICP-MS study. American Mineralogist, 100, 548-569. https://doi.org/10.2138/am-2015-4862

Gleisner, M. (2005). Quantification of mineral weathering rates in sulfidic mine tailings under water-saturated conditions. PhD Thesis, Stockholm University.

Gorakhki, M. H., \& Bareither, C. A. (2017). Sustainable reuse of mine tailings and waste rock as water-balance covers. Minerals, 7, 128. https://doi.org/10.3390/min7070128

Goumih, A., El Adnani, M., Hakkou, R., \& Benzaazoua, M. (2013). Geochemical Behavior of Mine Tailings and Waste Rock at the Abandoned Cu-Mo-W Azegour Mine (Occidental High Atlas, Morocco). Mine Water and the Environment, 32, 121-132. https://doi.org/10.1007/s10230-013-0221-0

Grey, I. E., \& Reid, A. F. (1975). The Structure of Pseudorutile and Its Role in The Natural Alteration of IImenite. The American Mineralogist, 60, 898-906.

Gunsinger, M. R., Ptacek, C. J., Blowes, D. W., \& Jambor, J. L. (2006a). Evaluation of long-term sulfide oxidation processes within pyrrhotite-rich tailings, Lynn Lake, Manitoba. Journal of Contaminant Hydrology, 83, 149170. https://doi.org/10.1016/j.jconhyd.2005.10.013

Gunsinger, M. R., Ptacek, C. J., Blowes, D. W., Jambor, J. L., \& Moncur, M. C. (2006b). Mechanisms controlling acid neutralization and metal mobility within a Ni-rich tailings impoundment. Applied Geochemistry, 21, 1301-1321. https://doi.org/10.1016/j.apgeochem.2006.06.006 
Hach. (2013). Sulfate, SulfaVer 4 Method 10248. Hach Company Headquarters. Document no. 316.53.01316.

Hach. (2014a). Sulfide, Methylene Blue Method 10254. Hach Company Headquarters. Document no. 316.53.01319.

Hach. (2014b). Alkalinity, Colorimetric Method 10239. Hach Company Headquarters. Document no. 316.54.01257.

Hach. (2014c). Ferrous Iron, 1,10-Phenanthroline Method 8146. Hach Company Headquarter. Document no. 316.53.01049.

Hamzeh, M., Bafti, S. B., \& Omrani, H. (2020). Trace element geochemistry of galena in fluorite deposits from central Alborz, Mazandaran Province. Journal of Economic Geology, 12, 227-247.

Harnois, L., \& Moore, J. M. (1988). Geochemistry and origin of the Ore Chimney Formation, a transported paleoregolith in the Grenville Province of southeastern Ontario, Canada. Chemical Geology, 69, 267-289. https://doi.org/10.1016/0009-2541(88)90039-3

Harnois, L., \& Moore, J. M. (1989). Geochemistry and genesis of two unconformity-associated gold deposits at the base of the Flinton Group, Grenville Province, southeastern Ontario, Canada. Economic Geology, 84, 676-693. https://doi.org/10.2113/gsecongeo.84.3.676

Harper, C., Walsh, C., Fong, C., \& Amos, R. T. (2021). Long Term Zinc Contamination and Transport at the Abandoned Ore Chimney Gold Mine. (In press; Canadian Geotechnical Journal).

Hayes, S. M., Root, R. A., Perdrial, N., Maier, R. M., \& Chorover, J. (2014). Surficial weathering of iron sulfide mine tailings under semi-arid climate. Geochimica et Cosmochimica Acta, 141, 240-257. https://doi.org/10.1016/i.gca.2014.05.030

Hedin, R. S., Watzlaf, G. R., \& Nairn, R. W. (1994). Passive treatment of acid mine drainage with limestone. Journal of Environmental Quality, 23, 13381345.

Heidel, C., Tichomirowa, M., \& Junghans, M. (2013). Oxygen and sulfur isotope investigations of the oxidation of sulfide mixtures containing pyrite, galena, and sphalerite. Chemical Geology, 342, 29-43. https://doi.org/10.1016/j.chemgeo.2013.01.016

Hsu, S. C., \& Maynard, J. B. (1999). The use of sulfur isotopes to monitor the effectiveness of constructed wetlands in controlling acid mine drainage. Environmental Engineering and Policy, 1, 223-233. 
Hudson-Edwards, K. A., Jamieson, H. E., \& Lottermoser, B. G. (2011). Mine Wastes: Past, Present, and Future. Elements, 7, 375-380. https://doi.org/10.1016/b978-0-12-381475-3.10005-1

ICOLD (International Commission on Large Dams). (1996). A guide to tailings dams and impoundments. Bulletin 106. pp 1-239.

INAC [Indian and Northern Affairs, Canada], 1993. Guidelines for Acid Rock Drainage Prediction in the North. Catalogue Number R71-50/1E.

Jambor, J. L., Dutrizac, J. E., Groat, L. A., \& Raudsepp, M. (2002). Static tests of neutralization potentials of silicate and aluminosilicate minerals.

Environmental Geology, 43, 1-17. https://doi.org/10.1007/s00254-002-0615Y

Jameson, E., Rowe, O. F., Hallberg, K. B., \& Johnson, D. B. (2010).

Sulfidogenesis and selective precipitation of metals at low $\mathrm{pH}$ mediated by Acidithiobacillus spp. and acidophilic sulfate-reducing bacteria. Hydrometallurgy, 104, 488-493.

Jamieson, H. E., Shaw, S. C., \& Clark, A. H. (1995). Mineralogical Factors Controlling Metal Release from Tailings at Geco, Manitouwage, Ontario. Conference on Mining and the Environment, 1 June 1995, Sudbury, Ontario.

Jeong, G. Y., \& Lee, B. Y. (2003). Secondary mineralogy and microtextures of weathered sulfides and manganoan carbonates in mine waste-rock dumps, with implications for heavy-metal fixation. American Mineralogist, 88, 19331942. https://doi.org/10.2138/am-2003-11-1236

Johnson, R. H., Blowes, D. W., Robertson, W. D., \& Jambor, J. L. (2000). The hydrogeochemistry of the Nickel Rim mine tailings impoundment, Sudbury, Ontario. Journal of Contaminant Hydrology, 41, 49-80. https://doi.org/10.1016/S0169-7722(99)00068-6

Jurjovec, J., Ptacek, C. J., \& Blowes, D. W. (2002). Acid neutralization mechanisms and metal release in mine tailings: A laboratory column experiment. Geochimica et Cosmochimica Acta, 66, 1511-1523. https://doi.org/10.1016/S0016-7037(01)00874-2

Kamerman, L. M. (2006). History of the Ontario Mining and Lands Commissioner. Ministry of Northern Development and Mines. Available at: https://www.ontario.ca/page/history-ontario-mining-and-lands-commissioner

Keim, M. F., \& Markl, G. (2015). Weathering of galena: Mineralogical processes, hydrogeochemical fluid path modeling, and estimation of the growth rate of pyromorphite. American Mineralogist, 100, 1584-1594.

https://doi.org/10.2138/am-2015-5183 
Kingston, P. W. (1980). Resident Geologist, Tweed, Ontario. Ministry of Northern Development and Mines. Extracted and modified from Archibald, J. C. (2012).

Kingston, P.W., \& Papertzian, V.C., (1982). Gold Development Potential in Eastern Ontario (Open File Report No. 5379), Ontario Geological Survey. Ministry of Natural Resources.

Komárek, M., Antelo, J., Králová, M., Veselská, V., Číhalová, S., Chrastný, V., Ettler, V., Filip, J., Yu, Q., Fein, J. B., \& Koretsky, C. M. (2018). Revisiting models of $\mathrm{Cd}, \mathrm{Cu}, \mathrm{Pb}$ and $\mathrm{Zn}$ adsorption onto $\mathrm{Fe}(\mathrm{III})$ oxides. Chemical Geology, 493, 189-198. https://doi.org/10.1016/j.chemgeo.2018.05.036

Kooner, Z. S. (1993). Comparative study of adsorption behavior of copper, lead, and zinc onto goethite in aqueous systems. Environmental Geology, 21, 242-250. https://doi.org/10.1007/BF00775914

Koski, R. A., Munk, L. A., Foster, A. L., Shanks, W. C., \& Stillings, L. L. (2008). Sulfide oxidation and distribution of metals near abandoned copper mines in coastal environments, Prince William Sound, Alaska, USA. Applied Geochemistry, 23, 227-254. https://doi.org/10.1016/j.apgeochem.2007.10.007

Kwong, Y. T. J., Roots, C. F., Roach, P., \& Kettley, W. (1997). Post-mine metal transport and attenuation in the Keno Hill mining district, central Yukon, Canada. Environmental Geology, 30, 98-107. https://doi.org/10.1007/s002540050137

La Brooy, S. R., Linge, H. G., \& Walker, G. S. (1994). Review of gold extraction from ores. Minerals Engineering, 7, 1213-1241.

Lahmira, B., Lefebvre, R., Aubertin, M., \& Bussière, B. (2016). Effect of heterogeneity and anisotropy related to the construction method on transfer processes in waste rock piles. Journal of Contaminant Hydrology, 184, 3549. https://doi.org/10.1016/j.jconhyd.2015.12.002

Lane, S. J., \& Dalton, J. A. (1994). Electron microprobe analysis of geological carbonates. American Mineralogist, 79, 745-749.

Langman, J. B., Moore, M. L., Ptacek, C. J., Smith, L., Sego, D., \& Blowes, D. W. (2014). Diavik waste rock project: Evolution of mineral weathering, element release, and acid generation and neutralization during a five-year humidity cell experiment. Minerals, 4, 257-278. https://doi.org/10.3390/min4020257 
Langman, J. B., Blowes, D. W., Veeramani, H., Wilson, D., Smith, L., Sego, D. C., \& Paktunc, D. (2015). The mineral and aqueous phase evolution of sulfur and nickel with weathering of pyrrhotite in a low sulfide, granitic waste rock. Chemical Geology, 401, 169-179.

https://doi.org/10.1016/j.chemgeo.2015.02.024

Langman, J. B., \& Moberly, J. G. (2018). Weathering of a mined quartzcarbonate, galena-sphalerite ore and release and transport of nanophase zinc carbonate in circumneutral drainage. Journal of Geochemical Exploration, 188, 185-193. https://doi.org/10.1016/j.gexplo.2018.01.024

Langmuir, D. (1997). Activity Coefficients of Dissolved Species in: Aqueous Environmental Geochemistry. Prentice-Hall, Inc.

Lapakko, K. (2002). Metal mine rock and waste characterization tools: An overview. International Institute for Environment and Development, 67, 1-30.

Laurenzi, L., Mayer, K. U., \& Beckie, R. (2015). A metal attenuation study on waste rock collected from the East Dump, Antamina Mine, Peru: A combined mineralogical and geochemical approach. International Conference on Acid Rock Drainage, April 2015, Santiago Chile, 1-11.

Leahy, M. J., \& Schwarz, M. P. (2009). Modelling jarosite precipitation in isothermal chalcopyrite bioleaching columns. Hydrometallurgy, 98, 181-191.

Lee, G., Bigham, J. M., \& Faure, G. (2002). Removal of trace metals by coprecipitation with $\mathrm{Fe}, \mathrm{Al}$ and $\mathrm{Mn}$ from natural waters contaminated with acid mine drainage in the Ducktown Mining District, Tennessee. Applied Geochemistry, 17, 569-581. https://doi.org/10.1016/S0883-2927(01)00125-1

Lefebvre, R., Hockley, D., Smolensky, J., \& Geélinas, P. (2001). Multiphase transfer processes in waste rock piles producing acid mine drainage. 1: Conceptual model and system characterization. Journal of Contaminant Hydrology, 52, 137-164. https://doi.org/10.1016/S0169-7722(01)00156-5

Lehner, S., Savage, K., Ciobanu, M., \& Cliffel, D. E. (2007). The effect of As, Co, and $\mathrm{Ni}$ impurities on pyrite oxidation kinetics: An electrochemical study of synthetic pyrite. Geochimica et Cosmochimica Acta, 71, 2491-2509. https://doi.org/10.1016/i.gca.2007.03.005

Lewkowicz, A. G., \& Bonnaventure, P. P. (2011). Equivalent elevation: A new method to incorporate variable surface lapse rates into mountain permafrost modelling. Permafrost and Periglacial Processes, 22, 153-162.

https://doi.org/10.1002/ppp.720 
Llera, A. R., Fuertes-Fuente, M., Cepedal, A., \& Martin-Izard, A. (2019). Barren and Li-Sn-Ta mineralized pegmatites from NW Spain (Central Galicia): A comparative study of their mineralogy, geochemistry, and wallrock metasomatism. Minerals, 9, 739. https://doi.org/10.3390/min9120739

Machemer, S. D., \& Wildeman, T. R. (1992). Adsorption compared with sulfide precipitation as metal removal processes from acid mine drainage in a constructed wetland. Journal of Contaminant Hydrology, 9, 115-131.

Mackasey, W. O. (2000). Abandoned Mines in Canada. WOM Geological Associates Inc.

Malmstrom, M., \& Banwart, S. (1997). Biotite dissolution at $25^{\circ} \mathrm{C}$ : The $\mathrm{pH}$ dependence of dissolution rate and stoichiometry. Geochimicha et Cosmochimica Acta, 61, 2779-2799.

Marani, D., Macchi, G., \& Pagano, M. (1995). Lead precipitation in the presence of sulphate and carbonate: Testing of thermodynamic predictions. Water Research, 29, 1085-1092. https://doi.org/10.1016/0043-1354(94)00232-V

Marshall, B. (2017). Facts and Figures of the Canadian Mining Industry. The Mining Association of Canada. Ottawa, Ontario, Canada. Available at: https://mining.ca/wp-content/uploads/2020/01/FF-English-Web-1.pdf

Martínez-Lladó, X., de Pablo, J., Giménez, J., Ayora, C., Marti, V., \& Rovira, M. (2008). Sorption of antimony (V) onto synthetic goethite in carbonate medium. Solvent Extraction and lon Exchange, 26, 289-300. https://doi.org/10.1080/07366290802053637

Mayer, K. U., Frind, E. O., \& Blowes, D. W. (2002). Multicomponent reactive transport modeling in variably saturated porous media using a generalized formulation for kinetically controlled reactions. Water Resources Research, 38, 1-21 https://doi.org/10.1029/2001wr000862

Mayes, W. M., Batty, L. C., Younger, P. L., Jarvis, A. P., Kõiv, M., Vohla, C., \& Mander, U. (2009). Wetland treatment at extremes of $\mathrm{pH}$ : a review. Science of the Total Environment, 407, 3944-3957.

McCarron, T., J., A. (2013). Unravelling the P-T-t history of Grenvillian Metamorphism in the Mazinaw Domain, southeastern Ontario: Insights from phase equilibria modeling and geospeedometry. PhD Thesis, Carleton University.

McCreadie, H., Blowes, D. W., Ptacek, C. J., \& Jambor, J. L. (2000). Influence of reduction reactions and solid-phase composition on porewater concentrations of arsenic. Environmental Science and Technology, 34, 3159-3166. https://doi.org/10.1021/es991194p 
Mead, S. (2011). Faro Mine remediation project - an overview. In Proceedings of the Sixth International Conference on Mine Closure, Australian Centre for Geomechanics, pp. 433-440. https://doi.org/10.36487/acg rep/1152 $111 \mathrm{mead}$

MNDM. (1994). Geology of Bon Echo Provincial Park, Frontenac and Lennox and Addington Counties, Grenville Province. Ontario Geological Survey. Available at:

http://www.geologyontario.mndmf.gov.on.ca/mndmfiles/pub/data/imaging/OF R5899//ofr5899.pdf

MNDM. (2008). Modernizing Ontario's Mining Act. Ministry of Northern Development and Mines. Government of Ontario.

Mohapatra, M., Mohapatra, L., Singh, P., Anand, S., \& Mishra, B. (2011). A comparative study on $\mathrm{Pb}(\mathrm{II}), \mathrm{Cd}(\mathrm{II}), \mathrm{Cu}(\mathrm{II}), \mathrm{Co}(\mathrm{II})$ adsorption from single and binary aqueous solutions on additive assisted nano-structured goethite. International Journal of Engineering, Science and Technology, 2, 89-103. https://doi.org/10.4314/ijest.v2i8.63784

Moncur, M. C., Ptacek, C. J., Blowes, D. W., \& Jambor, J. L. (2005). Release, transport and attenuation of metals from an old tailings impoundment. Applied Geochemistry, 20, 639-659. https://doi.org/10.1016/j.apgeochem.2004.09.019

Moncur, M. C., Jambor, J. L., Ptacek, C. J., \& Blowes, D. W. (2009). Mine drainage from the weathering of sulfide minerals and magnetite. Applied Geochemistry, 24, 2362-2373. https://doi.org/10.1016/j.apgeochem.2009.09.013

Moncur, Michael C., Ptacek, C. J., Lindsay, M. B. J., Blowes, D. W., \& Jambor, J. L. (2015). Long-term mineralogical and geochemical evolution of sulfide mine tailings under a shallow water cover. Applied Geochemistry, 57, 178193. https://doi.org/10.1016/j.apgeochem.2015.01.012

Mondillo, N., Arfè, G., Herrington, R., Boni, M., Wilkinson, C., \& Mormone, A. (2018). Germanium enrichment in supergene settings: evidence from the Cristal nonsulfide Zn prospect, Bongará district, northern Peru. Mineralium Deposita, 53, 155-169. https://doi.org/10.1007/s00126-017-0781-1

Moore, J., M., \& Morton, R., L. (1986). Geology of the Marble Lake Area. Counties of Frontenac and Lennox and Addington. Ontario Geological Survey. Available at: http://www.geologyontario.mndmf.gov.on.ca/mndmfiles/pub/data/imaging/R2 38//r238.pdf 
Moore, J. M., \& Thompson, P. H. (1980). The Flinton Group: a late Precambrian metasedimentary succession in the Grenville Province of eastern Ontario. Canadian Journal of Earth Sciences, 17, 1685-1707. https://doi.org/10.1139/e80-178

Muhammed, M., \& Zhang, Y. (1989). A hydrometallurgical process for the dephosphorization of iron ore. Hydrometallurgy, 21, 277-292.

Mussa, S. A. B., Elferjani, H. S., Haroun, F. A., \& Abdelnabi, F. F. (2009). Determination of available nitrate, phosphate and sulfate in soil samples. International Journal of PharmTech Research, 1: 598-604.

Natural Resources Canada. (2016). National Air Photo Library. Accessed in 2016. Ottawa, ON.

Natural Resources Canada. (2017). Canadian Mineral Production. Available at: https://www.nrcan.gc.ca/maps-tools-and-publications/publications/mineralsand-mining-publications/canadian-mineral-production/17722.

Nesbitt, H. W., Fedo, C. M., \& Young, G. M. (1997). Quartz and feldspar stability, steady and non-steady-state weathering, and petrogenesis of siliciclastic sands and muds. Journal of Geology, 105, 173-191. https://doi.org/10.1086/515908

Neuner, M., Smith, L., Blowes, D. W., Sego, D. C., Smith, L. J. D., Fretz, N., \& Gupton, M. (2013). The Diavik waste rock project: Water flow through mine waste rock in a permafrost terrain. Applied Geochemistry, 36, 222-233. https://doi.org/10.1016/j.apgeochem.2012.03.011

Nordstrom, D. K., \& Alpers, C. N. (1999). Geochemistry of Acid Mine Waters. The Environmental Geochemistry of Mineral Deposits, 6, 133-160. https://doi.org/10.5382/rev.06.06

Nordstrom, D. K., Blowes, D. W., \& Ptacek, C. J. (2015). Hydrogeochemistry and microbiology of mine drainage: An update. Applied Geochemistry, 57, 3-16. https://doi.org/10.1016/j.apgeochem.2015.02.008

Nordstrom, D. K. (1982). Aqueous pyrite oxidation and the consequent formation of secondary iron minerals. Acid Sulfate Weathering, 10, 37-56. https://doi.org/10.2136/sssaspecpub10.c3

Ontario's Ministry of Northern Development, Mines, Natural Resources, and Forestry (2018). Abandoned Mines database. Retrieved from: https://www.mndm.gov.on.ca/en/mines-andminerals/applications/ogsearth/abandoned-mines

O’Reilly, K. (2012). Giant Mine, giant legacy. Northern Public Affairs, 50-53. 
Parbhakar-Fox, A., \& Lottermoser, B. (2017). Environmental Indicators in Metal Mining. Springer. https://doi.org/10.1007/978-3-319-42731-7 2

Parkhurst, D.L., \& Appelo, C.A.J., (1999). User's Guide to PHREEQC (Version 2) - A Computer Program for Speciation, Batch-Reaction, One-Dimensional Transport, and Inverse Geochemical Calculations. U.S. Geological Survey Water-Resources Investigations Report 99-4259, pp. 1-312.

Pearce, S., Dobchuk, B., Shurniak, R., Song, J., \& Christensen, D. (2016). Linking waste rock dump construction and design with seepage geochemistry: an integrated approach using quantitative tools. In IMWA Annual Conference: Frieberg, Germany. pp 512-519.

Pedretti, D., Mayer, K. U., \& Beckie, R. D. (2017). Stochastic multicomponent reactive transport analysis of low quality drainage release from waste rock piles: Controls of the spatial distribution of acid generating and neutralizing minerals. Journal of Contaminant Hydrology, 201, 30-38. https://doi.org/10.1016/j.jconhyd.2017.04.004

Petrescu, M. I. (1999). Self consistency between the Mohs hardness and the vickers microhardness for some sulphides and sulphosalts. UPB Scientific Bulletin, Series B: Chemistry and Materials Science, 61, 145-151.

Pham, N. H., Sego, D. C., Arenson, L. U., Blowes, D. W., Amos, R. T., \& Smith, L. (2013). The diavik waste rock project: Measurement of the thermal regime of a waste-rock test pile in a permafrost environment. Applied Geochemistry, 36, 234-245. https://doi.org/10.1016/j.apgeochem.2013.05.007

Pham, N., Amos, R., Blowes, D., Smith, L., \& Sego, D. (2015). The Diavik Waste Rock Project: Heat Transfer in a Large Scale Waste Rock Pile Constructed in a Permafrost Region. International Conference on Acid Rock Drainage, April 2015, Santiago Chile, 1-11.

Piantone, P., Bodénan, F., \& Chatelet-Snidaro, L. (2004). Mineralogical study of secondary mineral phases from weathered MSWI bottom ash: Implications for the modelling and trapping of heavy metals. Applied Geochemistry, 19, 1891-1904. https://doi.org/10.1016/j.apgeochem.2004.05.006

Pillai, A., Abraham, B., \& Sridharan, A. (2007). Determination of sulphate content in marine clays. Res Appl (IJERA), 1: 1012-1016.

Plumlee, G. S. (1999). The Environmental Geology of Mineral Deposits. United States Geological Survey. pp 71-116.

Pourbaix, M. (1974). Atlas of Electrochemical Equilibria in Aqueous Solutions. Pergamon Press Ltd. https://doi.org/10.4028/www.scientific.net/msf.251254.143 
Qiu, Y., \& Sego, D. C. (2001). Laboratory properties of mine tailings. Canadian Geotechnical Journal, 38, 183-190. https://doi.org/10.1139/cgi-38-1-183

Ramos, C. G., Querol, X., Dalmora, A. C., de Jesus Pires, K. C., Schneider, I. A. H., Silva, L. F. O., \& Kautzmann, R. M. (2017). Evaluation of the potential of volcanic rock waste from southern Brazil as a natural soil fertilizer. Journal of Cleaner Production, 142, 2700-2706. https://doi.org/10.1016/j.jclepro.2016.11.006

Ripley, E. M., Li, C., Moore, C. H., Elswick, E. R., Maynard, J. B., Paul, R. L., Sylvester, P., Seo, J. H., \& Shimizu, N. (2011). Analytical methods for sulfur determination in glasses, rocks, minerals and fluid inclusions. Reviews in Mineralogy and Geochemistry, 73, 9-39.

Rivett, M. O., Chapman, S. W., Allen-King, R. M., Feenstra, S., \& Cherry, J. A. (2006). Pump-and-treat remediation of chlorinated solvent contamination at a controlled field-experiment site. Environmental science and technology, 40, 6770-6781.

Rodda, D. P., Johnson, B. B., \& Wells, J. D. (1993). The effect of temperature and $\mathrm{pH}$ on the adsorption of Copper(II), Lead(II), and Zinc(II) onto goethite. Journal of Colloid And Interface Science, 161, 57-62. https://doi.org/10.1006/jicis.1993.1440

Rose, A. W., \& Bianchi-Mosquera, G. C. (1993). Adsorption of Cu, Pb, Zn, Co, $\mathrm{Ni}$, and $\mathrm{Ag}$ on goethite and hematite: a control on metal mobilization from red beds into stratiform copper deposits. Economic Geology, 88, 1226-1236. https://doi.org/10.2113/gsecongeo.88.5.1226

Sangster, P. J., LeBaron, P. S., Charbonneau, S. J., Laidlaw, D. A., Wilson, A. C., Carter, T. R., \& Fortner, L. (2012). Report of Activities, 2011 Resident Geologist Program. Available at:

http://www.geologyontario.mndm.gov.on.ca/mndmfiles/pub/data/imaging/OF R6277/OFR6277.pdf

Schroeder, P. A., Le Golvan, J. J., \& Roden, M. F. (2002). Weathering of ilmenite from granite and chlorite schist in the Georgia Piedmont. American Mineralogist, 87, 1616-1625. https://doi.org/10.2138/am-2002-11-1211

Seal, R. R., \& Foley, N. K. (2002). Progress on Geoenvironmental Models for Selected Mineral Deposit Types. (Vol. 2, No. 195). US Department of the Interior, US Geological Survey.

Sharp, T. G., \& Buseck, P. R. (1993). The distribution of Ag and Sb in galena: inclusions versus solid solution. American Mineralogist, 78, 85-95. 
Sheoran, A. S., \& Sheoran, V. (2006). Heavy metal removal mechanism of acid mine drainage in wetlands: a critical review. Minerals engineering, 19, 105116.

Shum, M., \& Lavkulich, L. (1999). Speciation and solubility relationships of Al, Cu and $\mathrm{Fe}$ in solutions associated with sulfuric acid leached mine waste rock. Environmental Geology, 38, 59-68. https://doi.org/10.1007/s002540050401

Sinclair, S., A. (2014). Influence of Freeze-Thaw Dynamics and Spatial Contributions on Geochemical Loading from a Low Sulfide Waste-Rock Pile. Masters Thesis, University of Waterloo.

Skierszkan, E. K., Mayer, K. U., Weis, D., \& Beckie, R. D. (2016). Molybdenum and zinc stable isotope variation in mining waste rock drainage and waste rock at the Antamina mine, Peru. Science of the Total Environment, 550, 103-113. https://doi.org/10.1016/j.scitotenv.2016.01.053

Skousen, J. G., Sexstone, A., \& Ziemkiewicz, P. F. (2000). Acid mine drainage control and treatment. Reclamation of drastically disturbed lands, 41, 131168.

Skrabal, S. A., \& Terry, C. M. (2002). Distributions of dissolved titanium in porewaters of estuarine and coastal marine sediments. Marine Chemistry, 77, 109-122. https://doi.org/10.1016/S0304-4203(01)00077-9

Smith, L. J. D., Blowes, D. W., Jambor, J. L., Smith, L., Sego, D. C., \& Neuner, M. (2013a). The diavik waste rock project: Particle size distribution and sulfur characteristics of low-sulfide waste rock. Applied Geochemistry, 36, 200-209. https://doi.org/10.1016/j.apgeochem.2013.05.006

Smith, L. J. D., Bailey, B. L., Blowes, D. W., Jambor, J. L., Smith, L., \& Sego, D. C. (2013b). The Diavik waste rock project: Initial geochemical response from a low sulfide waste rock pile. Applied Geochemistry, 36, 210-221. https://doi.org/10.1016/j.apgeochem.2012.06.008

Smith, L. J. D., Paktunc, D., \& Blowes, D. W. (2021). Trace elements in sulfides and release to porewater from sulfide oxidation in a historical waste-rock pile, Ontario, Canada. Applied Geochemistry, 126, 104899. https://doi.org/10.1016/j.apgeochem.2021.104899

Smitheringale, W. G. B. (2011). Great mining camps of Canada 5. Britannia mines, British Columbia. Geoscience Canada, 38, 97-134.

Sobek, A. A., Schuller, W. A., Freeman, J. R., \& Smith, R. M. (1978). Field and Laboratory Methods Applicable to Overburdens and Mine Soils (p. EPA600/2-78-054). 
Sracek, O., Choquette, M., Gélinas, P., Lefebvre, R., \& Nicholson, R. V. (2004). Geochemical characterization of acid mine drainage from a waste rock pile, Mine Doyon, Québec, Canada. Journal of Contaminant Hydrology, 69, 4571. https://doi.org/10.1016/S0169-7722(03)00150-5

Statistics Canada. (2012). Human Activity and the Environment. Statistics Canada: Environment Accounts and Statistics Division, 16, 1-46.

Stedman, A., \& Green, K. P. (2019). Fraser Institute Annual Survey of Mining Companies 2018. Fraser Institute.

Stillings, L. L., Drever, J. I., Brantley, S. L., Sun, Y., \& Oxburgh, R. (1996). Rates of feldspar dissolution at pH 3-7 with 0-8 mM oxalic acid. Chemical Geology, 132, 79-89. https://doi.org/10.1016/s0009-2541(96)00043-5

Stipp, S. L. S., Hansen, M., Kristensen, R., Hochella, M. F., Bennedsen, L., Dideriksen, K., Balic-Zunic, T., Léonard, D., \& Mathieu, H. J. (2002). Behaviour of $\mathrm{Fe}$-oxides relevant to contaminant uptake in the environment. Chemical Geology, 190, 321-337. https://doi.org/10.1016/S00092541(02)00123-7

Strömberg, B., \& Banwart, S. A. (1999). Experimental study of acidity-consuming processes in mining waste rock: Some influences of mineralogy and particle size. Applied Geochemistry, 14, 1-16. https://doi.org/10.1016/S08832927(98)00028-6

Sudom, M. D., \& St. Arnaud, R. J. (1971). Use of Quartz, Zirconium and Titanium As Indices in Pedological Studies. Canadian Journal of Soil Science, 51, 385-396. https://doi.org/10.4141/cjss71-052

Swedlund, P. J., Webster, J. G., \& Miskelly, G. M. (2009). Goethite adsorption of $\mathrm{Cu}(\mathrm{II}), \mathrm{Pb}(\mathrm{II}), \mathrm{Cd}(\mathrm{II})$, and $\mathrm{Zn}(\mathrm{II})$ in the presence of sulfate: Properties of the ternary complex. Geochimica et Cosmochimica Acta, 73, 1548-1562. https://doi.org/10.1016/i.gca.2008.12.007

Takahashi, T. (1960). Supergene alteration of zinc and lead deposits in limestone. Economic Geology, 55, 1083-1115. https://doi.org/10.2113/gsecongeo.55.6.1083

Tischendorf, G., Förster, H.-J., \& Gottesmann, B. (2001). Minor- and traceelement composition of trioctahedral micas: a review. Mineralogical Magazine, 65, 249-276. https://doi.org/10.1180/002646101550244

Vriens, B., Peterson, H., Laurenzi, L., Smith, L., Aranda, C., Mayer, K. U., \& Beckie, R. D. (2019). Long-term monitoring of waste-rock weathering at the Antamina mine, Peru. Chemosphere, 215, 858-869. https://doi.org/10.1016/i.chemosphere.2018.10.105 
Watzlaf, G. R., Schroeder, K. T., Kleinmann, R. L., Kairies, C. L., \& Nairn, R. W. (2004). The passive treatment of coal mine drainage. United States Department of Energy National Energy Technology Laboratory Internal Publication, 1-72.

Weatherington, B. L., Cunningham, C. J. L., \& Pittenger, D. J. (2012). Understanding Business Research, First Edition; Appendix B: Statistical Tables. John Wiley \& Sons, Inc.

Wheeler, S. (2017). An assessment of sulfide mineral oxidation within a WRP from the decommissioned Ore Chimney gold mine in Northbrook, Ontario. Undergraduate Thesis, Carleton University.

White, A. F., Schulz, M. S., Lowenstern, J. B., Vivit, D. V., \& Bullen, T. D. (2005). The ubiquitous nature of accessory calcite in granitoid rocks: Implications for weathering, solute evolution, and petrogenesis. Geochimica et Cosmochimica Acta, 69, 1455-1471. https://doi.org/10.1016/i.gca.2004.09.012

Wickland, B. E., Wilson, G. W., Wijewickreme, D., \& Klein, B. (2006). Design and evaluation of mixtures of mine waste rock and tailings. Canadian Geotechnical Journal, 43, 928-945. https://doi.org/10.1139/T06-058

Wilson, M. J. (1970). A study of weathering in a soil derived from a biotitehornblende rock: I. The Weathering of biotite. Clay Minerals, 8, 291-303.

Wilson, M. J., \& Farmer, V. C. (1970). A study of weathering in a soil derived from a biotite-hornblende rock: II. The Weathering of Hornblende. Clay Minerals, 8, 435-444.

Winter, J. G. (1916). The prodromus of Nicolaus Steno's dissertation concerning a solid body enclosed by process of nature within a solid. University of Michigan Humanistic Study, 11, 229-230.

Ye, L., Cook, N. J., Ciobanu, C. L., Yuping, L., Qian, Z., Tiegeng, L., Wei, G., Yulong, Y., \& Danyushevskiy, L. (2011). Trace and minor elements in sphalerite from base metal deposits in South China: A LA-ICPMS study. Ore Geology Reviews, 39, 188-217. https://doi.org/10.1016/j.oregeorev.2011.03.001

Zak, J. (2013). Hydrologic Investigations of Waste Rock Test Piles in a Permafrost Environment. Masters thesis, University of Waterloo.

Zaitsev, A., \& Polezhaeva, L. (1994). Dolomite-calcite textures in early carbonatites of the Kovdor ore deposit, Kola peninsula, Russia: their genesis and application for calcite-dolomite geothermometry. Contributions to Mineralogy and Petrology, 115, 339-344. https://doi.org/10.1007/BF00310772 
Zhixun, L. (1996). Leachate Chemistry and Precipitates Mineralogy of Rudolfsgruvan Mine Waste Rock Dump in Central Sweden. Water Science and Technology, 33, 163-171.

Ziemkiewicz, P. F., Skousen, J. G., \& Simmons, J. (2003). Long-term performance of passive acid mine drainage treatment systems. Mine water and the Environment, 22, 118-129. 